\title{
Applications of single-molecule detection in early disease diagnosis and enzymatic reaction study
}

\author{
by
}

\author{
Jiangwei Li \\ A dissertation submitted to the graduate faculty \\ in partially fulfillment of the requirements for the degree of \\ DOCTOR OF PHILOSOPHY
}

Major: Analytical Chemistry

Program of Study Committee:

Edward S. Yeung, Major Professor

Robert S. Houk

Emily Smith

Klaus Schmidt-Rohr

Basil Nikolau

Iowa State University

Ames, Iowa

2008

Copyright (C) Jiangwei Li, 2008. All rights reserved. 
To My Families 


\section{TABLE OF CONTENTS}

ABSTRACT

CHAPTER 1. GENERAL INTRODUCTION 1

Dissertation Organization 1

Overview 1

Techniques $\quad 2$

Applications $\quad 8$

References 11

CHAPTER 2. QUANTITATIVE SCREENING OF SINGLE COPIES OF HUMAN PAPILLOMA VIRAL DNA WITHOUT AMPLIFICATION 20

$\begin{array}{ll}\text { Abstract } & 20\end{array}$

Introduction $\quad 21$

Experimental Section $\quad 24$

Results and Discussion $\quad 26$

Conclusions $\quad 32$

Acknowledgement 33

Tables $\quad 34$

References $\quad 35$

$\begin{array}{ll}\text { Figures } & 39\end{array}$

CHAPTER 3. SINGLE-MOLECULE DETECTION OF SURFACEHYBRIDIZED HUMAN PAPILLOMA VIRUS DNA FOR

QUANTITATIVE CLINICAL SCREENING 49

$\begin{array}{ll}\text { Abstract } & 49\end{array}$

Introduction $\quad 50$

Experimental Section $\quad 52$

Results and Discussion $\quad 55$

\begin{tabular}{ll} 
Conclusions & 62 \\
\hline
\end{tabular}

Acknowledgement $\quad 63$

$\begin{array}{ll}\text { Tables } & 65\end{array}$

References $\quad 69$

$\begin{array}{ll}\text { Figures } & 71\end{array}$

CHAPTER 4. SINGLE-MOLECULE IMMUNOSORBENT ASSAY OF HUMAN IMMUNODEFICIENCY VIRUS-1 ANTIGEN 77

$\begin{array}{ll}\text { Abstract } & 77\end{array}$

$\begin{array}{ll}\text { Introduction } & 78\end{array}$

Experimental Section $\quad 81$

Results and Discussion $\quad 85$

$\begin{array}{ll}\text { Conclusions } & 90\end{array}$

Acknowledgement 91

$\begin{array}{ll}\text { Tables } & 93\end{array}$ 
$\begin{array}{ll}\text { References } & 94\end{array}$

$\begin{array}{ll}\text { Figures } & 97\end{array}$

CHAPTER 5. REAL-TIME SINGLE-MOLECULE KINETICS OF TRYPSIN PROTEOLYSIS 105

$\begin{array}{ll}\text { Abstract } & 105\end{array}$

$\begin{array}{ll}\text { Introduction } & 106\end{array}$

$\begin{array}{ll}\text { Experimental Section } & 107\end{array}$

Results and Discussion $\quad 110$

$\begin{array}{ll}\text { Conclusions } & 115\end{array}$

$\begin{array}{ll}\text { Acknowledgement } & 115\end{array}$

$\begin{array}{ll}\text { References } & 117\end{array}$

$\begin{array}{ll}\text { Figures } & 120\end{array}$

CHAPTER 6. GENERAL CONCLUSIONS 129

ACKNOWLEDGEMENT 130 


\begin{abstract}
Various single-molecule techniques were utilized for ultra-sensitive early diagnosis of viral DNA and antigen and basic mechanism study of enzymatic reactions.

DNA of human papilloma virus (HPV) served as the screening target in a flow system. Alexa Fluor 532 (AF532) labeled single-stranded DNA probes were hybridized to the target HPV-16 DNA in solution. The individual hybridized molecules were imaged with an intensified charge-coupled device (ICCD) in two ways. In the single-color mode, target molecules were detected via fluorescence from hybridized probes only. This system could detect HPV-16 DNA in the presence of human genomic DNA down to 0.7 copy/cell and had a linear dynamic range of over 6 orders of magnitude. In the dual-color mode, fluorescence resonance energy transfer (FRET) was employed to achieve zero false-positive count. We also showed that DNA extracts from Pap test specimens did not interfere with the system.

A surface-based method was used to improve the throughput of the flow system. HPV-16 DNA was hybridized to probes on a glass surface and detected with a total internal reflection fluorescence (TIRF) microscope. In the single-probe mode, the whole genome and target DNA were fluorescently labeled before hybridization, and the detection limit is similar to the flow system. In the dual-probe mode, a second probe was introduced. The linear dynamic range covers $1.44-7000$ copies/cell, which is typical of early infection to nearcancer stages. The dual-probe method was tested with a crudely prepared sample. Even with reduced hybridization efficiency caused by the interference of cellular materials, we were still able to differentiate infected cells from healthy cells.
\end{abstract}


Detection and quantification of viral antigen with a novel single-molecule immunosorbent assay (SMISA) was achieved. Antigen from human immunodeficiency virus type $1(\mathrm{HIV}-1)$ was chosen to be the target in this study. The target was sandwiched between a monoclonal capture antibody and a polyclonal detector antibody. The capture antibody was covalently immobilized on modified glass slides. The detector antibody was conjugated with AF532 labeled secondary antibody prior to being used as probe for the antigen. Imaging was performed with a TIRF system. This technique is demonstrated for detecting HIV-1 p24 antigen down to $0.1 \mathrm{pg} / \mathrm{mL}$ with a dynamic range of over 4 orders of magnitude. A Langmuir isotherm fit the molecule count dependence on the target concentration. The results also showed that neither sensitivity nor dynamic range was affected by the biological matrix. SMISA is therefore a promising approach for the early diagnosis of virus-induced diseases.

Single-molecule enzymatic kinetics and enantioselectivity were monitored in real time by using TIRF microscopy. AF532 labeled poly-L-lysine (PLL) or poly-D-lysine (PDL) was covalently immobilized on a dithiobis (succinimidyl undecanoate) self-assembled monolayer (DSU SAM). Chain shortening due to enzymatic hydrolysis resulted in the reduction of the individual fluorescence intensities. A broad distribution was obtained when 100 single-molecule half-lives were analyzed. However, the detailed hydrolysis process involved also a long-lived component and an induction period that varied significantly among molecules. Charge and steric heterogeneity at the surface are responsible for these features. 


\section{CHAPTER 1. GENERAL INTRODUCTION}

\section{Dissertation Organization}

This dissertation starts with a general introduction about fluorescence single-molecule detection, including overview, techniques, and applications with a list of cited references. The following chapters are arranged in such a way that published papers and manuscripts to be submitted are each presented as separate chapters. Among them, chapters two and three described deoxyribonucleic acid (DNA)-based single-molecule scale early diagnosis; chapter four is on protein-based single-molecule scale early diagnosis; chapter five is the project related to basic research of enzymatic reaction mechanism. References for each paper or manuscript are attached to the end of each chapter. The final chapter (chapter six) summarizes the work and provides some prospects for future research.

\section{Overview}

"It is very easy to answer many of these fundamental biological questions; you just look at the thing!", as Nobel prize laureate Richard P. Feynman said in his famous lecture "There's Plenty of Room at the Bottom" at 1959 annual meeting of the American Physical Society. Development and gradual perfection of single-molecule techniques are bringing this aspiration to fruition.

Single-molecule techniques have expanded into areas of chemistry, physics and biology by revealing unique behaviors of individual molecules since the pioneering work by Moerner and Orrit in the late 1980s and early 1990s. ${ }^{1,2}$ The basic principles of singlemolecule detection are simple: (a) guarantee that only one molecule is in resonance in the 
volume probed by the laser, and (b) provide a signal-to-noise ratio $(\mathrm{S} / \mathrm{N})$ for the singlemolecule signal that is greater than unity for a reasonable averaging time. ${ }^{3}$ To meet these two criteria, many strategies have been developed in the last few decades. This introduction will focus on fluorescence imaging of single macro-biomolecules by fluorescence microscopy under ambient conditions, thus omitting the other research based on surface-enhanced Raman scattering, ${ }^{4-10}$ low-temperature spectroscopy, ${ }^{11-15}$ force spectroscopy, ${ }^{16-21}$ and near-field spectroscopy ${ }^{22-29}$ etc. The introduction is divided into two sections: techniques and applications. In the Techniques section, the diverse methodological advances in fluorescence single-molecule research, including commonly used labeling methods, sample formats, and microscopy configurations, are presented. In the Application section, broad applications of single-molecule spectroscopy in biochemistry, biophysics, and biology are discussed.

\section{Techniques}

Fluorescent Labeling. A suitable fluorophore for single-molecule detection needs to have: (a) high brightness, which is the product of the molar extinction coefficient of the fluorophore (a measurement of how strongly a compound absorbs light at the excitation wavelength) and the fluorescence quantum yield (the ratio of the number of photons emitted to the number of photons absorbed); (b) a relatively short excited-state lifetime to quickly replenish the ground state; (c) a large Stokes shift to facilitate rejection of scattered excitation light; (d) stable photophysical properties (rare photobleaching, low probability of dark states) $;^{30}$ (e) $\mathrm{pH}$ insensitivity (remaining highly fluorescent over a wide $\mathrm{pH}$ range); and (f) good water solubility. There are several categories of fluorophores adapted for singlemolecule detection: fluorescent organic dyes, fluorescent proteins, fluorescent microspheres, 
semiconductor nanocrystals also known as quantum dots (QDs), color centers and so on. For the specific methodology fluorescence resonance energy transfer (FRET), more stringent considerations apply: (a) the emission spectrum of donor overlaps with the excitation spectrum of the acceptor; (b) large spectral difference between donor and acceptor in their emission spectra; (c) similar quantum yields and characteristics. ${ }^{31}$ FRET is a useful tool as the absolute distance determination allows the structural and dynamic analysis of bimolecular systems. Small organic dyes, ${ }^{32}$ fluorescent proteins, ${ }^{33}$ and QDs ${ }^{34,}{ }^{35}$ have all been employed in FRET research.

Organic dyes are the most common tagging molecules, which were also utilized throughout the works in this dissertation. Early single-molecule research mainly used rhodamine- ${ }^{36-41}$ and cyanine-derivatives. ${ }^{42-45}$ Fluorescein isothiocyanate (FITC), a derivative of fluorescein, became popular since the excitation wavelength matches well with current lasers. ${ }^{46-49}$ The new generation of fluorophores is generally more photostable, brighter, and less $\mathrm{pH}$-sensitive than common dyes of comparable excitation and emission spectra. For example, Alexa Fluor dyes from Invitrogen (Carlsbad, CA) were extensively utilized in covalently labeling DNAs ${ }^{50,51}$ and proteins. ${ }^{52-54}$ DNAs could also be stained with intercalating TOTO-family dyes (Invitrogen), ${ }^{50,55-62}$ which are essentially nonfluorescent in the absence of nucleic acids and exhibit fluorescence enhancement upon DNA binding of 100 - to 1000 -fold. This property is advantageous because detection background is not elevated by free dye molecules and no separation is needed to remove the free dye molecules prior to imaging.

Fluorescent proteins, i.e. green fluorescent protein (GFP) and its mutants, are widely used in cell biology ${ }^{63}$ as well as single-motor experiments. ${ }^{64,65}$ After folding, three amino 
acids inside the beta-barrel of GFP are auto-catalytically converted into a fluorescent molecule. GFP labeling has advantages in working with cells because it is genetically encoded on the protein level and no chemical modifications are needed as small fluorescent dyes. However, the GFP molecule is rather large, easy to be photobleached, and shows a complicated blinking effect, ${ }^{66}$ all of which limit the application of GFP in single-molecule studies.

Luminescent colloidal inorganic semiconductor nanocrystals or QDs are an alternative way to fluorescently tag biomolecules in single molecule studies. ${ }^{67-74}$ In particular, CdSe-ZnS core-shell QDs exhibit size-dependent tunable photoluminescence with narrow emission bandwidth that span the visible spectrum and broad absorption spectra. This feature allows simultaneous excitation of several particle sizes at a single wavelength. QDs have a large quantum yield and a high resistance to photobleaching. ${ }^{67,75}$ However, their blinking effect, possible toxicity to biological systems, large size ( $>20 \mathrm{~nm}$ for commercial QDs), and lack of monovalent conjugation limit their use. ${ }^{31,76}$

Color centers in crystalline solid are a potentially interesting alternative to dyes and QDs. To name one, the N-V center in diamonds is a defect consisting of substitutional nitrogen atom adjacent to a carbon-atom vacancy. Single defect spectroscopy is based on the principle that the optical transition between the ground state and excited state has very high quantum efficiency. Single N-V center containing particles could serve as highly stable and efficient fluorescent labels. $^{77}$

Sample Formats. The target single molecules are detected in three formats: freely diffusing in solution, spatially restricted, or immobilized on the surface. Solution experiments are simple, eliminating concerns of potential surface interactions. In 1995, single molecule 
electrophoresis was realized by measuring the time required for individual molecules to travel a fixed distance between two laser beams. ${ }^{78}$ Folded and denatured subpopulations of diffusing single protein molecules were observed by FRET.$^{79}$ Fluorescently tagged viral DNAs can be counted in a capillary with a hydrodynamic-flow system, which is described in Chapter 2.

To use an evanescent field excitation scheme or extend the observation time window, partial or full immobilization of the target molecules is usually applied. Matrix-assisted trapping includes confinement inside porous polyacrylamide and agarose gel matrices, ${ }^{80,81}$ and inside phospholipid vesicles. Encapsulation of single molecules in surface-tethered vesicles (50-200 $\mathrm{nm}$ in diameter) offers a biologically relevant environment for many soluble proteins and nucleic acids. ${ }^{82-84}$ Vesicle encapsulation was adopted to ascertain that the extreme conformational diversity of human telomeric DNA does not result from surface tethering. ${ }^{85}$ Single-enzyme reaction was performed in a liposome to reveal the singlemolecule activities. ${ }^{86}$ Other spatial constraint ways included dielectrophoretic and electrokinetic trapping of single molecules in solution by direct suppression of Brownian motion. $^{87-89}$

DNAs and proteins can be affixed on glass/quartz slides or polymer coated surfaces. The mechanism of attachment on glass surface could be electrostatic interactions, ${ }^{90}$ hydrophobic forces,${ }^{59}$ covalent binds,${ }^{51}$ or biotin-streptavidin affinity. ${ }^{91,}{ }^{92}$ Polyethylene glycol is a typical polymer surface coating, and has been applied for reducing nonspecific binding in protein studies. ${ }^{93}$ Various protocols were selected to meet specific requirements in our work to immobilize DNAs and proteins. More detailed descriptions can be found in Chapters 3-5. 
Microscopy Configurations. There are several types of fluorescent microscopy used in single-molecule detection, such as total internal reflection fluorescence microscopy (TIRFM), epi-fluorescence microscopy, confocal microscopy, and near-field scanning optical microscopy (NSOM). In this section, the first three configurations are introduced.

TIRFM is a type of microscopy that evanescent field is applied to illuminate less than 200-nm thin layer of a specimen. Therefore, it can rule out the overwhelming background from the bulk solution to visualize single molecules with enhanced S/N. An evanescent field is created at the interface when the beam of light travels from high reflective index (RI) medium to low RI medium at an angle larger than the critical angle. The critical angle $\theta_{\mathrm{c}}$ is calculated by the equation:

$$
\theta_{c}=\sin ^{-1}\left(n_{2} / n_{1}\right)
$$

where $n_{1}$ and $n_{2}$ are the RI of the denser and less dense medium, respectively. In our work, the laser beam strikes at the boundary of a glass slide $\left(\mathrm{n}_{1}=1.5\right)$ and buffer $\left(\mathrm{n}_{2}=1.33\right)$, so the $\theta_{\mathrm{c}}$ is calculated to be $62.5^{\circ}$. The larger the difference between the media, the wider the operation range that is available for the adjustment of the laser beam. Thus, it is a common approach to employ a high-RI glass prism to achieve a wide adjustment range for variable angle

\section{TIRFM. $^{94}$}

Prism- and objective-based TIRFMs are the mainstream types. Prism-based TIRFM (Figure 1A) couples a laser beam into a prism larger than the critical angle to achieve the evanescent field. The prism shape can be right angle, dove shape, and hemisphere etc, while the microscope can be upright or inverted. The prism-based TIRFM provides a wide-field view with extremely clean background, easy alignment, and modification flexibility. Thus, it was 
utilized in our home-made TIRFM for single-molecule studies. High numerical aperture objectives are also used in TIRFM (Figure 1B). The excitation laser beam and fluorescence from the sample share the same path through the objective. The inverted objective-based TIRFM is a popular commercial instrument, and it has a large free space above the coverslip. This advantage makes it possible to combine the scanning probe technology into singlemolecule detection.

A

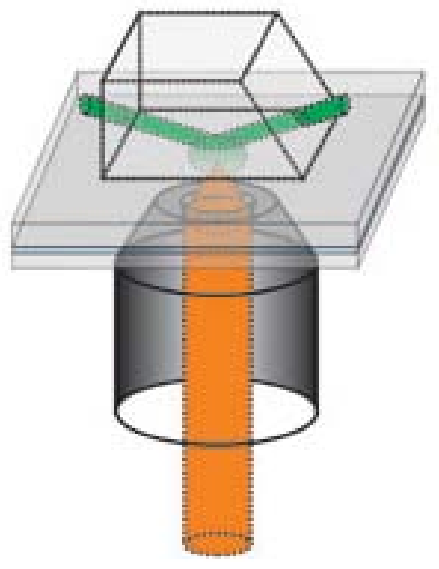

B

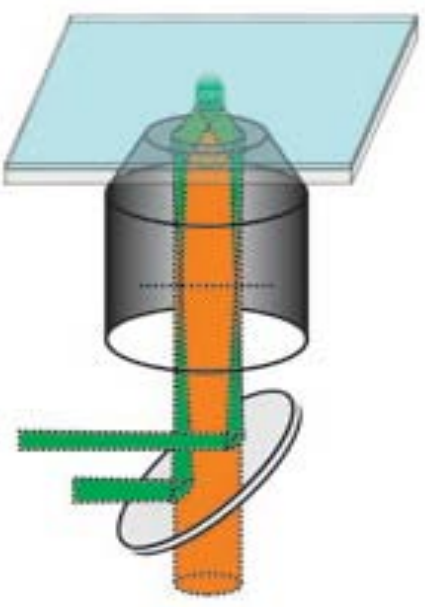

C

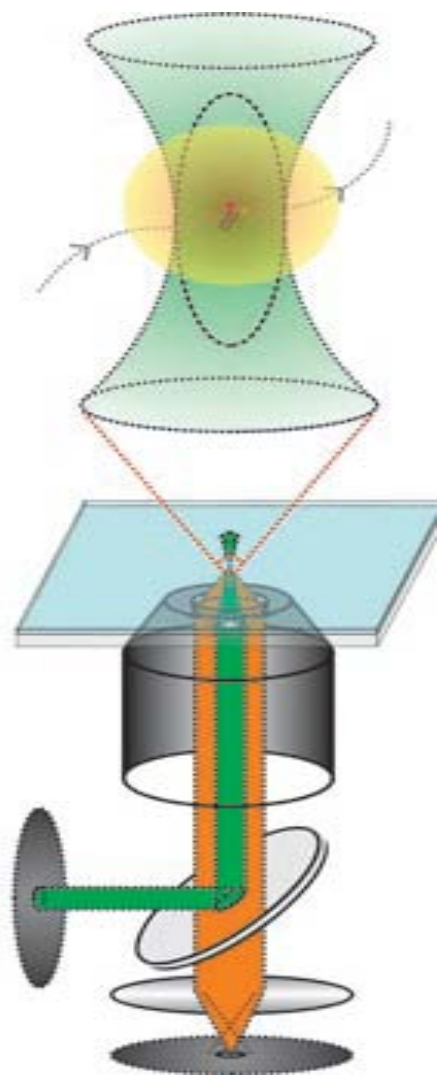

Figure 1. Schematics of common used fluorescent microscopes. (A) Prism-based TIRFM, (B) Objectivebased TIRFM. (C) Wide-field epi-fluorescence microscope (without the pinholes) and confocal microscope (with the pinholes on both the excitation and detection paths). The green and orange lights represent laser beam and fluorescence emitted from the sample, respectively. ${ }^{30}$ 
In wide-field epi-fluorescence microscopy (Figure 1C, without the pinholes), the excitation light is focused on the sample by the objective, and the fluorescence signal is collected with the same objective. A filter located between the objective and the detector eliminates the reflected and scattered light from the excitation beam. The excitation and detection volumes are usually constrained to several micrometers in diameter. The detection volume can be further decreased with a confocal microscope, which was first described in a patent by Minsky in $1957 .{ }^{95}$ As shown in Figure 1C, the confocal setup is essentially the epifluorescence system plus two pinholes (or apertures) that are located at the excitation and detection lightpaths. The incident laser beam passes through the first aperture and is focused by the objective lens into a diffraction-limited spot. The positions of the apertures are well correlated and adjusted, so that the out-of-focus fluorescent signal is rejected after the second pinhole, allowing detection of only one spot at a time. Some fluorescence cross-correlation spectroscopy uses a confocal geometry to probe molecules in solution by calculating the signal auto-correlation. ${ }^{96}$ Confocal laser scanning microscopy is also built on this system, where the laser beam rasters through the sample layer by layer, so that three dimensional high resolution images can be constructed.

\section{Applications}

Many aspects of the biosciences were revolutionized by single-molecule detection over the last two decades. I herein summarize the main applications in both basic research and biotechnology with several representative works.

Diffusion, Adsorption and Desorption. The diffusion path of single fluorescently

labeled lipid molecules in the phospholipid membrane was visualized. ${ }^{97,98}$ Additionally, 
diffusion coefficients of Rhodamine $6 \mathrm{G}$ in water/methanol and ethanol solutions were measured by FCS. ${ }^{99}$ Free-solution dynamics of individual single-stranded DNA were also continuously monitored, and diffusion coefficients were found smaller than in bulk studies. ${ }^{41}$ Furthermore, the adsorption/desorption properties of R-phycoerythrin on fused-silica surface were studied in single-molecule experiments to better explain the peak shape and molecule migration in affinity capillary electrophoresis..$^{90}$

Conformational Dynamics. The hypothesized three-state model of the conformational dynamics of the tetramethylrhodamine-DNA duplex was confirmed by realtime burst-integrated fluorescence lifetime spectroscopy. ${ }^{100}$ Moreover, single-molecule studies of ligand-induced conformational change of an RNA three-way junction, ${ }^{101}$ and single-domain protein folding chymotrypsin inhibitor 2 were carried out by FRET. ${ }^{102}$

Biomolecule Interactions. Protein-protein interactions were exploited as a tool for site-specific labeling of proteins. ${ }^{103}$ In 2006, the interactions of human odorant-receptor trafficking in living cells were demonstrated. ${ }^{104}$ DNA-protein interactions were also well studied with optical tweezers ${ }^{105}$ and laminar flow cells. ${ }^{106}$

Ion Channel. Simultaneous electrical and optical measurement of single ion channels were realized on an artificial lipid bilayer formed on an agarose-coated glass. ${ }^{107}$ Moreover, a single plasma membrane potassium ion channel was successfully detected with dual-color QD labeling. ${ }^{108}$ Other relevant works are excluded here, since they were mainly based on detection of electrical signals.

Intracellular Studies. In 2000, Nie and coworkers demonstrated that various types of fluorescent molecules in cytoplasm or nucleus of a live cell could be imaged on a confocal microscope. ${ }^{109}$ Later, influx and efflux pump machinery in live bacterial cells was proven by 
real-time monitoring the fluorescent intensity of individual ethidium bromide molecules in and out of the cell. ${ }^{110}$ Recently, protein expression in a single cell was detected at the singlemolecule level. ${ }^{111,112}$

DNA Sizing, Sequencing, and Mapping. A mixture of DNA restriction fragments can be separated according to their sizes by single-molecule electrophoresis. ${ }^{78,113}$ In the early 1990s, a rapid DNA sequencing scheme based on the detection of single, fluorescently tagged nucleotides cleaved from a single DNA fragment was proposed. ${ }^{114,115}$ The first application of direct linear analysis to the mapping of bacterial artificial chromosome was described in $1995 .^{116}$

Biosensors. Various highly sensitive biosensors were developed based on singlemolecule detection. For example, single-molecule environmental sensors can be used to monitor microorganisms in food production and clinical environment. ${ }^{117}$ Meanwhile, fluorescent protein biosensors were designed to monitor molecular dynamics in living cells. ${ }^{118}$ In addition, an implantable $\beta$-D-glucose biosensor was built on single-walled carbon nanotubes. ${ }^{119}$

Early clinical diagnosis and single-molecule enzymatic reactions research are two additional significant applications of single-molecule techniques. More detailed descriptions on these two fields are presented in the following chapters of this dissertation. 


\section{References}

(1) Moerner, W. E.; Kador, L. Phys. Rev. Lett. 1989, 62, 2535-2538.

(2) Orrit, M.; Bernard, J. Phys. Rev. Lett. 1990, 65, 2716-2719.

(3) Moerner, W. E.; Fromm, D. P. Rev. Sci. Instrum. 2003, 74, 3597-3619.

(4) Kneipp, K.; Wang, Y.; Kneipp, H.; Perelman, L. T.; Itzkan, I.; Dasari, R.; Feld, M. S. Phys. Rev. Lett. 1997, 78, 1667-1670.

(5) Kneipp, K.; Kneipp, H.; Manoharan, R.; Itzkan, I.; Dasari, R. R.; Feld, M. S. Bioimaging 1998, 6, 104-110.

(6) Xu, H. X.; Bjerneld, E. J.; Kall, M.; Borjesson, L. Phys. Rev. Lett. 1999, 83, 43574360.

(7) Moskovits, M.; Tay, L. L.; Yang, J.; Haslett, T. Top. Appl. Phys. 2002, 82, 215-226.

(8) Ruan, C. M.; Wang, W.; Gu, B. H. J. Raman Spectrosc. 2007, 38, 568-573.

(9) Vlckova, B.; Pavel, I.; Sladkova, M.; Siskova, K.; Slouf, M. J. Mol. Struct. 2007, 834, $42-47$.

(10) Qian, X. M.; Nie, S. M. Chem. Soc. Rev. 2008, 37, 912-920.

(11) Kummer, S.; Basche, T.; Brauchle, C. Chem. Phys. Lett. 1994, 229, 309-316.

(12) Moerner, W. E. J. Lumin. 1994, 60-61, 997-1002.

(13) Jasny, J.; Sepiol, J.; Irngartinger, T.; Traber, M.; Renn, A.; Wild, U. P. Rev. Sci. Instrum. 1996, 67, 1425-1430.

(14) Kiraz, A.; Ehrl, M.; Brauchle, C.; Zumbusch, A. J. Chem. Phys. 2003, 118, 1082110824.

(15) Moerner, W. E.; Orrit, M. Science 1999, 283, 1670-1676. 
(16) Janshoff, A.; Neitzert, M.; Oberdorfer, Y.; Fuchs, H. Angew. Chem. Int. Ed. 2000, 39, $3212-3237$.

(17) Matthias Rief, H. G. Chemphyschem 2002, 3, 255-261.

(18) Zhang, W.; Zhang, X. Prog. Polym. Sci. 2003, 28, 1271-1295.

(19) Sinha, D. K.; Bhattacharya, D.; Banerjee, B.; Hameed, F. M.; Shivashankar, G. V. Curr. Sci. 2004, 87, 239-244.

(20) Levy, R.; Maaloum, M. Ultramicroscopy 2005, 102, 311-315.

(21) Tropini, C.; Marziali, A. Biophys. J. 2007, 92, 1632-1637.

(22) Ambrose, W. P.; Goodwin, P. M.; Martin, J. C.; Keller, R. A. Phys. Rev. Lett. 1994, $72,160-163$.

(23) Ruiter, A. G. T.; Veerman, J. A.; GarciaParajo, M. F.; van Hulst, N. F. J. Phys. Chem. A 1997, 101, 7318-7323.

(24) Garcia-Parajo, M. F.; Veerman, J. A.; van Noort, S. J. T.; de Grooth, B. G.; Greve, J.; van Hulst, N. F. Bioimaging 1998, 6, 43-53.

(25) Talley, C. E.; Lee, M. A.; Dunn, R. C. Appl. Phys. Lett. 1998, 72, 2954-2956.

(26) Durand, Y.; Woehl, J. C.; Viellerobe, B.; Gohde, W.; Orrit, M. Rev. Sci. Instrum. 1999, 70, 1318-1325.

(27) Gersen, H.; Garcia-Parajo, M. F.; Novotny, L.; Veerman, J. A.; Kuipers, L.; van Hulst, N. F. J. Microsc. 2001, 202, 374-378.

(28) Gerhardt, I.; Wrigge, G.; Bushev, P.; Zumofen, G.; Agio, M.; Pfab, R.; Sandoghdar, V. Phys. Rev. Lett. 2007, 98, 033601/033601-033601/033604.

(29) Park, H. K.; Gokarna, A.; Hulme, J. P.; Park, H. G.; Chung, B. H. Nanotechnology 2008, 19, 235103/235101-235103/235107. 
(30) Walter, N. G.; Huang, C. Y.; Manzo, A. J.; Sobhy, M. A. Nat. Methods 2008, 5, 475489.

(31) Roy, R.; Hohng, S.; Ha, T. Nat. Methods 2008, 5, 507-516.

(32) Kapanidis, A. N.; Weiss, S. J. Chem. Phys. 2002, 117, 10953-10964.

(33) Brasselet, S.; Peterman, E. J. G.; Miyawaki, A.; Moerner, W. E. J. Phys. Chem. B 2000, 104, 3676-3682.

(34) Hohng, S.; Ha, T. J. Am. Chem. Soc. 2004, 126, 1324-1325.

(35) Hohng, S.; Ha, T. Chemphyschem 2005, 6, 956-960.

(36) Ambrose, W. P.; Goodwin, P. M.; Jett, J. H.; Johnson, M. E.; Martin, J. C.; Marrone, B. L.; Schecker, J. A.; Wilkerson, C. W.; Keller, R. A.; Haces, A.; Shih, P. J.;

Harding, J. D. Ber. Bunsen-Ges. Phys. Chem. 1993, 97, 1535-1542.

(37) Mertz, J.; Xu, C.; Webb, W. W. Opt. Lett. 1995, 20, 2532-2534.

(38) Nie, S. M.; Chiu, D. T.; Zare, R. N. Anal. Chem. 1995, 67, 2849-2857.

(39) Hong, L.; Liu, T. T.; Luo, G. B.; Zhao, X. S. Acta Phys.-Chim. Sin. 2002, 18, 769775.

(40) Tani, T.; Yamaguchi, Y.; Ohuchi, K.; Oda, M. J. Lumin. 2004, 107, 42-50.

(41) Xu, X. H.; Yeung, E. S. Science 1997, 275, 1106-1109.

(42) Waddell, E.; Wang, Y.; Stryjewski, W.; McWhorter, S.; Henry, A. C.; Evans, D.; McCarley, R. L.; Soper, S. A. Anal. Chem. 2000, 72, 5907-5917.

(43) Tan, W. H.; Wang, X. W. Thin Solid Films 1998, 331, 189-193.

(44) Jing, P.; Kaneta, T.; Imasaka, T. Electrophoresis 2002, 23, 2465-2470.

(45) Piwonski, H.; Kolos, R.; Meixner, A.; Sepiol, J. Chem. Phys. Lett. 2005, 405, 352356. 
(46) Ou, J. P.; Wang, Q. G.; Cheung, T. M.; Chan, S. T. H.; Yeung, W. S. B. J. Chromatogr. B 1999, 727, 63-71.

(47) Guiot, E.; Enescu, M.; Arrio, B.; Johannin, G.; Roger, G.; Tosti, S.; Tfibel, F.; Merola, F.; Brun, A.; Georges, P.; Fontaine-Aupart, M. P. J. Fluoresc. 2000, 10, 413419.

(48) Ros, A.; Hellmich, W.; Duong, T.; Anselmetti, D. J. Biotechnol. 2004, 112, 65-72.

(49) Schiro, P. G.; Kuyper, C. L.; Chiu, D. T. Electrophoresis 2007, 28, 2430-2438.

(50) Li, J.; Lee, J. Y.; Yeung, E. S. Anal. Chem. 2006, 78, 6490-6496.

(51) Lee, J. Y.; Li, J.; Yeung, E. S. Anal. Chem. 2007, 79, 8083-8089.

(52) Kinoshita, M.; Kamagata, K.; Maeda, A.; Goto, Y.; Komatsuzaki, T.; Takahashi, S. Proc. Natl. Acad. Sci. U. S. A. 2007, 104, 10453-10458.

(53) Wang, L.; Xu, G.; Shia, Z. K.; Jiang, W.; Jin, W. R. Anal. Chim. Acta 2007, 590, 104109.

(54) Li, L.; Tian, X. Z.; Zou, G. Z.; Shi, Z. K.; Zhang, X. L.; Jin, W. R. Anal. Chem. 2008, $80,3999-4006$.

(55) Ma, Y.; Shortreed, M. R.; Yeung, E. S. Anal. Chem. 2000, 72, 4640-4645.

(56) Anazawa, T.; Matsunaga, H.; Yeung, E. S. Anal. Chem. 2002, 74, 5033-5038.

(57) Zheng, J. J.; Yeung, E. S. Aust. J. Chem. 2003, 56, 149-153.

(58) Kang, S. H.; Lee, S.; Yeung, E. S. Anal. Chem. 2004, 76, 4459-4464.

(59) Li, H. W.; Park, H. Y.; Porter, M. D.; Yeung, E. S. Anal. Chem. 2005, 77, 3256-3260.

(60) Donner, S.; Li, H. W.; Yeung, E. S.; Porter, M. D. Anal. Chem. 2006, 78, 2816-2822.

(61) Park, H. Y.; Li, H. W.; Yeung, E. S.; Porter, M. D. Langmuir 2006, 22, 4244-4249. 
(62) Liu, X.; Wu, Z.; Nie, H.; Liu, Z.; He, Y.; Yeung, E. S. Anal. Chim. Acta 2007, 602, 229-235.

(63) Tsien, R. Y. Annu. Rev. Biochem. 1998, 67, 509-544.

(64) Case, R. B.; Pierce, D. W.; Hom-Booher, N.; Hart, C. L.; Vale, R. D. Cell 1997, 90 , 959-966.

(65) Pierce, D. W.; Vale, R. D. Methods Cell Biol. 1999, 58, 49-73.

(66) Peterman, E. J. G.; Sosa, H.; Moerner, W. E. Annu. Rev. Phys. Chem. 2004, 55, 7996.

(67) Goldman, E. R.; Anderson, G. P.; Tran, P. T.; Mattoussi, H.; Charles, P. T.; Mauro, J. M. Anal. Chem. 2002, 74, 841-847.

(68) Bonneau, S.; Dahan, M.; Cohen, L. D. IEEE Trans. Image Process. 2005, 14, 13841395.

(69) Crut, A.; Geron-Landre, B.; Bonnet, I.; Bonneau, S.; Desbiolles, P.; Escude, C. Nucleic Acids Res. 2005, 33, e98/91-e98/99.

(70) Stavis, S. M.; Edel, J. B.; Samiee, K. T.; Craighead, H. G. Lab Chip 2005, 5, 337343.

(71) Zhang, C. Y.; Yeh, H. C.; Kuroki, M. T.; Wang, T. H. Nat. Mat. 2005, 4, 826-831.

(72) Chen, H. H.; Leong, K. W. Nanomedicine 2006, 1, 119-122.

(73) Kaji, N.; Tokeshi, M.; Baba, Y. Anal. Sci. 2007, 23, 21-24.

(74) Agrawal, A.; Deo, R.; Wang, G. D.; Wang, M. D.; Nie, S. M. Proc. Natl. Acad. Sci. U. S. A. 2008, 105, 3298-3303.

(75) Dabbousi, B. O.; Rodriguez-Viejo, J.; Mikulec, F. V.; Heine, J. R.; Mattoussi, H.; Ober, R.; Jensen, K. F.; Bawendi, M. G. J. Phys. Chem. B 1997, 101, 9463-9475. 
(76) Arndt-Jovin, D. J.; Lopez-Quintela, M. A.; Lidke, D. S.; Rodriguez, M. J.; Martinez Santos, F.; Lidke, K. A.; Hagen, G. M.; Jovin, T. M. Proc. SPIE-Int. Soc. Opt. Eng. 2006, 6096, 60960P/60961-60960P/60910.

(77) Jelezko, F.; Tietz, C.; Gruber, A.; Popa, I.; Nizovtsev, A.; Kilin, S.; Wrachtrup, J. Single Mol. 2001, 2, 255-260.

(78) Castro, A.; Shera, E. B. Anal. Chem. 1995, 67, 3181-3186.

(79) Schuler, B.; Lipman, E. A.; Eaton, W. A. Nature (London, U. K.) 2002, 419, 743-747.

(80) Dickson, R. M.; Cubitt, A. B.; Tsien, R. Y.; Moerner, W. E. Nature 1997, 388, 355358.

(81) Lu, H. P.; Xun, L. Y.; Xie, X. S. Science 1998, 282, 1877-1882.

(82) Okumus, B.; Wilson, T. J.; Lilley, D. M. J.; Ha, T. Biophys. J. 2004, 87, 2798-2806.

(83) Benitez, J. J.; Keller, A. M.; Ochieng, P.; Yatsunyk, L. A.; Huffman, D. L.; Rosenzweig, A. C.; Chen, P. J. Am. Chem. Soc. 2008, 130, 2446-2447.

(84) Cisse, I.; Okumus, B.; Joo, C.; Ha, T. J. Proc. Natl. Acad. Sci. U. S. A. 2007, 104, 12646-12650.

(85) Lee, J. Y.; Okumus, B.; Kim, D. S.; Ha, T. J. Proc. Natl. Acad. Sci. U. S. A. 2005, 102, 18938-18943.

(86) Hsin, T.-M.; Yeung, E. S. Angew. Chem. Int. Ed. 2007, 46, 8032-8035.

(87) Gosse, C.; Croquette, V. Biophys. J. 2002, 82, 3314-3329.

(88) Voldman, J.; Braff, R. A.; Toner, M.; Gray, M. L.; Schmidt, M. A. Biophys. J. 2001, $80,531-541$.

(89) Cohen, A. E.; Moerner, W. E. Appl. Phys. Lett. 2005, 86, 093109/093101093109/093103. 
(90) Fang, N.; Zhang, H.; Li, J.; Li, H. W.; Yeung, E. S. Anal. Chem. 2007, 79, 60476054.

(91) Zhuang, X. W.; Bartley, L. E.; Babcock, H. P.; Russell, R.; Ha, T. J.; Herschlag, D.; Chu, S. Science 2000, 288, 2048-2051.

(92) McKinney, S. A.; Declais, A. C.; Lilley, D. M. J.; Ha, T. Nat. Struct. Biol. 2003, 10, 93-97.

(93) Ha, T.; Rasnik, I.; Cheng, W.; Babcock, H. P.; Gauss, G. H.; Lohman, T. M.; Chu, S. Nature 2002, 419, 638-641.

(94) He, Y.; Li, H. W.; Yeung, E. S. J. Phys. Chem. B 2005, 109, 8820-8832.

(95) Minsky, M. US patent 30134671957.

(96) Haustein, E.; Schwille, P. Annu. Rev. Biophys. Biomol. Struct. 2007, 36, 151-169.

(97) Schmidt, T.; Schutz, G. J.; Baumgartner, W.; Gruber, H. J.; Schindler, H. Proc. Natl. Acad. Sci. U. S. A. 1996, 93, 2926-2929.

(98) Liu, T. T.; Luo, G. B.; Ying, L. M.; Zhao, X. S. Acta Phys.-Chim. Sin. 2000, 16, 393397.

(99) Hansen, R. L.; Zhu, X. R.; Harris, J. M. Anal. Chem. 1998, 70, 1281-1287.

(100) Eggeling, C.; Fries, J. R.; Brand, L.; Gunther, R.; Seidel, C. A. M. Proc. Natl. Acad. Sci. U. S. A. 1998, 95, 1556-1561.

(101) Ha, T.; Zhuang, X. W.; Kim, H. D.; Orr, J. W.; Williamson, J. R.; Chu, S. Proc. Natl. Acad. Sci. U. S. A. 1999, 96, 9077-9082.

(102) Deniz, A. A.; Laurence, T. A.; Beligere, G. S.; Dahan, M.; Martin, A. B.; Chemla, D. S.; Dawson, P. E.; Schultz, P. G.; Weiss, S. Proc. Natl. Acad. Sci. U. S. A. 2000, 97, 5179-5184. 
(103) Jager, M.; Michalet, X.; Weiss, S. Protein Sci. 2005, 14, 2059-2068.

(104) Jacquier, V.; Prummer, M.; Segura, J. M.; Pick, H.; Vogel, H. Proc. Natl. Acad. Sci. U. S. A. 2006, 103, 14325-14330.

(105) Halford, S. E.; Marko, J. F. Nucleic Acids Res. 2004, 32, 3040-3052.

(106) Brewer, L. R.; Bianco, P. R. Nat. Methods 2008, 5, 517-525.

(107) Ide, T.; Yanagida, T. Biochem. Biophys. Res. Commun. 1999, 265, 595-599.

(108) Nechyporuk-Zloy, V.; Stock, C.; Schillers, H.; Oberleithner, H.; Schwab, A. Am. J. Physiol. Cell Physiol. 2006, 291, C266-C269.

(109) Byassee, T. A.; Chan, W. C. W.; Nie, S. M. Anal. Chem. 2000, 72, 5606-5611.

(110) Xu, X. H. N.; Brownlow, W.; Huang, S.; Chen, J. Biochem. Biophys. Res. Commun. 2003, 305, 79-86.

(111) Cai, L.; Friedman, N.; Xie, X. S. Nature 2006, 440, 358-362.

(112) Yu, J.; Xiao, J.; Ren, X. J.; Lao, K. Q.; Xie, X. S. Science 2006, 311, 1600-1603.

(113) Zheng, J. J.; Yeung, E. S. Anal. Chem. 2003, 75, 3675-3680.

(114) Jett, J. H.; Keller, R. A.; Martin, J. C.; Marrone, B. L.; Moyzis, R. K.; Ratliff, R. L.; Seitzinger, N. K.; Shera, E. B.; Stewart, C. C. J. Biomol. Struct. Dyn. 1989, 7, 301 309.

(115) Davis, L. M.; Fairfield, F. R.; Harger, C. A.; Jett, J. H.; Keller, R. A.; Hahn, J. H.; Krakowski, L. A.; Marrone, B. L.; Martin, J. C.; Nutter, H. L.; Ratliff, R. L.; Shera, E. B.; Simpson, D. J.; Soper, S. A. Genet. Anal.- Biomol. Eng. 1991, 8, 1-7.

(116) Phillips, K. M.; Larson, J. W.; Yantz, G. R.; D'Antoni, C. M.; Gallo, M. V.; Gillis, K. A.; Goncalves, N. M.; Neely, L. A.; Gullans, S. R.; Gilmanshin, R. Nucleic Acids Res. 2005, 33, 5829-5837. 
(117) Smith, C. L.; Kricka, L.; Krull, U. J. Genet. Anal.- Biomol. Eng. 1995, 12, 33-37.

(118) Giuliano, K. A.; Post, P. L.; Hahn, K. M.; Taylor, D. L. Annu. Rev. Biophys. Biomol. Struct. 1995, 24, 405-434.

(119) Ziegler, K. J. Trends Biotechnol. 2005, 23, 440-444. 


\title{
CHAPTER 2. QUANTITATIVE SCREENING OF SINGLE COPIES OF HUMAN PAPILLOMA VIRAL DNA WITHOUT AMPLIFICATION
}

\author{
A paper published in Analytical Chemistry* \\ Jiangwei Li, Ji-young Lee, and Edward S. Yeung
}

\begin{abstract}
We describe a novel quantitative viral screening method based on single-molecule detection that does not require amplification. DNA of human papilloma virus (HPV), the major etiological agent of cervical cancer, served as the screening target in this study. Eight 100-nucleotide single-stranded DNA probes were designed complementary to the E6-E7 gene of HPV-16 DNA. The probes were covalently stained with Alexa Fluor 532 and hybridized to the target in solution. The individual hybridized molecules were imaged with an intensified charge-coupled device (ICCD) in two ways. In the single-color mode, target molecules were detected via fluorescence from hybridized probes only. This system could detect HPV-16 DNA in the presence of human genomic DNA down to 0.7 copy/cell and had a linear dynamic range of over 6 orders of magnitude. In the dual-color mode, we employed fluorescence resonance energy transfer and added YOYO-3 dye as the acceptor. The two
\end{abstract}

\footnotetext{
* Reprint with permission from Analytical Chemistry, 2006, 78 (18), 6490-6496. Copyright@ 2006 American Chemical Society
} 
colors from Alexa Fluor 532 and YOYO-3 were dispersed by a transmission grating located in front of the ICCD. With this reinforced criterion for identifying the hybridized molecules, zero false-positive count was achieved. We also showed that DNA extracts from Pap test specimens did not interfere with the measurements.

\section{Introduction}

Single-molecule techniques opened up new research frontiers for the study of biological macro-molecules. They provided insights into biochemistry, biophysics and biology by revealing unique behaviors of individual molecules. In the early 1990s, a rapid DNA sequencing scheme based on the detection of single, fluorescently tagged nucleotides (nt) cleaved from a single DNA fragment was proposed. ${ }^{1,2}$ Fluorescence resonance energy transfer (FRET) between different chromophores enabled the investigation of protein dynamic interactions in living cells. ${ }^{3,4}$ Gene expression has been analyzed at the singlemolecule scale by fluorescence cross-correlation spectroscopy (FCS) ${ }^{5,6}$ Characteristics of individual biomolecules, such as activity of enzyme molecules, ${ }^{7-9}$ diffusion variations of single DNA molecules, ${ }^{10,11}$ and electrostatic behavior of protein molecules, ${ }^{11}$ have been studied as well. Here, we try to exploit the enormous potential of single-molecule detection in clinical diagnostic applications.

Cervical cancer is the second most common cancer among women worldwide with over $50 \%$ mortality rate, ${ }^{12}$ resulting in 300,000 deaths annually according to the World Health Organization (WHO). In the late 1990s, high-risk subtypes of human papilloma virus (HPV) such as HPV-16 and HPV-18 proved to be the major etiological agents of cervical

cancer. An overall HPV prevalence of $99.7 \%$ among patients was estimated. ${ }^{13}$ Although the 
threshold of the viral load to the cancer stage is not exactly known, it has been established that there is a positive relationship between viral load and cervical cancer risk. ${ }^{14-16}$ The major reason for cervical cancer's high mortality rate is that it does not produce any early-warning symptoms or physical changes until it is so advanced that is usually unresponsive to any treatments.

Early detection of HPV could decrease the incidence of cervical cancer and increase the curability. High sensitivity is the key. Currently, the simple, inexpensive Papanicolaou smear (Pap smear) screening is the most widely used method. It clearly helps in reducing the incidence of cervical cancer, but it suffers from a significant false-negative rate of $20-40 \%{ }^{17}$ as a result of inherent screening errors. ${ }^{18} \mathrm{HPV}$ testing based on viral DNA detection has drawn increasing attention and been suggested as a supplement to the Pap test. ${ }^{19,20}$ Several amplification-based technologies have been developed for viral nucleic acid screening. The most frequently used validated HPV testing methods are polymerase chain reaction (PCR) assay and the U.S. Food and Drug Administration (FDA)-approved hybridization capture assay (HC). PCR is a target-amplification-based method in which the viral DNA fragments can be replicated millions of times during thermal cycles. ${ }^{21-23} \mathrm{HC}$ assay is a signalamplification-based method involving enzymatic reaction. In this assay, cellular DNA is hybridized in a solution containing mixtures of RNA probes. Then, the hybridization complexes are captured to the tube wall coated with an antibody to the RNA-DNA hybrids. After binding to another antibody conjugated with alkaline phosphatase, the hybrids are detected by chemiluminescence reaction with a substrate. ${ }^{24,25}$ Although both of these methods are highly sensitive, ${ }^{25-27}$ the process of amplification often leads to false positive due to contamination. PCR may not start at low copy levels. HC may not achieve $100 \%$ capture 
efficiency. Quantification is another major concern in clinical diagnosis especially since viral load is an important number. PCR is only semiquantitative, since amplification is exponential and the gain depends critically on temperature, solution composition, enzyme activity, etc. ${ }^{28}$ On the other hand, single-molecule detection, ${ }^{29,30}$ which can count individual copies of DNA with $100 \%$ efficiency down to $10^{-17} \mathrm{M}$, can be more reliable than amplification-based schemes. In addition, the elimination of amplification simplifies the operation and the analysis time.

Here, we demonstrate a new quantitative single-molecule method for detecting HPV DNA without amplification. This approach avoids problems with contamination, enzyme inhibition, or both. The assay is based on the hybridization between HPV DNA and fluorescently labeled complementary DNA probes. Among more than 100 types of HPV, HPV type 16 (HPV-16), which alone accounts for $\sim 50 \%$ of the cancer cases ${ }^{31}$ was the target DNA. The length of HPV-16 DNA is $~ 8000$ base pairs (bp), and its oncogene E6-E7 that is $800 \mathrm{bp}$ is expressed in all HPV-containing tumors and derived cell lines. E6-E7 gene is required not only for initiation but also for the maintenance of a proliferative and malignant phenotype in host cells. ${ }^{32}$ This gene can be found in both episomal and integrated forms in human chromosomes of the cells it infects, ${ }^{33}$ thereby making it suitable for recognition. We have previously shown that the smallest DNA molecule size detectable with this apparatus is $120 \mathrm{bp} .{ }^{29}$ Therefore, the viral DNA was probed by eight 100 -nt complementary singlestranded (ss)-DNA. The individual probe molecules were below the threshold for detection of individual hybrid molecules. This technique not only allows the detection and quantification of viral DNA with low detection limit, but also offers a universal approach to any other DNA sequence typing by simply changing the sequence-specific probes. 


\section{Experimental Section}

Sample Preparation. Eight 100-nt ss-DNA probes were designed according to the sequences of the E6/E7 region of HPV-16 from Genbank (K02718), and synthesized by Integrated DNA Technologies (Coralville, IA). The probes were dissolved in $\mathrm{pH} 8.01 \times$ TrisEDTA (TE) buffer (Ambion, Austin, TX) and labeled individually with a Ulysis Alexa Fluor 532 nucleic acid labeling kit (Molecular Probes, Eugene, OR) according to the manufacturer's instructions. After the staining reaction, tubes were snap-cooled on ice, and the probes were subjected to a cleanup procedure with micro bio-spin columns (Bio-Rad Laboratories, Philadelphia, PA) to get rid of excess labeling reagents. All eight probes were mixed together for the subsequent hybridization step.

In hybridization samples, the total amount of HPV-16 DNA (Maxim Biotech, San

Francisco, CA) and female human genomic DNA (Promega, Madison, IL) was kept at $1 \mu \mathrm{g}$, while the ratio of them was varied to achieve a series of HPV-16 contents from 0 to $10 \%$. The probe solution was mixed with the DNA so that the concentration of each probe was 8 times that of HPV-16 DNA. Finally, hybridization buffer (Maxim Biotech) was added to make a total volume of $30 \mu \mathrm{L}$. The samples were kept at $95^{\circ} \mathrm{C}$ for $10 \mathrm{~min}$ for denaturation and at $42{ }^{\circ} \mathrm{C}$ overnight for hybridization in a thermal cycler (GeneAmp PCR System 9700, Applied Biosystems, Foster City, CA). The hybridization samples were diluted with nuclease-free water (Ambion, Austin, TX) to proper concentrations right before imaging (see Table 1).

In dual-color detection, the samples were further labeled with YOYO-3 (Molecular Probes) at a ratio of one dye molecule per five bases. Restriction endonuclease reaction was 
carried out to reach low detection limit. HPV-16 DNA and human genomic DNA were mixed together and digested by $5 \times$ HindIII (New England Biolabs, Ipswich, MA) at $37{ }^{\circ} \mathrm{C}$ for $1 \mathrm{~h}$. The enzyme was deactivated at $65^{\circ} \mathrm{C}$ for $20 \mathrm{~min}$. Then, the probes were added into the digested DNA for hybridization in the same way as for single-color detection.

Cervical cancer-derived cell lines CaSki and SiHa were purchased from ATCC (Manassas, VA). Normal Pap test specimens were donated by a healthy adult female. DNA from these specimens were extracted by the DNeasy tissue kit (Qiagen, Valencia, CA) and used without further purification. DNA extraction yield is $60-80 \%$ according to the manufacture's handbook. The DNA concentration was calculated from UV absorption at 260 nm. The amount of extracted DNA from each Pap sample was $8 \mu \mathrm{g}$.

Imaging System. The imaging system was similar to the previous apparatus used in our group, ${ }^{34,35}$ with some modifications (Figure 1). A 532-nm solid-state continuous wave laser (45 mW, $\mu$-green Model 4611, Uniphase, San Jose, CA) was used as the excitation source. A Uniblitz mechanical shutter (model LS2Z2, Vincent Associates, Rochester, NY) and a driver (model T132, Vincent Associates) were synchronized to the Pentamax 512EFT/1EIA intensified charge-coupled device (ICCD) camera (Princeton Instruments, Princeton, NJ). The shutter let the laser beam pass through only when the ICCD was on to reduce photobleaching. After the mechanical shutter, the laser beam was expanded by the first cylindrical lens (focal length, $200 \mathrm{~mm}$; Thorlabs, Newton, NJ) in the $Y$-direction. The expanded beam was then focused into the capillary at normal angle as a thin sheet by the second cylindrical lens (focal length, 25 mm; Edmund Industrial Optics, Barrington, NJ). The image of the laser focusing plane was schematically shown in the enlarged part in Figure 1. Only molecules inside the laser focusing plane could be excited and detected. The 
illuminated volume was $\sim 0.2 \mathrm{~nL}$, implying a detection efficiency of $13 \%$ considering the illuminated portion compared to the total thickness of capillary bore. Hybridization samples were injected into a 30 -cm-long square capillary $(75 \mu \mathrm{m}$ i.d. $\times 365 \mu \mathrm{m}$ o.d.; Polymicro Technologies, Phoenix, AZ), and the flow was driven hydrodynamically. Fluorescence from single molecules was collected by a Zeiss 20×/0.75 NA Plan-Apochromat microscope objective lens. A 532-nm long-pass edge filter (Semrock, Rochester, NY) and a 532-nm holographic notch filter (OD >6, Kaiser Optical, Ann Arbor, MI) were placed between the objective lens and the ICCD to cut off scattering from the excitation beam. A transmission grating with 70 grooves $/ \mathrm{mm}$ (Edmund) was mounted in front of the ICCD camera to disperse fluorescence collected from the molecules. The distance between the transmission grating and the ICCD was set to be $6.5 \mathrm{~cm}$ so that the zeroth-order and first-order images of the 75$\mu \mathrm{m}$-i.d. capillary would not overlap each other. The sampling frequency was $2 \mathrm{~Hz}$, with the shutter driver set to $40-\mathrm{ms}$ exposure and 460-ms delay. Data were processed on a personal computer with the WinView software provided by Princeton Instruments.

\section{Results and Discussion}

Single-Color Detection. In the single-color detection system, only one fluorophor was utilized to visualize the target. Alexa Fluor 532 was selected since its absorption maximum matches the wavelength of a readily accessible excitation source. Sequencespecific Alexa Fluor 532 labeled oligonucleotide probes were hybridized to target HPV-16 DNA and the hybrids were visualized by a single-molecule imaging system (Figure 2A). About one label was incorporated for every $20 \mathrm{nt}$. When light passes through a transmission grating, it is divided into a nondispersed zero-order image and higher-order spectrally 
dispersed images. The physical separation between the orders is a function of the distance between the grating and the ICCD and the wavelength of the light. As the grating is located further away from the ICCD camera, the separation between the orders increases and the fluorescence spectrum covers a greater number of pixels to provide higher resolution. A typical fluorescence image of single DNA molecules in a capillary dispersed with a transmission grating is shown in Figure 2B. The left half is the zeroth-order image of molecules in the capillary, which is identical to that obtained without the grating. The right half is the first-order imaging from the transmission grating, where light was dispersed horizontally according to the wavelength. The dispersion distances in the images were measured between the highest intensity pixels in the zeroth order and the first order as shown in Figure 2B. Since the dispersion distance is proportional to the fluorescence wavelength, impurities can be easily distinguished from hybrids based on wavelength differences. A histogram of the dispersion distances of pure Alexa Fluor 532 probes/HPV-16 DNA hybrids is plotted as Figure 2C. With the grating positioned $6.5 \mathrm{~cm}$ from the ICCD and a 20x objective, the average dispersion of the 550 -nm emission was $106.0 \pm 1.1$ pixels. Note that Figure 2B shows only 1 molecule for clarity. We have previously shown that up to 200 molecules can be imaged at a time in such an arrangement. ${ }^{36}$

As shown in Figure 1, the sample volume of each frame is $75 \times 75 \times 300 \mu \mathrm{m}^{3}$, which is $1.7 \mathrm{~nL}$. To make sure that the spots are molecules instead of random noise bursts of the ICCD, the molecules were tracked for five consecutive frames. So, $1.7 \mathrm{~nL}$ of liquid flowed through the capillary every five frames. If the movie has 7500 frames, the total volume that flowed through the detection area was $2.6 \mu \mathrm{L}$. 
To evaluate quantification, HPV-16 DNA was added into commercial human genomic DNA matrix. The total amount of viral and human genomic DNA in a vial was kept constant, while the ratio between them was varied to achieve a series of HPV-16 percentages from 0 to $10 \%\left(\sim 7 \times 10^{5}\right.$ copy/cell). HPV-16 DNA percentage higher than $10 \%$ was not included as clinical specimens rarely reach such a high concentration. After hybridization, the samples were diluted to suitable concentrations for counting individual molecules. The dilution factor for each sample was designed (Table 1) to make sure that molecules did not overlap with each other in the high-concentration samples, and the number of hybridized molecules was higher than three times that of false-positive counts in the low-concentration samples. A flow system was selected to allow screening of a much larger volume of sample than that within the detection window. Note that only a small fraction of the total sample passed through the observation region per count period. For a meaningful comparison, it was necessary to keep the probed volume constant from run to run. The volume probed per detection experiment (movie) was proportional to the flow rate. Since the flow was driven by hydrodynamic force, the heights of the sample reservoirs at the two ends of the capillary were fixed to ensure reproducibility. After the movies were recorded, the molecules were counted manually while fast-forwarding the movies. The numbers were further normalized to the same standard considering the movie length and dilution factor. The blue data points in Figure 2D, corresponding to normalized data column in Table 1, showed that a good linear relationship between HPV-16 DNA percentage and the number of molecules detected was obtained over a range of 6 orders of magnitude. At low concentrations, the precision is limited by counting statistics. Furthermore, intensity variations among molecules relative to 
the preset threshold, sample manipulation and loss of material due to adsorption limit the precision to about $\pm 8 \%$.

To test the compatibility of the current Pap test sampling method with this assay, we extracted DNA from normal Pap smear specimens. About $8 \mu \mathrm{g}$ of total DNA could be obtained from each specimen. Viral DNA was added to the extracted DNA matrix in the same way as in the commercial human genomic DNA experiments (Table 1). In Figure 2D, the red data points for the extracted DNA matched well with the blue ones for the standard samples. The results also show that the background levels of the two matrixes were similar, indicating that DNA extracts from Pap test specimens did not have biological impurities that would interfere with single-molecule detection.

Single-molecule screening was further tested for cell lines with known viral load. The HPV-16 viral loads in cervical cancer-derived cell lines CaSki and SiHa are $\sim 600$ copies/cell and 1-2 copies/cell, respectively, as specified by American Type Culture Collection (ATCC). DNA was extracted in the same way as in the Pap test samples. We detected an average of 8200 and 49 molecules per experiment for these two cell lines, respectively. The detected numbers were converted to the HPV-16 DNA percentages based on the flow rate and the sample volume. Then, the DNA content of each cell is calculated by dividing the extracted DNA amount by the cell population. The calculated viral loads were 540 and 2.4 copies/cell, respectively. The agreement with the numbers from ATCC means that this quantitative assay is well-behaved.

The number of molecules measured for the 0\% HPV-16 DNA sample (inset of Figure 2D) represents false positives. The three possible sources of false positives are: aggregation of unbound probes, nonsequence-specific hybridization with human genomic DNA, and random 
noise of the ICCD camera. The first factor could be neglected as no counts were found in control experiments that contained probes only. Cross-hybridization could be minimized by optimization of hybridization conditions, such as temperature and ionic strength. When two random noise spikes accidentally showed up in the images with reasonable dispersion distance, they would be counted as false positives as well. These could be greatly reduced by the dual-color detection mode described below. The ratio of the number of detected HPV-16 DNA molecules to that of false positives is the signal-to-noise ratio $(\mathrm{S} / \mathrm{N})$. The detection limit of HPV-16 DNA is $0.0001 \%(\sim 0.7$ copy/cell) when $\mathrm{S} / \mathrm{N}$ equals three. This sensitivity is extremely high among the quantitative assays of nucleic acids. Moreover, this was achieved without amplification.

Dual-Color Detection. To improve the selectivity in identifying the target, a second fluorophor was added to the single-color detection scheme. Dual-color detection can greatly reduce the possibility of false positives from ICCD noise because there will be three spots per image for each hybridized molecule rather than two. The chance of three random noise spikes accidentally appearing with the correct dispersion distance is negligible. FRET can be involved in the dual-color detection system in the vicinity of the probes. The intercalating dye YOYO-3 was added after hybridization of Alexa Fluor 532-labeled probes to the target so that it stains the whole genome. YOYO-3 was chosen as the second dye according to three criteria. First, it has emission maximum at $661 \mathrm{~nm}$, which is easily distinguished from that of Alexa Fluor 532. Second, its absorption maximum $(612 \mathrm{~nm})$ is far away from the excitation wavelength $(532 \mathrm{~nm})$ so that it is very dim without energy transfer from Alexa Fluor 532. Third, its fluorescent intensity is comparable to that of the Alexa Fluor 532 donor when 
partial FRET occurs. These features allowed us to identify the dual-color molecules conveniently.

Figure $3 \mathrm{~A}$ shows the hybridized molecules labeled with YOYO-3 as an enhancement to the single-color system. When excited by a 532-nm laser, fluorescence from both Alexa Fluor 532 and YOYO-3 were detected. A typical dual-color image of pure HPV-16 DNA hybridization sample is shown in Figure 3B. The left peak in the first-order image corresponds to the emission of Alexa Fluor 532 at $550 \mathrm{~nm}$ while the right peak corresponds to the emission of YOYO-3 at $661 \mathrm{~nm}$. The average dispersion of Alexa Fluor 532 was 106.6 \pm 0.9 pixels and that of YOYO- 3 was $121.8 \pm 1.2$ pixels. The difference between the two averages was 15.2 pixels, which was 14.4 times the average of the two standard deviations. That is, the two peaks are clearly separated from each other. The statistical information was collected in the same way as for single-color detection, and the histogram is shown in Figure 3C. There were 90 molecules counted in the experiment, in which 77 molecules had two peaks and 13 molecules had one. All the single-color molecules were associated with the dispersion distance of YOYO-3, which represented the target DNA bound with too few number of probes. The hybrids with at least five probes clearly appeared as bright spots in our setup (data not shown).

When bulky human genomic DNA was added as the matrix for two-color DNA detection, YOYO-3 made them appear as bright single-color molecules. The background level increased, and it was not practical to seek out the dual-color hybridized molecules among the single-color matrix especially when the HPV-16 DNA content was low. This problem resulted in poor sensitivity, and the detection limit was only $1 \%\left(\sim 7 \times 10^{3}\right.$ copies/cell) HPV-16 DNA. To solve this problem, we used a restriction endonuclease to 
digest human genomic DNA into small pieces, with an average length of $4 \mathrm{~kb}$. HindIII worked very well for cutting human genomic DNA while preserving the E6-E7 region of HPV-16 DNA. There was 1 order of magnitude improvement in detection limit, that is, down to $0.1 \%\left(\sim 7 \times 10^{2}\right.$ copies/cell $)$ with this digestion step. In the negative control experiment, where the sample contained everything except the target DNA, no dual-color signal was detected. It is worth pointing out that although the sensitivity could not compete with singlecolor detection, the lack of false positives was a significant advantage for dual-color detection.

\section{Conclusions}

This viral DNA screening system is sensitive with a detection limit of 0.7 copy/cell and has a wide linear dynamic range over 6 orders of magnitude. It is reliable in quantification since no amplification is involved. Although PCR methods have enabled the

detection of the level of 0.05 copy/cell, ${ }^{37}$ they require many $(>10)$ copies for proper amplification. False positives, contamination, and enzyme inhibition are other concerns. The probe design is a key step in this method. The single unbound probes are invisible at the selected threshold but become visible when at least five of them hybridized to the target. So, the digital counting approach avoids the need to remove the unbound probes or add quenchers after hybridization to decrease background. The whole procedure could involve little more than cell lysis, DNA denaturation, hybridization, and imaging. Dual-color detection could achieve zero false-positive count. Moreover, this technique can be directly coupled with current sampling methods such as Pap smears. Since this screening technology does not require other HPV-16 DNA specific features (e.g., antibodies) except for the probe 
sequence, it is readily applicable to any DNA detection and quantification by changing the probes. In comparison with photon-burst detection, ${ }^{38}$ imaging allows substantially higher throughput in molecule counting. Up to 2500 molecules can be screened in $25 \mathrm{~ms}^{35}$ The transmission grating offers simple, accurate, and sensitive spectral analysis when compared to using multiple optical filters or multiple lasers. ${ }^{38}$ The detection efficiency can be further increased to near $100 \%$ with radial focusing of molecules inside the capillary when an electric field is applied across the capillary along with hydrodynamic flow, ${ }^{30}$ while confocal systems $^{38}$ inherently miss the larger fraction of molecules that pass outside the laser focal point. That feature allowed us to count molecules down to $10^{-17} \mathrm{M}$ compared to $5 \times 10^{-13} \mathrm{M}$ in confocal systems.

\section{Acknowledgement}

We thank Hung-Wing Li for valuable discussions, and Dr. Mary Jo Schmerr for the help with cellular DNA extraction. E.S.Y. thanks the Robert Allen Wright Endowment for Excellence for support. The Ames Laboratory is operated for the U.S. Department of Energy by Iowa State University under Contract No. W-7405-Eng-82. This work was supported by the Director of Science, Office of Basic Energy Sciences, Division of Chemical Sciences and by the National Institutes of Health. 
Table 1. Contents of hybridization samples and the corresponding dilution factors for imaging

\begin{tabular}{|c|c|c|c|c|c|c|c|c|}
\hline $\begin{array}{l}\text { HPV-16 } \\
\text { DNA }(\mu \mathrm{g})\end{array}$ & $\begin{array}{l}\text { HPV-16 } \\
\text { DNA (\%) }\end{array}$ & $\begin{array}{l}\text { Human genomic } \\
\text { DNA }(\mu \mathrm{g})\end{array}$ & $\begin{array}{l}\text { probes } \\
(\mu \mathrm{L})^{\mathrm{a}}\end{array}$ & $\begin{array}{l}\text { volume } \\
(\mu \mathrm{L})\end{array}$ & $\begin{array}{l}\text { dilution } \\
\text { factor }\end{array}$ & $\begin{array}{l}\text { movie length } \\
\text { (no. of frames) }\end{array}$ & $\begin{array}{l}\text { observed no. } \\
\text { of molecules }\end{array}$ & $\begin{array}{l}\text { normalized no. } \\
\text { of molecules }\end{array}$ \\
\hline 0.1 & $10 \%$ & 0.9 & 1 & 30 & 5000 & 1500 & $280 \pm 16$ & $700000 \pm 39000$ \\
\hline 0.05 & $5 \%$ & 0.95 & $5(10)$ & 30 & 5000 & 1500 & $144 \pm 8$ & $359000 \pm 29000$ \\
\hline 0.01 & $1 \%$ & 0.99 & $1(10)$ & 30 & 1000 & 1500 & $135 \pm 8$ & $67700 \pm 4800$ \\
\hline 0.005 & $0.5 \%$ & 0.995 & $5(100)$ & 30 & 500 & 1500 & $154 \pm 10$ & $38600 \pm 3000$ \\
\hline 0.001 & $0.1 \%$ & 0.999 & $1(100)$ & 30 & 100 & 1500 & $157 \pm 12$ & $7830 \pm 600$ \\
\hline 0.0005 & $0.05 \%$ & 0.9995 & $5(1000)$ & 30 & 100 & 1500 & $73 \pm 10$ & $3600 \pm 500$ \\
\hline 0.0001 & $0.01 \%$ & 0.9999 & $1(1000)$ & 30 & 50 & 1500 & $36 \pm 4$ & $890 \pm 110$ \\
\hline 0.00005 & $0.005 \%$ & 0.99995 & $5(10000)$ & 30 & 20 & 1500 & $44 \pm 3$ & $440 \pm 50$ \\
\hline 0.00001 & $0.001 \%$ & 0.99999 & $1(10000)$ & 30 & 20 & 1500 & $13 \pm 1$ & $130 \pm 10$ \\
\hline 0.000005 & $0.0005 \%$ & 0.999995 & $5(100000)$ & 30 & 10 & 7500 & $67 \pm 4$ & $67 \pm 4$ \\
\hline 0.000001 & $0.0001 \%$ & 0.999999 & $1(100000)$ & 30 & 10 & 7500 & $9 \pm 3$ & $9 \pm 3$ \\
\hline 0 & 0 & 1 & $1(100000)$ & 30 & 10 & 7500 & $3 \pm 2$ & $3 \pm 2$ \\
\hline
\end{tabular}

a The values in parentheses are the dilution factors for the probes: e.g. for 5\% HPV-16 DNA, the original probe solution was diluted 10 times and then $5 \mu \mathrm{L}$ of the diluted probe solution was added into the sample. 


\section{References}

(1) Jett, J. H.; Keller, R. A.; Martin, J. C.; Marrone, B. L.; Moyzis, R. K.; Ratliff, R. L.; Seitzinger, N. K.; Shera, E. B.; Stewart, C. C. J. Biomol. Struct. Dyn. 1989, 7, 301309.

(2) Davis, L. M.; Fairfield, F. R.; Harger, C. A.; Jett, J. H.; Keller, R. A.; Hahn, J. H.; Krakowski, L. A.; Marrone, B. L.; Martin, J. C.; Nutter, H. L.; Ratliff, R. L.; Shera, E. B.; Simpson, D. J.; Soper, S. A. Genet. Anal.- Biomol. Eng. 1991, 8, 1-7.

(3) Miyawaki, A.; Llopis, J.; Heim, R.; McCaffery, J. M.; Adams, J. A.; Ikura, M.; Tsien, R. Y. Nature 1997, 388, 882-887.

(4) Jares-Erijman, E. A.; Jovin, T. M. Nat. Biotechnol. 2003, 21, 1387-1395.

(5) Eigen, M.; Rigler, R. Proc. Natl. Acad. Sci. U. S. A. 1994, 91, 5740-5747.

(6) Korn, K.; Gardellin, P.; Liao, B.; Amacker, M.; Bergstroem, A.; Bjoerkman, H.; Camacho, A.; Doerhoefer, S.; Doerre, K.; Enstroem, J.; Ericson, T.; Favez, T.; Goesch, M.; Honegger, A.; Jaccoud, S.; Lapczyna, M.; Litborn, E.; Thyberg, P.; Winter, H.; Rigler, R. Nucleic Acids Res. 2003, 31, e89/81-e89/88.

(7) Xue, Q. F.; Yeung, E. S. Nature 1995, 373, 681-683.

(8) Tan, W.; Yeung, E. S. Anal. Chem. 1997, 69, 4242-4248.

(9) Craig, D. B.; Arriaga, E. A.; Wong, J. C. Y.; Lu, H.; Dovichi, N. J. J. Am. Chem. Soc. 1996, $118,5245-5253$.

(10) Xu, X. H.; Yeung, E. S. Science 1997, 275, 1106-1109.

(11) Lu, H. P.; Xun, L. Y.; Xie, X. S. Science 1998, 282, 1877-1882.

(12) Parkin, D. M.; Bray, F.; Ferlay, J.; Pisani, P. CA. Cancer J. Clin. 2005, 55, 74-108. 
(13) Walboomers, J. M. M.; Jacobs, M. V.; Manos, M. M.; Bosch, F. X.; Kummer, J. A.; Shah, K. V.; Snijders, P. J. F.; Peto, J.; Meijer, C. J. L. M.; Munoz, N. J. Pathol. 1999, 189, 12-19.

(14) Swan, D. C.; Tucker, R. A.; Tortolero-Luna, G.; Mitchell, M. F.; Wideroff, L.; Unger, E. R.; Nisenbaum, R. A.; Reeves, W. C.; Icenogle, J. P. J. Clin. Microbiol. 1999, 37, 1030-1034.

(15) Josefsson, A. M.; Magnusson, P. K. E.; Ylitalo, N.; Sorensen, P.; Qwarforth-Tubbin, P.; Andersen, P. K.; Melbye, M.; Adami, H. O.; Gyllensten, U. B. Lancet 2000, 355, 2189-2193.

(16) Ylitalo, N.; Sorensen, P.; Josefsson, A. M.; Magnusson, P. K. E.; Andersen, P. K.; Ponten, J.; Adami, H. O.; Gyllensten, U. B.; Melbye, M. Lancet 2000, 355, 21942198.

(17) Larsen, N. S. J. Natl. Cancer Inst. 1994, 86, 6-7.

(18) Koss, L. G. J. Amer. Med. Assoc. 1989, 261, 737-743.

(19) Meijer, C. J. L. M.; Helmerhorst, T. J. M.; Rozendaal, L.; van der Linden, J. C.; Voorhorst, F. J.; Walboomers, J. M. M. Histopathology 1998, 33, 83-86.

(20) Cuzick, J. J. Amer. Med. Assoc. 2000, 283, 108-109.

(21) Saiki, R. K.; Scharf, S.; Faloona, F.; Mullis, K. B.; Horn, G. T.; Erlich, H. A.; Arnheim, N. Science 1985, 230, 1350-1354.

(22) Resnick, R. M.; Cornelissen, M. T. E.; Wright, D. K.; Eichinger, G. H.; Fox, H. S.; Terschegget, J.; Manos, M. M. J. Natl. Cancer Inst. 1990, 82, 1477-1484.

(23) Yoshikawa, H.; Kawana, T.; Kitagawa, K.; Mizuno, M.; Yoshikura, H.; Iwamoto, A. Int. J. Cancer 1990, 45, 990-992. 
(24) Clavel, C.; Masure, M.; Bory, J. P.; Putaud, I.; Mangeonjean, C.; Lorenzato, M.; Gabriel, R.; Quereux, C.; Birembaut, P. Br. J. Cancer 1999, 80, 1306-1311.

(25) Poljak, M.; Brencic, A.; Seme, K.; Vince, A.; Marin, I. J. J. Clin. Microbiol. 1999, 37, 796-797.

(26) Sherman, M. E.; Lorincz, A. T.; Scott, D. R.; Wacholder, S.; Castle, P. E.; Glass, A. G.; Mielzynska-Lohnas, I.; Rush, B. B.; Schiffman, M. J. Natl. Cancer Inst. 2003, 95, 46-52.

(27) Coutlee, F.; Mayrand, M. H.; Provencher, D.; Franco, E. Clin. Diagn. Virol. 1997, 8, $123-141$.

(28) Yeung, E. S. Chem. Rec. 2001, 1, 123-139.

(29) Anazawa, T.; Matsunaga, H.; Yeung, E. S. Anal. Chem. 2002, 74, 5033-5038.

(30) Zheng, J. J.; Yeung, E. S. Aust. J. Chem. 2003, 56, 149-153.

(31) Bosch, F. X.; Manos, M. M.; Munoz, N.; Sherman, M.; Jansen, A. M.; Peto, J.; Schiffman, M. H.; Moreno, V.; Kurman, R.; Shah, K. V.; Alihonou, E.; Bayo, S.; Mokhtar, H. C.; Chicareon, S.; Daudt, A.; Delosrios, E.; Ghadirian, P.; Kitinya, J. N.; Koulibaly, M.; Ngelangel, C.; Tintore, L. M. P.; Riosdalenz, J. L.; Sarjadi; Schneider, A.; Tafur, L.; Teyssie, A. R.; Rolon, P. A.; Torroella, M.; Tapia, A. V.; Wabinga, H. R.; Zatonski, W.; Sylla, B.; Vizcaino, P.; Magnin, D.; Kaldor, J.; Greer, C.; Wheeler, C. J. Natl. Cancer Inst. 1995, 87, 796-802.

(32) Hausen, H. Z. Science 1991, 254, 1167-1173.

(33) Choo, K. B.; Pan, C. C.; Han, S. H. Virology 1987, 161, 259-261.

(34) Zheng, J. J.; Yeung, E. S. Anal. Chem. 2002, 74, 4536-4547.

(35) Lee, J. Y.; Li, H. W.; Yeung, E. S. J. Chromatogr. A 2004, 1053, 173-179. 
(36) Ma, Y.; Shortreed, M. R.; Yeung, E. S. Anal. Chem. 2000, 72, 4640-4645.

(37) Hart, K. W.; Williams, O. M.; Thelwell, N.; Fiander, A. N.; Brown, T.; Borysiewicz, L. K.; Gelder, C. M. J. Clin. Microbiol. 2001, 39, 3204-3212.

(38) Neely, L. A.; Patel, S.; Garver, J.; Gallo, M.; Hackett, M.; McLaughlin, S.; Nadel, M.; Harris, J.; Gullans, S.; Rooke, J. Nat. Methods 2006, 3, 41-46. 


\section{Figure Captions}

Figure 1. Schematic illustration of the experimental setup: Laser, $532 \mathrm{~nm}$ continuouswave solid-state laser; MS, mechanical shutter; CL1, cylindrical lens, FL= $200 \mathrm{~mm}$; CL2, cylindrical lens, $\mathrm{FL}=25 \mathrm{~mm}$; SC, square capillary; $\mathrm{O}$, objective lens, $20 \times$ NA $0.75 ;$ F1, $532 \mathrm{~nm}$ long pass edge filter; F2, $532 \mathrm{~nm}$ holographic notch filter; TG, transmission grating; ICCD, intensified CCD camera; PG-200, function generator for controlling the ICCD; PC, personal computer for data acquisition and analysis. The inset shows the excitation and detection regions.

Figure 2. Single-molecule detection of HPV-16 DNA in single-color mode. (A) Schematic diagram of single-color mode. After heat denaturing, HPV-16 DNA was hybridized to the 8 complementary oligonucleotide probes labeled with Alexa Fluor 532. The 550-nm fluorescence images of the hybrids were record by ICCD camera when excited by 532-nm laser. (B) Fluorescence images of a single Alexa Fluor 532-labeled probes/HPV-16 DNA hybrid molecule dispersed with a 70 grooves $/ \mathrm{mm}$ transmission grating. The dispersion distance between the zeroth-order image and first-order image was proportional to the fluorescent wavelength. (C) Distribution of dispersion distances from Alexa Fluor 532-labeled probes/HPV-16 DNA hybridized molecules. Total sampling number, 100; average dispersion, $106.0 \pm 1.1$ pixels. (D) Standard curve of the quantification of HPV-16 DNA. Both axes are logarithmic scales. The blue points depict the averages over three 
experiments with commercial human genomic DNA and the error bars are the standard deviations (Table 1) of these three sets; the red points are data from one experiment with extracted DNA from Pap smear sample. The inset shows the number of counts in negative control and the low concentration region.

Figure 3. Single-molecule detection of HPV-16 DNA in dual-color mode. (A) Schematic drawing of dual-color imaging. After heat denaturing, HPV-16 DNA was hybridized to the complementary oligonucleotide probes labeled with Alexa Fluor 532. The hybrids were then labeled with YOYO-3. Both 550- and 631-nm fluorescence images of the hybrids were recorded by the ICCD camera when excited by 532-nm laser. (B) Fluorescence images of two Alexa Fluor 532 + YOYO-3 colabeled probes/HPV-16 DNA hybrid molecule. (C) Distribution of dispersion distances from Alexa Fluor $532+$ YOYO-3 colabeled probes/HPV-16 DNA hybridized molecules. For the left group of data, total sampling number is 77 , average dispersion, $106.6 \pm 0.9$ pixels; for the right group of data, total sampling number is 90 , average dispersion, 121.8 \pm 1.2 pixels. The difference between the populations of these two groups is the count of YOYO-3 stained molecules bound to fewer than 5 probes. 
Figure 1.

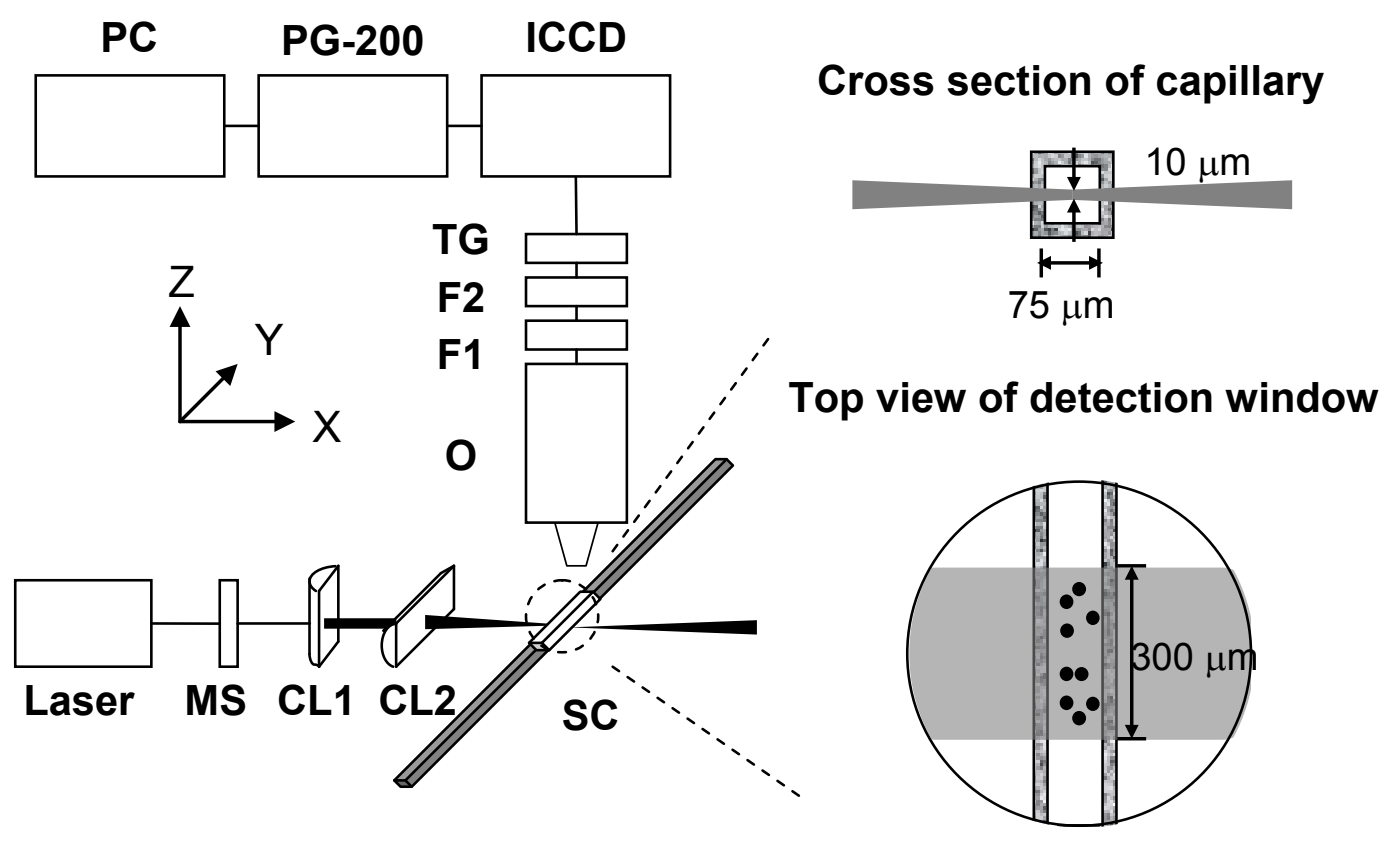


Figure 2.

A

ds-HPV-16 DNA Targets and Alexa Fluor 532-ss-

DNA Probes mixture

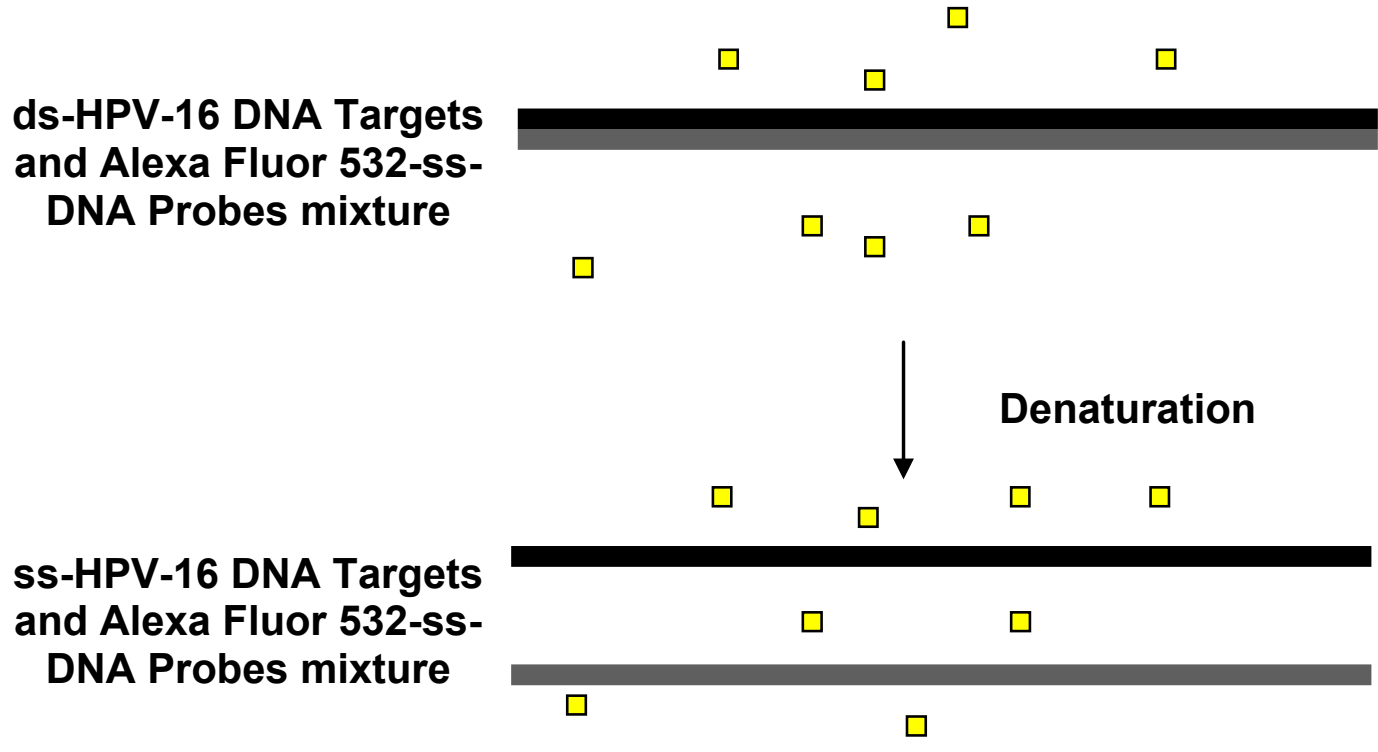

Alexa Fluor 532-Probes /HPV-16 DNA Hybrids

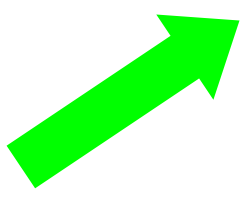

532 nm laser in
$550 \mathrm{~nm}$ fluorescence out 
Figure 2. (Contd.)

B

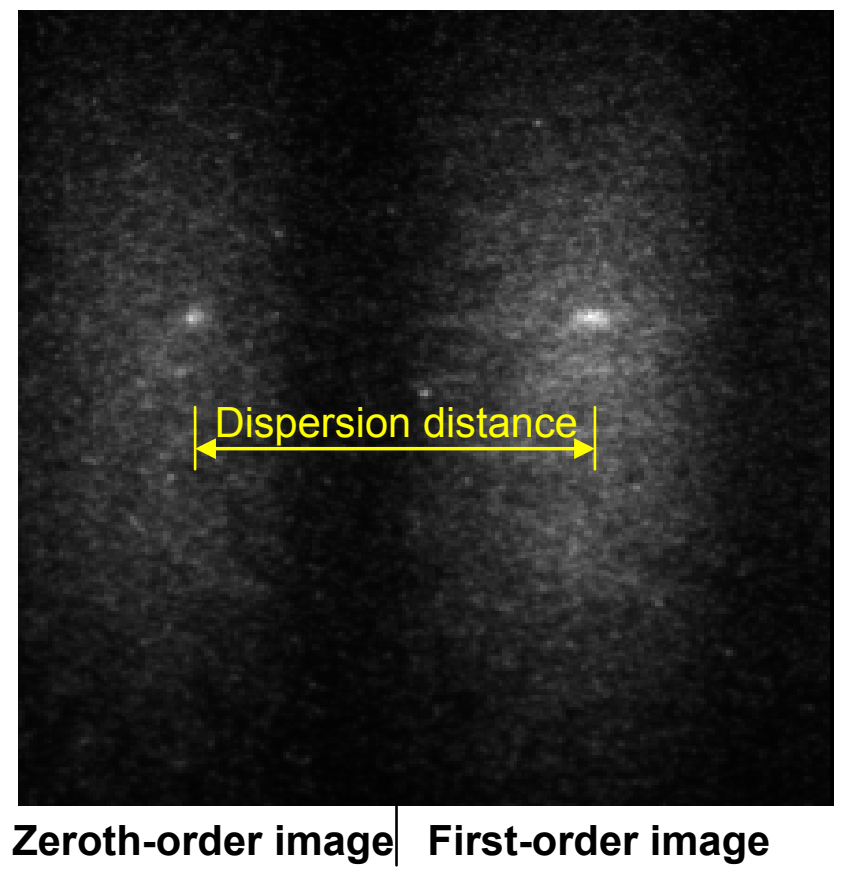


Figure 2. (Contd.)

C

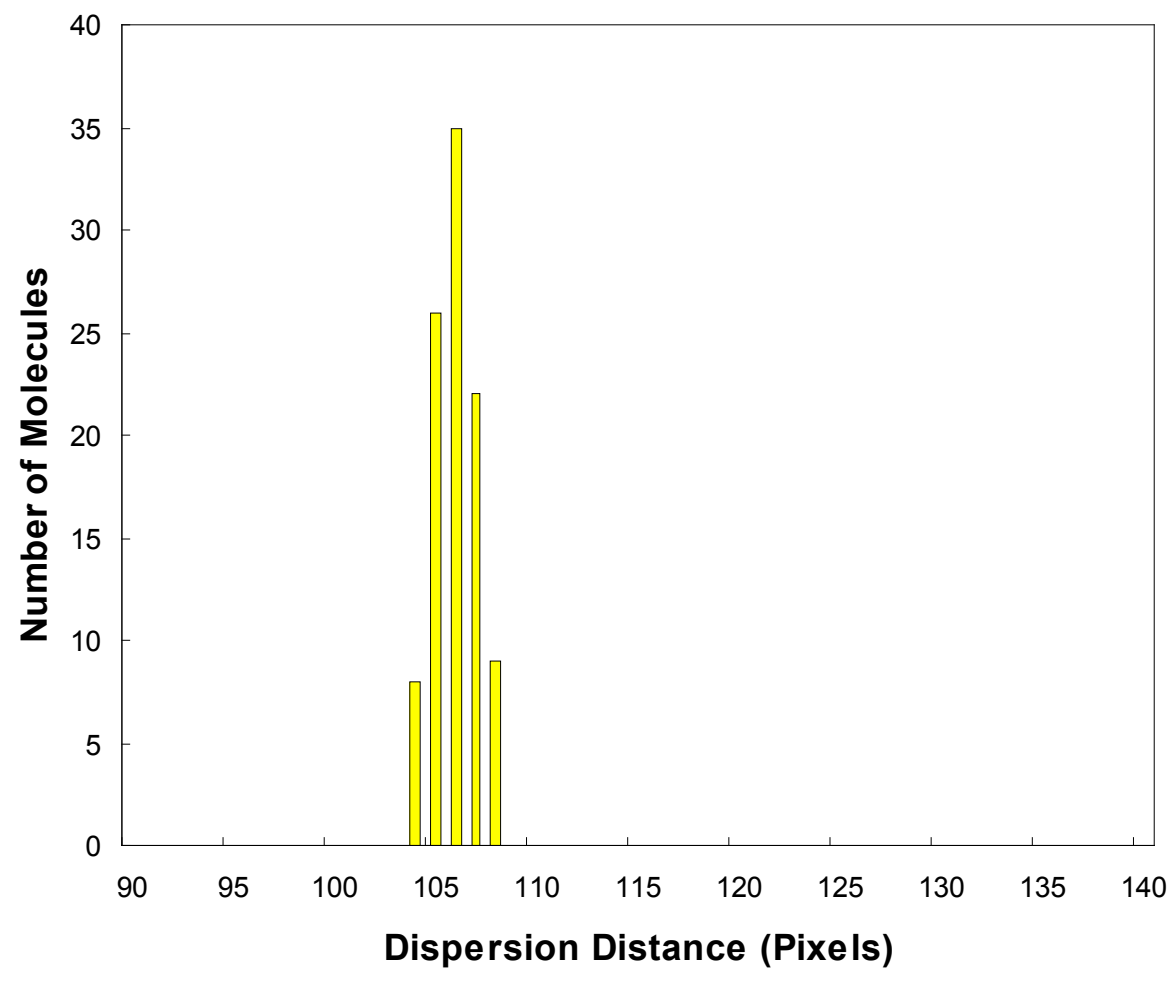


Figure 2. (Contd.)

D

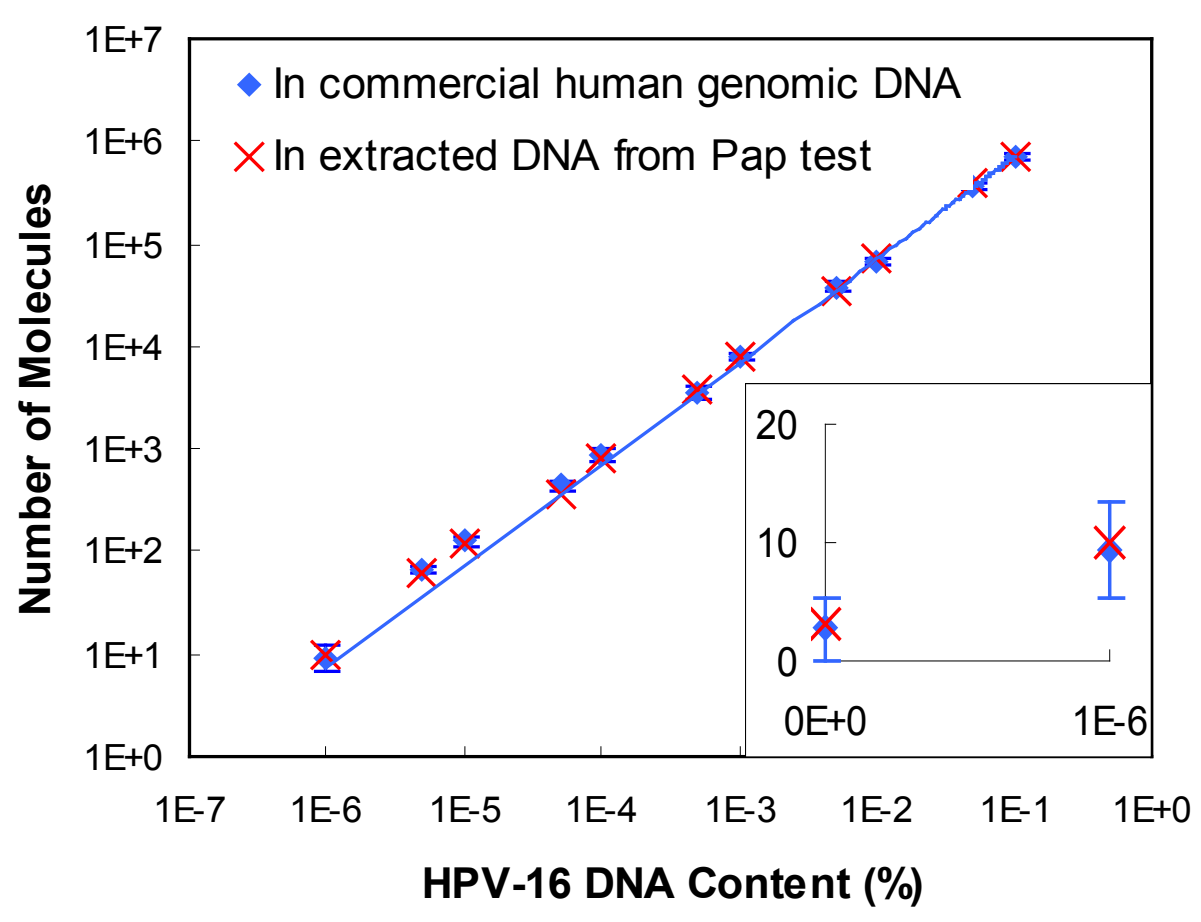


Figure 3.

A

ds-HPV-16 DNA Targets and Alexa Fluor 532-ss-

DNA Probes mixture

ss-HPV-16 DNA Targets and Alexa Fluor 532-ss-

DNA Probes mixture

Alexa Fluor 532-Probes

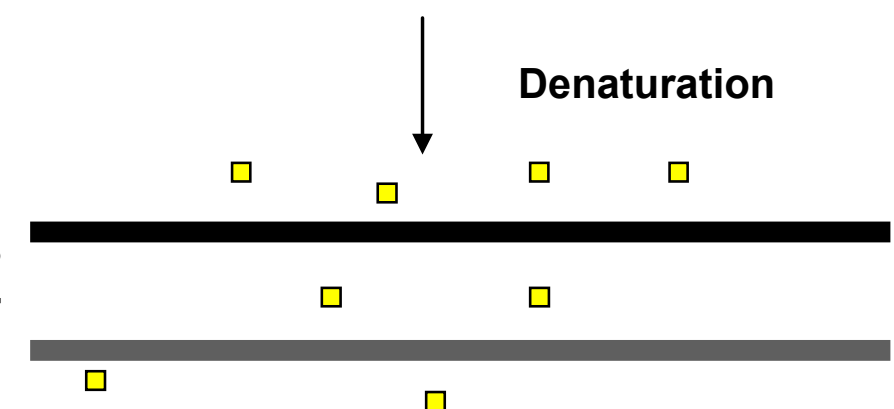

/HPV-16 DNA Hybrids

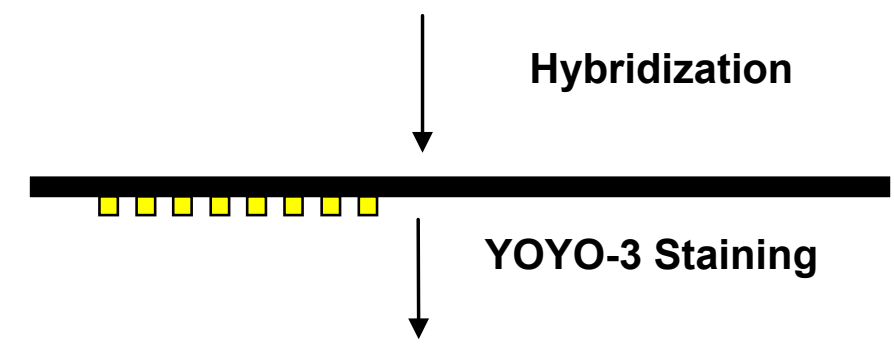

Alexa Fluor 532\&YOYO-3

Probes/HPV-16 DNA

Hybrids

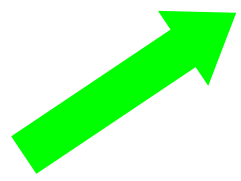

$532 \mathrm{~nm}$ laser in
ㅁपㅁㅁㅁำ $\square$ 
Figure 3. (Contd.)

B

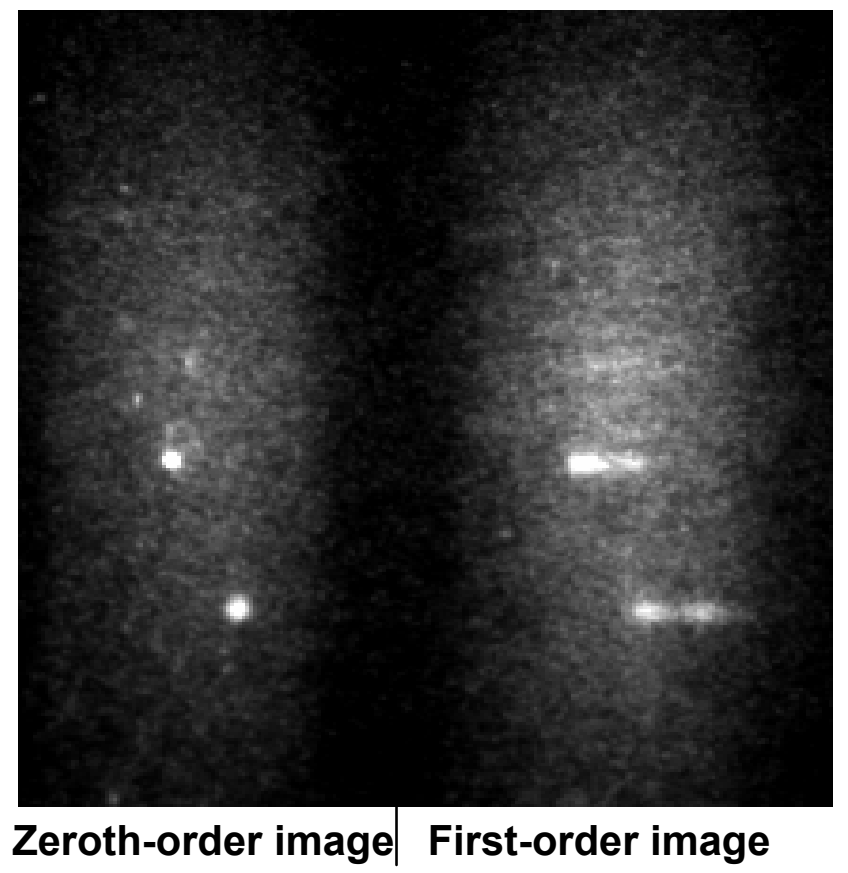


Figure 3. (Contd.)

C

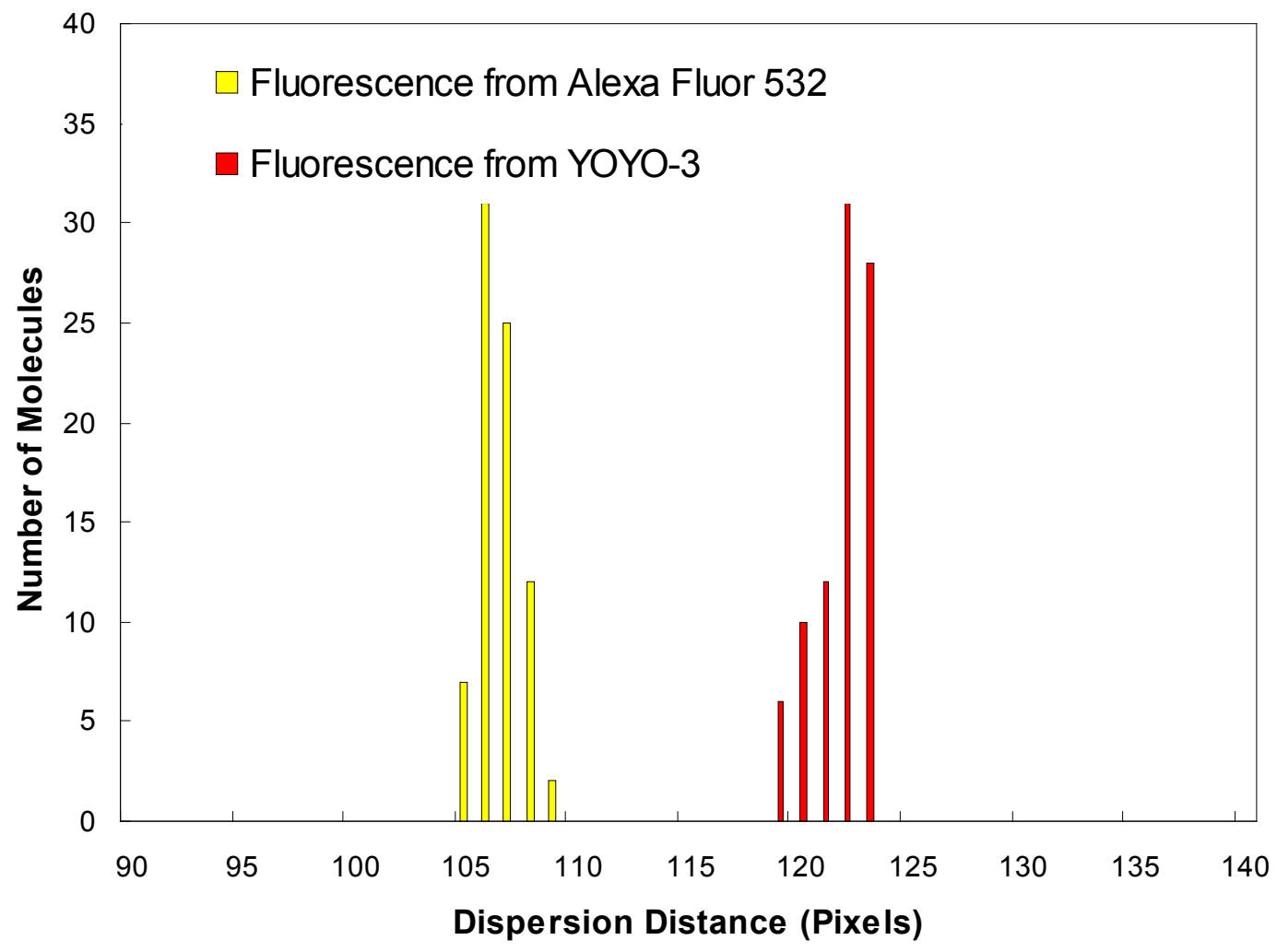




\title{
CHAPTER 3. SINGLE-MOLECULE DETECTION OF SURFACE- HYBRIDIZED HUMAN PAPILLOMA VIRUS DNA FOR QUANTITATIVE CLINICAL SCREENING
}

\author{
A paper published in Analytical Chemistry* \\ Ji-young Lee, Jiangwei Li, and Edward S. Yeung
}

\begin{abstract}
We present an improved method to quantify viral DNA in human cells at the singlemolecule level. Human papilloma virus (HPV)-16 DNA was hybridized to probes that were covalently bound to a glass surface and detected with a single-molecule imaging system. In the single-probe mode, the whole genome and target DNA were fluorescently labeled before hybridization. In the dual-probe mode, a second probe was introduced that has a fluorescently labeled 1-kb DNA strand connected to the 50-nt probe sequence. With the single-probe method, the detection limit was 0.7 copy/cell, which was similar to that reported in a flow system earlier. With the dual-probe method, the linear dynamic range covers 1.447000 copies/cell, which is typical of early infection to near-cancer stages. Both methods were applied to cell line samples with known HPV-16 infection and the result showed good match with the reported viral load. DNA from cervical cells, collected with the Pap-smear sampling

* Reprint with permission from Analytical Chemistry, 2007, 79 (21), 8083-8089.

Copyright@2007 American Chemical Society
\end{abstract}


method, was spiked with HPV-16 DNA and submitted to this assay to show compatibility with conventional sampling methods. The dual-probe method was further tested with a crudely prepared sample. The cells were heat lyzed and spun down, and the supernatant was immediately submitted to hybridization. Even with reduced hybridization efficiency caused by the interference of cellular materials, we were still able to differentiate infected cells with 600 copies/cell from healthy cells.

\section{Introduction}

Detection and quantification of nucleic acids with a specific sequence have depended heavily upon amplification methods. To detect viral DNA such as human papilloma virus (HPV), target amplification is widely used as well as other signal amplification schemes. ${ }^{1,2}$ Although their efficiencies are high and the mechanisms are well studied, amplification suffers from both false-positive and false-negative errors. Polymerase chain reaction (PCR) is the most widely used target amplification method because of its well-known sequence specificity and high amplification yield. ${ }^{1,3,4}$ However in PCR, small contaminants can also be amplified ${ }^{5,6}$ to lead to false-positives. The efficiency depends on many factors such as enzyme activity, primer design, temperature and metal ion concentrations. Further, the increase of amplicon is exponential rather than linear, which make quantification difficult. ${ }^{7-9}$ In signal amplification, there are many steps of operation involved, each of which can introduce artifacts. Also, many signal amplification protocols are mediated by enzymes with reactions that are slow (3-10 min). Bypassing amplification steps can significantly cut down the time and effort required as well as the chance for errors.

With the ultimate ability of counting molecules one by one, single-molecule 
spectroscopy can be a good detection and quantification method that does not require amplification. ${ }^{10-13}$ It has been demonstrated in various applications such as minor abnormality detection in DNA, ${ }^{14,15}$ quantification of gene expression, ${ }^{16,17}$ and viral DNA detection for clinical screening. ${ }^{18}$ Mutation or single-nucleotide polymorphism detection is one of the most active areas involving single-molecule spectroscopy, suggesting potential applications as a clinical screening method. ${ }^{19,20}$

Here we present an improved single-molecule strategy to detect and quantify viral DNA. We have shown that a flow system can be employed based on a thin fused-silica capillary through which fluorescently tagged target DNA molecules pass. ${ }^{18}$ While that method had a very low detection limit of 0.7 copy of HPV DNA per cell, it had a few shortcomings. Data collection time was long for very low concentration samples and sample dilution was required in case of high concentration samples. Detection efficiency was limited since the observation volume was determined by laser illumination focused into a very narrow region in the center of a capillary. To overcome such problems, surface hybridization was evaluated as an alternative. Target HPV-16 DNA was hybridized to probes covalently bound on the glass surface. This is analogous to DNA arrays but engineered for singlemolecule counting. Other merits include elimination of unhybridized DNA by washing, increased detection efficiency by rapid scanning over a large surface area, and a wide linear dynamic range without involving sample dilution. Surface hybridization was tested with single- and dual-probe methods with purified commercial DNA before applying to cell line extracts and human cervix cells collected by the conventional Pap test sampling procedure. Then, DNA extracted from HPV-16 cell line with minimal purification was hybridized and detected using the dual-probe method. 


\section{Experimental Section}

Slide Pretreatment. Custom-made cover glass coated with poly-L-lysine $(22 \times 40$ $\mathrm{mm}$ ) was purchased from TeleChem International (Sunnyvale, CA). The surface probe was 100-nt oligonucleotide of the 661-760 base region in the E7 gene of HPV-16 (Genbank K02718) and was synthesized by IDT (Coralville, IA, sequence shown in Table 1). The probe was dissolved in $10 \mathrm{mM}$ Gly-Gly solution (pH 8.2) (Sigma, St. Louis, MO) to a concentration of $0.02 \mu \mathrm{g} / \mu \mathrm{L}$. A total of $5-7 \mu \mathrm{L}$ of this solution was pipetted onto the poly-Llysine-coated cover glass ("slide"), sandwiched with an uncoated $22 \times 22 \mathrm{~mm}$ cover glass, and kept at room temperature for $1 \mathrm{~h}$. The top cover glass was removed before UV crosslinking in StrataLinker UV-cross-linker (Stratagene, La Jolla, CA) at $150 \mathrm{~mJ}$. The slides were dipped in deionized water 2-3 times and dried under a nitrogen stream. To deactivate unreacted functional groups on poly-L-lysine, the slides were immersed in a solution of $3 \mathrm{~g}$ succinic anhydride (Fluka, Seelze, Germany) dissolved in $170 \mathrm{ml} \mathrm{1-methyl-2-pyrrolidinone}$ (Sigma), buffered with $7.5 \mathrm{~mL} 1 \mathrm{M}$ sodium borate (pH 8.3, Fluka) for $20 \mathrm{~min}^{21}$ After gentle washing in $200 \mathrm{~mL}$ of deionized water for $5 \mathrm{~min}$, slides were immersed in $95^{\circ} \mathrm{C}$ deionized water for 2 min, dipped 5-10 times in 95\% ethanol and blow-dried with nitrogen.

DNA Preparation. HPV-16 genomic DNA (Maxim Biotech, San Francisco, CA) and human female genomic DNA (Promega, Madison, IL) were digested with three restriction enzymes: HaeIII, NcoI, and BstNI (New England Biolabs, Ipswich, MA). After digestion, both DNAs were cleaned with a QiaQuick PCR purification kit (Qiagen, Valencia, CA) and redissolved in $10 \mathrm{mM}$ Tris- $\mathrm{HCl}$ (Sigma). For the single-probe detection experiment, both HPV and human genomic DNAs were stained with a Ulysis Alexa Fluor 532 kit (Molecular 
Probes, Eugene, OR) and purified with the PCR purification kit. At the final elution step of purification, Maxim Bio Hybridization II solution (Maxim Biotech) was used to redissolve DNA. HPV DNA was added to the human genomic DNA according to the concentration ratios shown in Table 2.

Second Probe Preparation for Dual-Probe Detection. For dual-probe detection, the 1-kb second probe was synthesized by PCR by using one scorpion primer that has 50-nt HPV probe sequence on the 5'-end of the primer for clockwise PCR (Table 1, complementary part is underlined) and one regular counter-clockwise primer for the pBR322 vector (Table 1). These primers were also custom-made by IDT. SuperTaq PCR kit (Ambion, Austin, TX) was used for PCR reactions. After purification with the PCR purification kit, the product was submitted to gel electrophoresis with 2\% agarose E-gels (Invitrogen, Carlsbad, CA). The main 1-kb DNA band was excised and DNA was extracted with a QiaQuick gel extraction kit. After quantification by UV absorption measurement, $1 \mu \mathrm{g}$ of probe was submitted to labeling reaction with a Ulysis Alexa Fluor 532 kit. The DNA was dissolved in Corning Pronto! long oligo hybridization solution (Corning, Lowell, MA) after purification with the PCR purification kit.

Loading, Hybridization and Washing. At least 30 min before sample loading, the slide and hybridization chamber (Corning) were preheated to $55-60{ }^{\circ} \mathrm{C}$ on a slide warmer. The hybridization mixtures with different concentrations of HPV-16 were prepared as shown in Table 2. The mixtures were kept at $95{ }^{\circ} \mathrm{C}$ for $10 \mathrm{~min}$ and then at $72{ }^{\circ} \mathrm{C}$ until they were loaded on the slide. On each slide, a $19 \times 6 \mathrm{~mm}$ silicon gasket perfusion chamber (Molecular Probes) was set up to accommodate the solution. A total of $70 \mu \mathrm{L}$ of hybridization mixture was injected into the chamber and sealed with adhesive sealers. Slides with samples were 
enclosed in the hybridization chambers and kept in a $55^{\circ} \mathrm{C}$ oven for $\sim 16 \mathrm{~h}$. After hybridization, the slides were submitted to a series of washing with wash solutions from the hybridization kit following the manufacturer's instruction. After washing, the slides were dried under a gentle nitrogen stream and kept in a dark box. Right before imaging, the slide was hydrated with $5 \mu \mathrm{L} 10 \mathrm{mM}$ Gly-Gly buffer (pH 8.2) and covered with a clean $22 \times 22$ $\mathrm{mm}$ cover glass.

Cell Line Extracts. Two cell lines with known HPV infection (CaSki, SiHa) and one normal cell line (C-33A) were purchased from ATCC (Manassas, VA). The cells were directly submitted to DNA extraction using a DNeasy kit (Qiagen) without culture. Two normal Pap test specimens were donated by a healthy adult female, and the DNA was extracted with the DNeasy kit as well. The DNA extraction yield is $\sim 80 \%$ according to the manufacturer's handbook. The DNA concentration was calculated from UV absorption at $260 \mathrm{~nm}$. The amount of extracted DNA from Pap test specimens was $\sim 10 \mu \mathrm{g}$ each.

All DNA samples were digested with three restriction enzymes, HaeIII, NcoI, and $B s t$ NI. After cutting, the DNA was purified. Each slide was loaded with DNA extracted from $10^{6}$ cells and dissolved in $70 \mu \mathrm{L}$ hybridization solution. A total of $5 \mu \mathrm{g}$ of the DNA from Pap test specimen was spiked with enzyme-digested HPV-16 DNA to the level of 10 copies/cell. The Pap sample was only tested with the dual-probe method.

Crude Preparation of Cells. Cervical cancer cell lines CaSki with 600 HPV copies/cell and healthy C-33A (ATCC) were thawed immediately after receipt. Cells were spinned down, rid of culture medium, and resuspended in Tris- $\mathrm{HCl}(\mathrm{pH} 8.0)$ buffer to a concentration of $\sim 10^{6}$ cells $/ 50 \mu \mathrm{L}$. A total of $10 \mu \mathrm{L}$ of lysozyme solution $(10 \mathrm{mg} / \mathrm{mL})$ was added at least $10 \mathrm{~min}$ before heat lysis for $1 \mathrm{~min}$ at $98^{\circ} \mathrm{C}$. The cell lysate was centrifuged at 
$14000 \mathrm{rpm}$ for $10 \mathrm{~min}$ to settle the debris. The supernatant was carefully transferred to a new tube and mixed with the second probe to be hybridized, without restriction enzyme digestion. The extract of $10^{6}$ cells was loaded onto each slide at a total volume of $70 \mu \mathrm{L}$.

Imaging System. The evanescent-field layer illumination used here to image molecules on the glass slide is similar to ones that have been reported previously in our group $^{22,23}$ (Figure 1). The slide was located on top of a right-angle fused-silica prism (Melles Griot, Carlsbad, CA), with immersion oil in between. A 532-nm solid-state continuous wave laser (45 mW, $\mu$-Green model 4611, Uniphase, San Jose, CA) was used as the excitation source. The laser was modulated with a Uniblitz mechanical shutter (model LS2Z2, Vincent Associates, Rochester, NY) and a driver (model T132, Vincent Associates), which were synchronized to the Pentamax 512-EFT/1EIA intensified charge-coupled device (ICCD) camera (Princeton Instruments, Princeton, NJ). Fluorescence from individual hybridized molecules was collected by a Zeiss $\times 100 / 1.3$ NA Plan-Neofluar microscope objective lens. Two 532-nm long-pass edge filters (Semrock, Rochester, NY) were placed between the objective lens and the ICCD to cut off scattering from the excitation beam. The sampling frequency was $2 \mathrm{~Hz}$, with 20-ms exposure. The slide was manually moved around for imaging various locations. Typically, $\sim 30$ locations were imaged on a single slide. Images were obtained with WinView software provided by Princeton Instruments. At least four sets of experiments were carried out with two duplicate slides for each concentration of each sample.

\section{Results and Discussion}

Single-Probe Detection. In this assay, female human genomic DNA and HPV-16 
DNA (the matrix and target DNA, respectively) were stained with Alexa Fluor 532 dye. Since DNA fragments larger than $1 \mathrm{~kb}$ are likely to precipitate out when stained with the dye, both DNAs were cut with restriction enzymes before staining. NcoI and HaeIII cut near the E6/E7 gene of HPV-16 and make the target fragment 1001 bp in size. BstNI enzyme was used to chop up human genomic DNA smaller than $1 \mathrm{~kb}$ without affecting the size of the HPV target. Figure 2A is a schematic diagram of the surface hybridization strategy. After overnight hybridization, the slide was washed, dried and submitted to imaging. Evanescent field illumination was used to excite surface-hybridized molecules. The incident laser beam angle was set to create a maximum evanescent field depth. With an oil type $\times 100 / 1.3$ N.A microscope objective lens, the imaged area was $0.0132 \mathrm{~mm}^{2}$.

Figure 3 shows typical images of single-probe hybridization. In the negative-control sample (Figure 3A), nonspecific adsorption was high, ${ }^{23,24}$ resulting in a high background. This nonspecific adsorption also caused large aggregation spots on the surface and background signals that were different from location to location in a single scan. To eliminate the bias caused by different background levels, the average of the background signal and the standard deviation $(\sigma)$ of each frame was obtained with WinView software and the display range of the images was set in between (average $+2 \sigma)$ and (average $+7 \sigma)$ during counting. Further, data collection was carried out while examining the images repeatedly to rule out camera shot noise.

Table 3 shows the results from single-probe experiments. When the imaged area is $0.0132 \mathrm{~mm}^{2}$, the expected number of the target (hybridized) molecules was 60 for $10^{-4} \%$ HPV, 600 for $10^{-3} \%$ HPV (per frame), and so on. Considering the observed net count (total molecule count less the background count) compared to the expected population in the 
imaged area, the overall hybridization and counting efficiency of this assay is between 50$60 \%$ on average for $10^{-4}-10^{-3} \%$ HPV samples (Table 3 ). The maximum number of molecules that can be imaged in a $512 \times 512$ pixel camera is 2500 , assuming each spot occupies a $10 \times$ 10 pixel area. So, a $10^{-2} \%$ HPV (70 copies/cell) sample should be the upper limit of detection. However, the actual increase in molecule count slows dramatically beyond $10^{-3} \% \mathrm{HPV}$. The $10^{-2} \%$ HPV samples shows $398 \pm 101$ counts, only $10 \%$ higher than the $10^{-3} \%$ sample. This is because the equilibrium hybridization isotherm is of a Langmuir form, and in general reflects the electrostatic penalty incurred because each hybridization event increases the charge of the probe layer. ${ }^{25,26}$

For the detection limit estimates, the average count in the negative-control sample was considered as background, and its standard deviation was considered as noise. At a $\mathrm{S} / \mathrm{N}$ ratio of 3 , the detection limit was $10^{-4} \% \mathrm{HPV}$ ( 0.7 copy/cell), which is equal to that achieved in the flow system. ${ }^{18}$ In molar concentration units, this HPV content is $\sim 16 \mathrm{fM}$ in a loaded volume of $70 \mu \mathrm{L}$.

Cell line extracts with known HPV-16 contents were tested with the single-probe surface hybridization method. On each slide, DNA extract from $10^{6}$ cells was loaded. A human cell contains $6 \mathrm{pg}$ of DNA. With $\sim 80 \%$ yield through the extraction and staining procedures, the actual DNA loaded per slide is $\sim 5 \mu \mathrm{g}$, the same as in the purified commercial DNA experiments above. The counted number of each cell line sample is shown in Table 4. For SiHa cells, the measured copy number was $\sim 0.7$ copy/cell, which was slightly lower than the known value of 1-2 copies/cell. A normal cell line without HPV-16 (C-33A) showed a number counted per frame very close to that of the negative-control sample. The known viral content for the CaSki cell line is $\sim 600$ copies/cell, and is beyond our high-end detection 
range. The counted molecule number was $393 \pm 138$ per frame, which was close to the saturation value of our system. Consequently, the calculated copy number is much lower than the known viral load.

Dual-Probe Detection. Instead of staining the entire human genome and the HPV, a second probe with a 1-kb tail was added to lower the background caused by nonspecific adsorption (Figure 2B). The second probe consists of a 50-nt hybridization region and a 1-kb strand for fluorescence labeling. The probe region is complementary to the 121-170th base region of the HPV-16 genome located in the E6 gene. The surface probe targets the 661760th base region of HPV, so there is a $\sim 490$-nt gap between the two hybridization locations. The 1-kb tail is attached to the 3 '-end of the probe region via two C-18 spacers. The labeled strand was made by PCR amplification of a part of pBR322 DNA between the BamHI and StyI restriction enzyme cutting sites so that the sequence would not match either HPV or human genomic DNA. The PCR products were run with gel electrophoresis, and the exact 1$\mathrm{kb}$ band was excised and extracted to ensure size uniformity. In dual-probe hybridization, only the second probe was stained with Alexa Fluor 532 dye. An equal amount of the second probe $(0.025 \mu \mathrm{g} / \mathrm{slide})$ was added to the 0 and $0.1 \%$ samples and $0.05 \mu \mathrm{g} / \mathrm{slide}$ was added to the $1 \%$ samples. Extra care was used during the washing steps, and blow drying was omitted. Instead, the slides sat for $30 \mathrm{~min}$ at room temperature to allow evaporation.

Figure 4 shows a series of images from a hybridization experiment. With a 1-kb DNA strand labeled with Alexa Fluor 532 dye, the signal from the target clearly stands out with a signal-to-noise ratio of $>10$. The amount of DNA stained with fluorescent dye in dual-probe detection was $1 / 200$ of that used in the single-probe mode. Compared to single-probe experiments, the apparent non-specific adsorption is far less (1.88 count/frame) but 
hybridization efficiency was also reduced. The average molecule counts for each concentration from 0.7 to 7000 copies/cell are shown in Table 3 . When plotted in a log-log relationship, the viral contents and the number of molecules counted have a linear relationship given by $\mathrm{y}=0.478 \mathrm{x}+3.55$ (Figure 5). The assay has nearly 5 orders of magnitude of linear dynamic range. When the average molecule count in the negative-control sample and its standard deviation were considered as background and noise respectively, the detection limit of this assay is 1.44 copies/cell. The low background level and slower increase in the number of counted molecules make the linear dynamic range much larger.

The linear correlation in the log-log plot with a slope of $\sim 0.5$ indicates there is likely a square root relationship between the target concentration and the number of molecules counted. This agrees with one of the deviation models of the Langmuir isotherm suggested by Halperin et al. ${ }^{27}$ Briefly, when the target in solution is double-stranded DNA and the total length is longer than the probe length, the amount of surface hybridized DNA shows a square root relationship with target concentration, especially in the range of $10^{-12}-10^{-9} \mathrm{M}$. Although the size of our target $(\sim 1 \mathrm{~kb})$ is larger than those in the Halperin model (100 bp) and there are two kinds of hybridization in our dual-probe method, it still serves as a good explanation for Figure 5. This phenomenon could also be present in our single-probe scheme, but the high background and the small dynamic range made it difficult to test the square root relationship. Another possible reason for deviation from the Langmuir isotherm is that hybridization of the target molecules changes the surface environment. In dual-probe hybridization, there are two mechanisms for hybridization: (1) target + second probe, and then this hybrid attaches to the surface probe; (2) target + surface probe, and then the second probe attaches to the target on the surface. 
Scheme 1 is similar to hybridization in the single-probe experiment, except that the target is now a $2-\mathrm{kb}$ fragment hybridizing to the surface probe. In scheme 2 , however, target hybridization increases the surface charge density in that area. Electrostatic repulsion reduces the probability of hybridization with the second probe. At low target concentrations this effect can be neglected, but at high concentrations it becomes important. As a result, when both schemes proceed simultaneously, the number of three-component hybridizations is lower than expected.

Cell line extracts were also used directly with the dual-probe scheme to test the performance of a real sample. By using the same protocol as the single-probe experiments, three cell line extracts were loaded on slides at a concentration of $10^{6}$ cells per slide. The HPV contents for CaSki, SiHa and C-33A cell line experiments were determined from the average molecule counts from each image (Table 4) using the log-log plot (Figure 5). The results were 558 copies/cell for CaSki and 1.15 copies/cell for SiHa. The molecule count for C-33A was 3.40 counts/frame, which falls within the range of the negative control (1.88 \pm 1.64 counts/frame). The viral content of the SiHa cell line was near the detection limit (1.44 copies/cell), but the number counted of $6.09 \pm 3.25$ counts per image was slightly higher than that of the C-33A sample. All three results showed good agreement with known viral loads, results from other assays from our flow system, ${ }^{18}$ and the single-probe surface hybridization scheme described above.

Cervix cells scraped with Pap Smear sample collection kit were donated by a healthy female and the DNA was extracted. Since the cells were healthy, HPV-16 DNA was added to a level of 10 copies/cell. Slides were prepared and submitted to the hybridization in the same way used for the cell-line extracts. The viral content calculated from the molecule count 
(Table 4) for Pap Smear cell sample was 6.1 copies/cell, which is close to the added HPV-16 concentration. This shows a good compatibility of our hybridization and detection method with conventional cell collecting method.

The low background signal and the low false-positive performance of the dual-probe method was further challenged with samples that had gone through simplified DNA sample preparation. CaSki and C-33A cell lines were tested. The cells were thawed, spun down to change the medium, mixed with lysozyme, and heat lysed at $98{ }^{\circ} \mathrm{C}$ for 1 min. Changing medium was necessary since the frozen cells from ATCC contained red $\mathrm{pH}$ indicator, which would increase the background significantly. After final spinning, the clear supernatant was transferred for hybridization. Even though cell debris had mostly settled down at the bottom of the tube, the supernatant contained some of it as well as proteins and soluble cellular materials. Hybridization was carried out without restriction enzyme digestion of the extracted DNA. Table 4 shows the results of the crude sample tests. The number of molecules counted in CaSki sample was $\sim 50$, which is $\sim 35 \%$ of that of the standard sample that contained DNA purified with a commercial kit and digested with restriction enzymes. The lower molecule count was primarily due to two effects: nonspecific adsorption of cellular materials that hindered proper probe hybridization and the lower mobility of uncut HPV DNA that was now 8 times bulkier than cut DNA. On the other hand, healthy C-33A cells showed a higher count than expected. That could also be attributed to cellular materials that led to random adsorption of the probe DNA. Despite the compressed dynamic range, the difference between CaSki and C-33A molecule counts was significant enough to distinguish them. 


\section{Conclusions}

A new strategy to detect HPV-16 DNA hybridized on a glass surface at the singlemolecule level was performed and tested for clinical applications. Two strategies were employed. In the single-probe scheme, whole human genomic DNA and HPV-16 DNA were stained and hybridized to the surface probe. The detection limit was 0.7 copy/cell, but the linear dynamic range was less than 2 orders of magnitude. Nonspecific absorption of fluorescently stained DNA caused a higher background, as well as saturation of available spots for hybridization on the surface. A dual-probe strategy was introduced with a second probe that has a 1-kb DNA strand as a fluorescence label. The dual-probe method showed dramatically lowered background and a linear log-log relationship over nearly 5 orders of magnitude. Both methods were tested with cell-line extracts and showed good agreement between the counts and known HPV-16 contents. Cervical cells that were collected with the regular Pap-smear sampling procedure were tested with spiked HPV-16 DNA. The results also showed good agreement, confirming compatibility of our method with current clinical sampling without any interference or restrictions.

The performance of the dual-probe method suggests that it can become a good clinical screening/quantification method for viral DNA in cells. The wide linear dynamic range covers the clinically important range, from early infection to cancer-forming stage. Quantification by single-molecule detection is simpler and more robust because no amplification is involved. Compared to our previous flow system for single-virus detection, the present approach has higher throughput without sacrificing detection performance. Furthermore, all of the sample handling and processing steps can be performed off-line, prior to imaging by the single-molecule microscope. 
Although the performance of our surface hybridization method cannot be directly compared to that of conventional microarrays, where up to $10^{5}$ genes can be analyzed in a single experiment, the detection limit and dynamic range of our surface experiments showed 1-10 times improvement in both categories. ${ }^{28}$ The genomic DNA or cDNA labeling procedure that is often employed in microarrays involves amplification either by PCR $(>1000 \times)$ or using random hexamer primers $(>7-10 \times)$. Since amplification makes the original amount or fraction of the target sequence in the cell difficult to determine, the sample set of DNA in the microarray is usually run together with a control set (without mutation) for comparison. The ratio between their fluorescence intensities is recorded. With singlemolecule detection, an actual molecule count is obtained that can be directly multiplied by the dilution factor to obtain the target nucleic acid quantity in the original cell. Furthermore, without an amplification step, single-molecule detection is less error-prone. When a transmission grating is incorporated to recognize the spectrum of individual molecules, multiple color dyes can be used to simultaneously compare the target amounts from several cells from different origins. ${ }^{18}$ In addition, different probes can still be arranged spatially on the slide as in microarrays to allow another dimension of multiplexed detection while maintaining single-molecule sensitivity. Application of single-molecule assay and detection strategy can therefore make conventional microarrays an even more efficient and quantitative method to analyze genomes.

\section{Acknowledgment}

We thank Dr. Mary Jo Schmerr for help with cellular DNA extraction and Dr. Seong Ho Kang and Seung-A Lee at Chonbuk University in Korea for valuable discussions. E.S.Y. 
thanks the Robert Allen Wright Endowment for Excellence for support. The Ames Laboratory is operated for the U.S. Department of Energy by Iowa State University under Contract No. DE-AC02-07CH1 1358. This work was supported by the Director of Science, Office of Basic Energy Sciences, Division of Chemical Sciences and by the National Institutes of Health. 
Table 1. Probe sequences

\begin{tabular}{|c|c|}
\hline surface probe & $\begin{array}{l}\text { 5'- GAG GAG GAT GAA ATA GAT GGT CCA GCT GGA CAA GCA GAA CCG GAC } \\
\text { AGA GCC CAT TAC AAT ATT GTA ACC TTT TGT TGC AAG TGT GAC TCT ACG } \\
\text { CTT CGG T - } 3^{\prime}\end{array}$ \\
\hline $\begin{array}{l}\text { second probe } \\
\text { (clock-wise primer) }\end{array}$ & $\begin{array}{l}\text { 5'- GGA GCG ACC CAG AAA GTT ACC ACA GTT ATG CAC AGA GCT GCA AAC } \\
\underline{\text { AAC TA }-(\text { Spacer C-18)-(Spacer C-18)-TAC TTG GAG CCA CTA TCG ACT ACG C -3' }}\end{array}$ \\
\hline $\begin{array}{l}\text { second probe } \\
\text { (counter-clock-wise primer) }\end{array}$ & 5'-GCT GGA GAT GGC GGA CG-3' \\
\hline
\end{tabular}


Table 2. Contents of hybridization mixtures loaded onto the slides

\begin{tabular}{|l|c|c|c|c|}
\hline & HPV-16 & Human & Second probe in & \\
HPV-16 DNA $(\mu \mathrm{g})$ & cell) & DNA $(\mu \mathrm{g})$ & experiments $(\mu \mathrm{g})$ & $(\mu \mathrm{L})$ \\
\hline $5 \times 10^{-2}(1 \%)$ & 7000 & 5 & 0.05 & 70 \\
\hline $5 \times 10^{-3}(0.1 \%)$ & 700 & 5 & 0.025 & 70 \\
\hline $5 \times 10^{-4}(0.01 \%)$ & 70 & 5 & 0.025 & 70 \\
\hline $5 \times 10^{-5}(0.001 \%)$ & 7 & 5 & 0.025 & 70 \\
\hline $5 \times 10^{-6}(0.0001 \%)$ & 0.7 & 5 & 0.025 & 70 \\
\hline 0 & 0 & 5 & 0.025 & \\
\hline
\end{tabular}


Table 3. Number of molecules observed in surface hybridization assay

\begin{tabular}{|c|c|c|c|c|c|c|}
\hline & $\begin{array}{l}0 \% \text { HPV DNA } \\
\text { (Negative } \\
\text { Control) }\end{array}$ & $\begin{array}{l}10^{-4} \% \mathrm{HPV} \\
\text { DNA } \\
(0.7 \text { copy } / \text { cell })\end{array}$ & $\begin{array}{l}10^{-3} \% \mathrm{HPV} \\
\text { DNA } \\
\text { (7 copy/cell) }\end{array}$ & $\begin{array}{l}10^{-2} \% \mathrm{HPV} \\
\text { DNA } \\
\text { (70 copy/cell) }\end{array}$ & $\begin{array}{l}10^{-1} \% \mathrm{HPV} \\
\text { DNA (700 } \\
\text { copy/cell) }\end{array}$ & $\begin{array}{l}1 \% \mathrm{HPV} \text { DNA } \\
(7000 \\
\text { copy/cell) }\end{array}$ \\
\hline \multicolumn{7}{|c|}{ Single-probe hybridization } \\
\hline number counted & 128 & 177 & 369 & 398 & - & - \\
\hline standard deviation & 21 & 19 & 77 & 101 & - & - \\
\hline net count ${ }^{\mathrm{a}}$ (Expected) & $0(0)$ & $49(60)$ & $241(600)$ & $270(6000)$ & - & - \\
\hline \multicolumn{7}{|c|}{ Dual-probe hybridization } \\
\hline number counted & 1.88 & 6.10 & 11.7 & 36.0 & 140 & 432 \\
\hline standard deviation & 1.64 & 1.88 & 3.37 & 6 & 25 & 57 \\
\hline
\end{tabular}

${ }^{a}$ Net count $=($ Number counted for each $)-($ Number counted in the negative-control samples $)$

${ }^{\mathrm{b}}$ Expected number $=$ Number of molecules expected in one image when the hybridization efficiency is $100 \%$ 
Table 4. Average and standard deviation of counted molecules in cell-line extracts and calculated HPV-16 DNA content per cell

\begin{tabular}{|c|c|c|c|c|c|c|c|c|c|}
\hline & \multicolumn{3}{|c|}{ single-probe hybridization } & \multicolumn{4}{|c|}{ dual-probe hybridization } & \multicolumn{2}{|c|}{$\begin{array}{l}\text { crude DNA } \\
\text { preparation }\end{array}$} \\
\hline cell Line & $\begin{array}{l}\text { CaSki } \\
(600 / \\
\text { cell })\end{array}$ & $\begin{array}{l}\mathrm{SiHa} \\
(1-2 / \\
\text { cell })\end{array}$ & $\begin{array}{l}\text { C-33A } \\
(0 / \text { cell })\end{array}$ & $\begin{array}{l}\text { CaSki } \\
(600 / \\
\text { cell) }\end{array}$ & $\begin{array}{l}\mathrm{SiHa} \\
(1-2 / \\
\text { cell })\end{array}$ & $\begin{array}{l}\text { C-33A } \\
(0 / \text { cell })\end{array}$ & $\begin{array}{l}\text { Pap-test } \\
\text { specimen } \\
\text { (10/cell) }\end{array}$ & $\begin{array}{l}\text { CaSki } \\
(600 / \\
\text { cell) }\end{array}$ & $\begin{array}{l}\text { C-33A } \\
(0 / \text { cell })\end{array}$ \\
\hline $\begin{array}{l}\text { average } \\
\text { count }\end{array}$ & 393 & 177 & 128 & 117 & 6.1 & 3.4 & 13.6 & 50.1 & 15.7 \\
\hline Std Dev & 138 & 23 & 28 & 16.5 & 3.2 & 1.8 & 3.5 & 9.4 & 3.1 \\
\hline $\begin{array}{l}\text { calculated } \\
\text { contents } \\
(\text { copy/cell) }\end{array}$ & $\geq 70$ & 0.7 & $\sim 0$ & $559^{\mathrm{a}}$ & $1.15^{\mathrm{a}}$ & $0.34^{\mathrm{a}}$ & $6.1^{\mathrm{a}}$ & - & - \\
\hline
\end{tabular}

${ }^{\mathrm{a}}$ Calculated values using the standard curve shown in Figure 5. 


\section{References}

(1) Saiki, R. K.; Scharf, S.; Faloona, F.; Mullis, K. B.; Horn, G. T.; Erlich, H. A.; Arnheim, N. Science 1985, 230, 1350-1354.

(2) Sandri, M. T.; Lentati, P.; Benini, E.; Dell'Orto, P.; Zorzino, L.; Carozzi, F. M.; Maisonneuve, P.; Passerini, R.; Salvatici, M.; Casadio, C.; Boveri, S.; Sideri, M. J. Clin. Microbiol. 2006, 44, 2141-2146.

(3) Yoshikawa, H.; Kawana, T.; Kitagawa, K.; Mizuno, M.; Yoshikura, H.; Iwamoto, A. Int. J. Cancer 1990, 45, 990-992.

(4) Resnick, R. M.; Cornelissen, M. T. E.; Wright, D. K.; Eichinger, G. H.; Fox, H. S.; Terschegget, J.; Manos, M. M. J. Natl. Cancer Inst. 1990, 82, 1477-1484.

(5) Kwok, S.; Higuchi, R. Nature 1989, 339, 237-238.

(6) Victor, T.; Jordaan, A.; duToit, R. Eur. J. Clin. Chem. Clin. Biochem. 1993, 31, 531535.

(7) Yeung, E. S. Chem. Rec. 2001, 1, 123-139.

(8) Lorincz, A. T. Obstetr. Gyn. Clin. N. Amer. 1996, 23, 707-730.

(9) Bustin, S. A.; Muller, R. Clin. Sci. 2005, 109, 365-379.

(10) Lee, J. Y.; Li, H. W.; Yeung, E. S. J. Chromatogr. A 2004, 1053, 173-179.

(11) Anazawa, T.; Matsunaga, H.; Yeung, E. S. Anal. Chem. 2002, 74, 5033-5038.

(12) Shortreed, M. R.; Li, H.; Huang, W.-H.; Yeung, E. S. Anal. Chem. 2000, 72, 28792885.

(13) Ma, Y.; Shortreed, M. R.; Yeung, E. S. Anal. Chem. 2000, 72, 4640-4645.

(14) Hirose, T.; Otani, T.; Muramatsu, H.; Tanaka, A. Photochem. Photobiol. 2002, 76, 123-126. 
(15) Twist, C. R.; Winson, M. K.; Rowland, J. J.; Kell, D. B. Anal. Biochem. 2004, 327, $35-44$.

(16) Korn, K.; Gardellin, P.; Liao, B.; Amacker, M.; Bergstroem, A.; Bjoerkman, H.; Camacho, A.; Doerhoefer, S.; Doerre, K.; Enstroem, J.; Ericson, T.; Favez, T.; Goesch, M.; Honegger, A.; Jaccoud, S.; Lapczyna, M.; Litborn, E.; Thyberg, P.; Winter, H.; Rigler, R. Nucleic Acids Res. 2003, 31, e89/81-e89/88.

(17) Camacho, A.; Korn, K.; Damond, M.; Cajot, J. F.; Litborn, E.; Liao, B.; Thyberg, P.; Winter, H.; Honegger, A.; Gardellin, P.; Rigler, R. J. Biotechnol. 2004, 107, 107-114.

(18) Li, J.; Lee, J. Y.; Yeung, E. S. Anal. Chem. 2006, 78, 6490-6496.

(19) Yeh, H. C.; Ho, Y. P.; Shih, I. M.; Wang, T. H. Nucleic Acids Res. 2006, 34, e35/31e35/38.

(20) Zhang, C. Y.; Yeh, H. C.; Kuroki, M. T.; Wang, T. H. Nat. Mat. 2005, 4, 826-831.

(21) Brown Lab

Protocol, http://cmgm.stanford.edu/pbrown/protocols/PolyLysinePostProcess.html.

(22) Lu, H. P.; Xun, L. Y.; Xie, X. S. Science 1998, 282, 1877-1882.

(23) Kang, S. H.; Shortreed, M. R.; Yeung, E. S. Anal. Chem. 2001, 73, 1091-1099.

(24) Kang, S. H.; Yeung, E. S. Anal. Chem. 2002, 74, 6334-6339.

(25) Halperin, A.; Buhot, A.; Zhulina, E. B. Clin. Chem. 2004, 50, 2254-2262.

(26) Vainrub, A.; Montgomery Pettitt, B. Phys. Rev. E 2002, 66, 041905-041908.

(27) Halperin, A.; Buhot, A.; Zhulina, E. B. J. Phys.: Condens. Matter 2006, 18, S463S490.

(28) Oostlander, A. E.; Meijer, G. A.; Ylstra, B. Clin. Genet. 2004, 66, 488-495. 


\section{Figure Captions}

Figure 1. Schematic diagram of the evanescent field illumination system: FP, fusedsilica right angle prism; IO, immersion oil; CG, cover glass; PLL, poly-Llysine coating; SP, sample layer of hybridized molecules on the surface; EF, evanescent-field layer; BF, buffer solution.

Figure 2. Two surface hybridization approaches. (A) Single-probe hybridization, and (B) dual-probe hybridization. SP, surface-tethered probe; HPV-AF, target DNA (HPV-16) stained with Alexa Fluor 532; GL, poly-L-lysine-coated cover glass; HPV, target DNA (HPV-16); and 2P-AF, second probe with Alexa Fluor 532 labeled with a 1-kb strand.

Figure 3. Single molecule images after single-probe surface hybridization. (A) 0, (B) $10^{-4}$, (C) $10^{-3}$, and (D) $10^{-2} \%$ HPV DNA. A total amount of $5 \mu \mathrm{g}$ human genomic DNA with added HPV-16 DNA was loaded on a glass slide that had 100-nt oligonucleotide probes on the surface. All slides were hybridized at 55

${ }^{\circ} \mathrm{C}$ for $16 \mathrm{~h}$. Display range: (background average $+2 \sigma$ ) to (background average $+7 \sigma)$.

Figure 4. Images from dual-probe hybridization detection. Each dot represents one probe molecule (second probe with 1-kb strand) stained with Alexa Fluor 532 dye. (A) 0 , (B) $10^{-4}$, (C) $10^{-3}$, (D) $10^{-2}$, (E) $10^{-1}$, and (F) $1 \%$ HPV DNA. Display range: 67 to 4095 .

Figure 5. Standard curve of quantification of HPV-16 DNA with dual-probe surface hybridization. Both axes are shown in logarithmic scales. 
Figure 1.

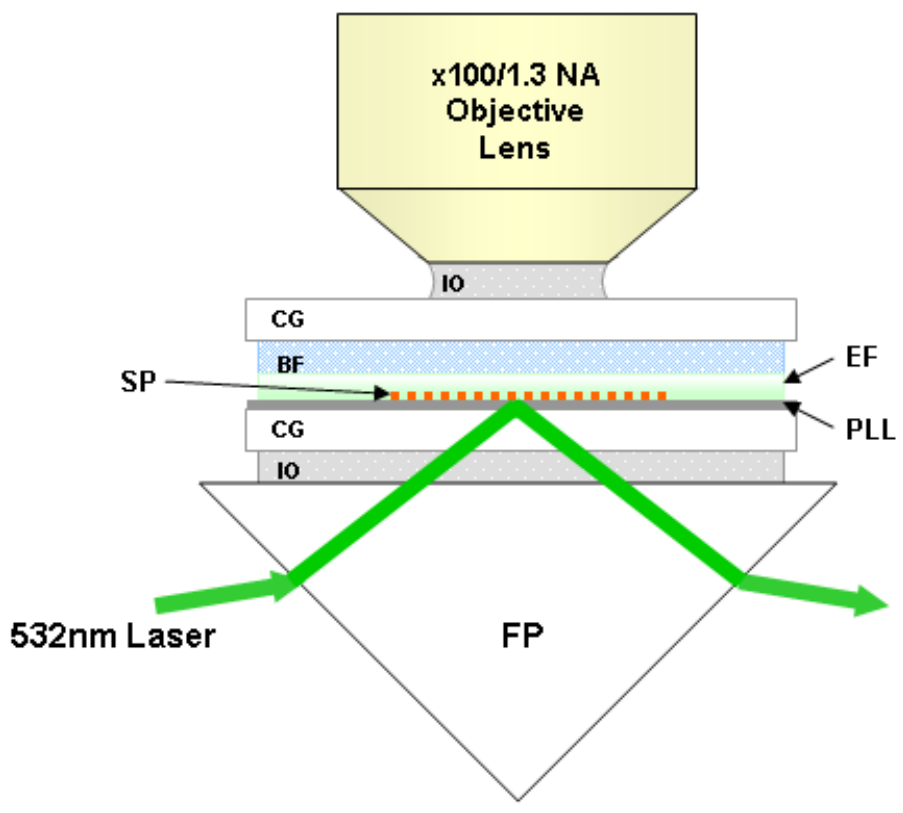


Figure 2.

A

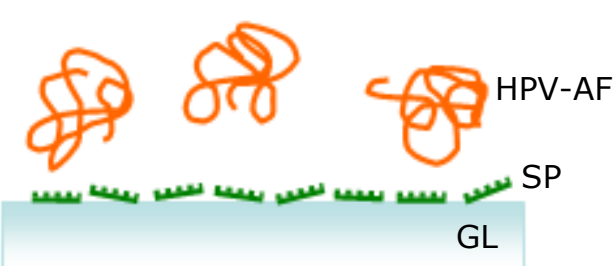

Hybridization

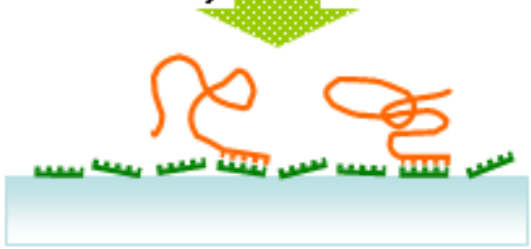

B

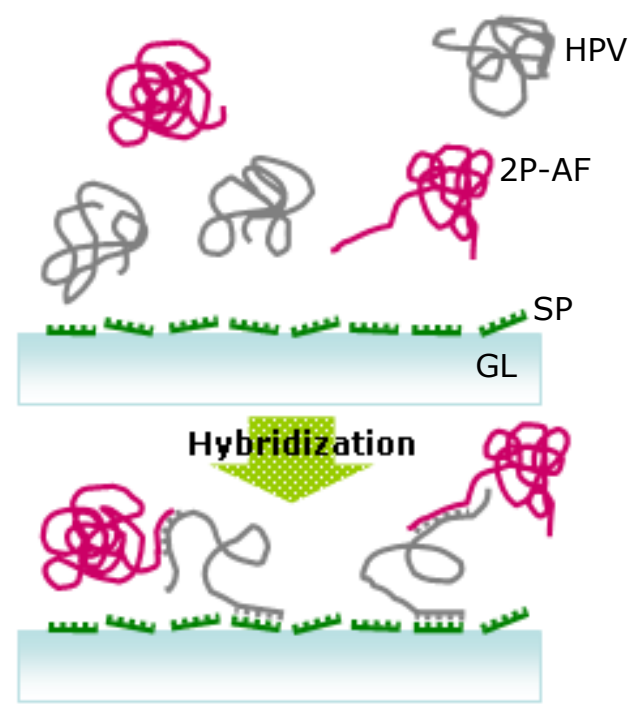


Figure 3.

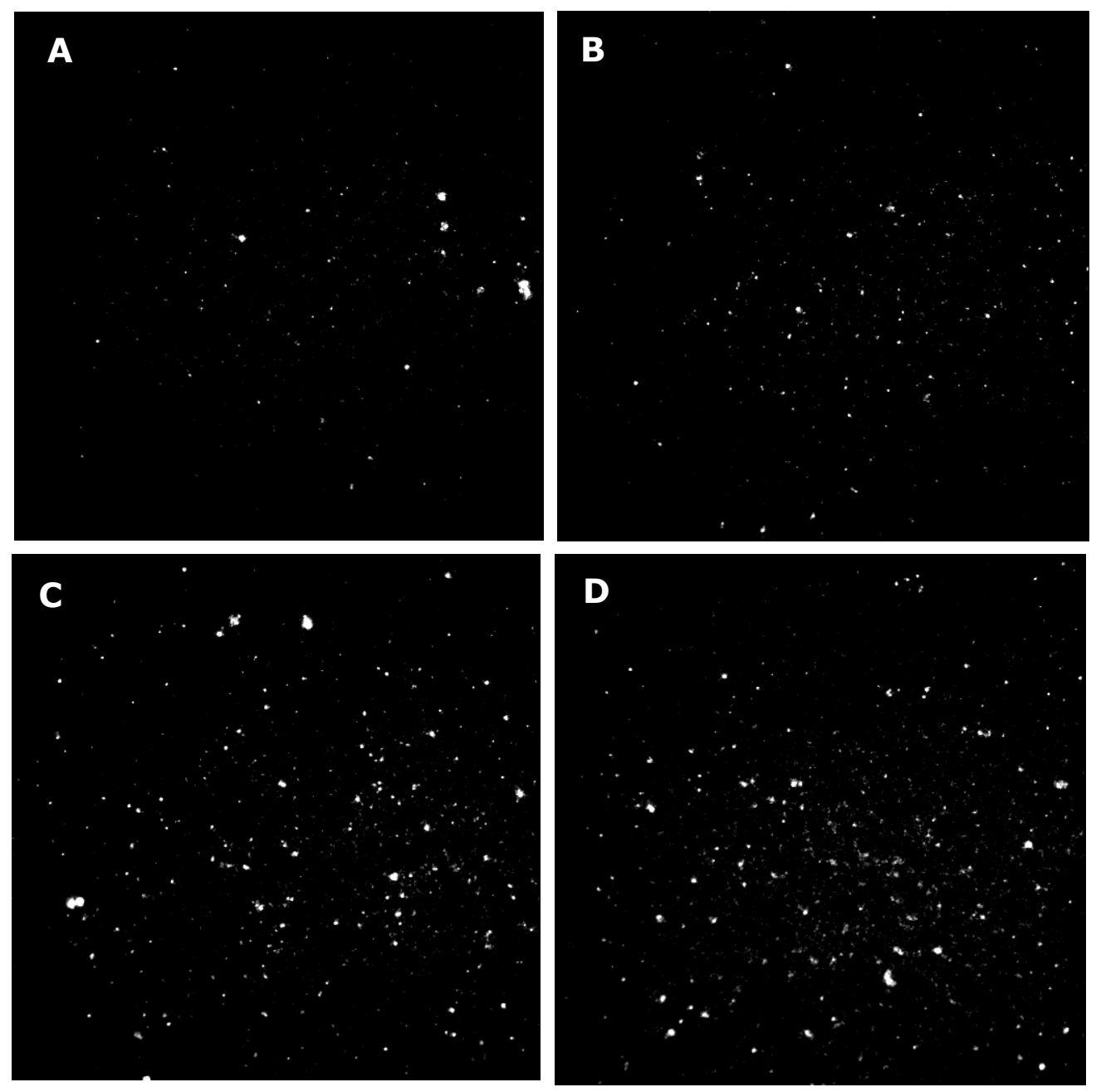


Figure 4.
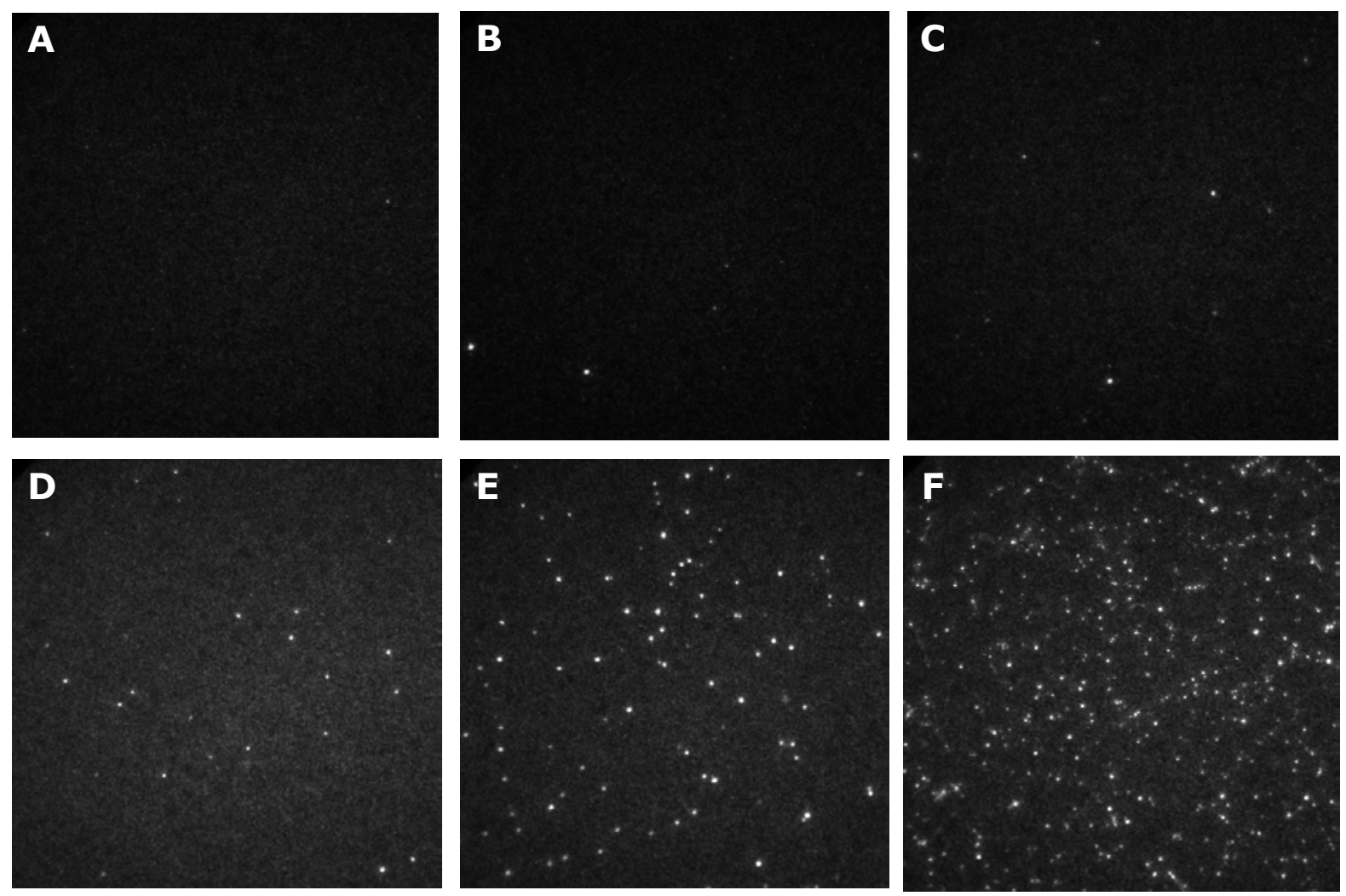
Figure 5.

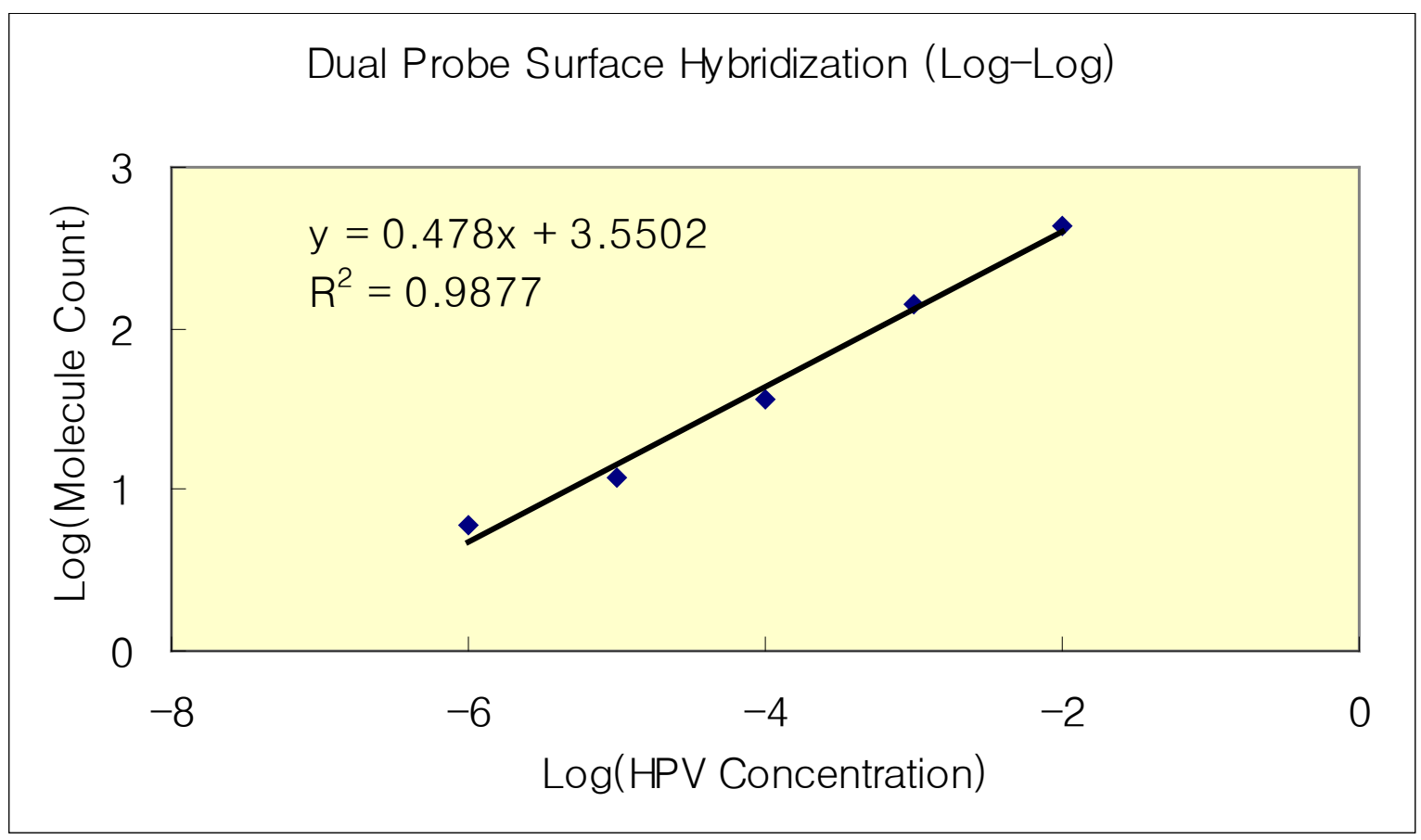




\title{
CHAPTER 4. SINGLE-MOLECULE IMMUNOSORBENT ASSAY OF HUMAN IMMUNODEFICIENCY VIRUS-1 ANTIGEN
}

\author{
A paper submitted to Analytical Chemistry \\ Jiangwei Li, Wenjun Xie, Ning Fang, and Edward S. Yeung
}

\begin{abstract}
Ultrasensitive detection and quantification of viral antigen with a novel singlemolecule immunosorbent assay (SMISA) was achieved. Antigen from human immunodeficiency virus type $1(\mathrm{HIV}-1)$, the major etiological agent of acquired immune deficiency syndrome (AIDS), served as the screening target in this study. The target molecule was sandwiched between a monoclonal capture antibody and a polyclonal detector antibody. The capture antibody was covalently immobilized on (3-glycidoxypropyl) trimethoxy silane (GPTS) modified glass slides. The detector antibody was conjugated with fluorescent Alexa Fluor 532 labeled secondary antibody prior to being used as a probe for the antigen. Imaging was performed with a total internal reflection fluorescence (TIRF) singlemolecule detection system. This technique is demonstrated for detecting HIV-1 p24 antigen down to $0.1 \mathrm{pg} / \mathrm{mL}$ with a dynamic range of over 4 orders of magnitude. A Langmuir isotherm fits the molecule count dependence on the target concentration. The target antigen was further tested in $20 \%$ human serum, and the results showed that neither sensitivity nor dynamic range was affected by the biological matrix. SMISA is therefore a promising approach for the early diagnosis of viral induced diseases.
\end{abstract}




\section{Introduction}

Over the last few decades, rapid advances in single-molecule detection have inspired the development of applications in early clinical diagnostics and screening. The most common bioanalytical methods for recognizing target biomarkers in complex biomatrixes are the specific hybridization of nucleic acids and antibody affinity for antigens. Many DNAbased diagnostic systems have been developed. ${ }^{1-7}$ Human mitochondrial DNA deletion was identified by directly measuring the electrophoretic mobility of fluorescently tagged DNA molecules. ${ }^{2}$ Low abundant point mutations in K-ras oncogenes were enumerated using the allele-specific ligation of fluorescence resonance energy transfer (FRET) probes to generate molecular beacons upon successful ligation. ${ }^{3}$ DNA of human papiloma virus, the major etiological agent of cervical cancer, was quantitatively screened by both solution- and surface- hybridization techniques. ${ }^{5,6}$ Although robust nucleic acid-based analysis always delivered excellent performance, it is restricted to the detection of cells and viruses. Antigens are more common clinical biomarkers that include small molecules such as pesticides, small toxins, and pharmaceuticals; biopolymers (e.g., toxins, allergens, viral proteins); and complex biological entities like bacterial cells and viruses. ${ }^{8}$ Many single-molecule-scale protocols were reported for antigen identifications. ${ }^{9-15}$ Fluorescent cross-correlation spectroscopy (FCS) was used in an immunoassay format to determine the antibodydigoxigenin equilibrium dissociation constant. ${ }^{11}$ The human gonadotropin follicle-stimulating hormone (FSH), which plays a central role on fertility, served as the analyte in a heterogeneous immunometric assay using confocal microscopic detection. ${ }^{13}$ Fluorescent 
single-molecule counting assays for the analysis of cytokines and chemokines were also developed recently. ${ }^{14}$

Acquired immune deficiency syndrome (AIDS) is a set of symptoms and infectious results from the damage to the human immune system caused by human immunodeficiency virus (HIV). ${ }^{16}$ As of January 2006, the Joint Nations Programme on HIV/AIDS (UNAIDS) and the World Health Organization (WHO) reported that more than 25 million people were killed since HIV was first recognized in 1981, making it one of the most destructive pandemics in recorded history. According to the latest AIDS epidemic update from UNAIDS and WHO, AIDS claimed an estimated 2.1 million lives in year 2007 alone, including 330,000 children. Unfortunately, there is no vaccine or cure available, even though current antiretroviral treatment, such as highly active antiretroviral therapy (HAART or cocktail treatment), ${ }^{17}$ can slow the course of the disease and prolong lives. The early detection of HIV infection has shown to be beneficial for the prompt initiation of appropriate antiretroviral therapy in a clinically relevant time frame. Meanwhile, early diagnosis will help in the timely implementation of interventions such as the counseling of patients, prevention of transmission, and management of infection. ${ }^{18}$ Another treatment, post-exposure prophylaxis (PEP), is drawing more and more attention. In 1996, the first U.S. Public Health Service (PHS) recommendations for the use of PEP after occupational exposure to HIV were published; these recommendations have been updated twice. ${ }^{19-21}$ PEP has proven effective for reducing $81 \%$ of the risk of seroconversion after exposure. ${ }^{22,23}$ In order to be effective, PEP treatment should begin as soon as possible or within 72 hours post HIV exposure. However, there is no means to detect HIV within 3 days after exposure to this date. As a consequence, most exposed people take this drastic treatment blindly along with its serious side effects. As 
a result of toxicity and adverse effects among healthcare workers, a substantial proportion of them have been unable to complete a full course of HIV PEP. ${ }^{24}$ If an accurate and rapid early diagnostic procedure is available, patients could delay the treatment until positive infection is confirmed. Therefore, development of early diagnostic methodology is absolutely necessary and significant for AIDS treatment.

Current protein-based HIV diagnostic methods include the detections of viral antibody, antigen, or both. As a routine test for adults, antibody test is inexpensive and extremely accurate. However, it usually gives false negative results during the "window period", which refers to a time range from three weeks to six months that is required to develop measurable antibodies from HIV serocoversion in the human body after infection. ${ }^{18}$ In comparison, detection of HIV antigen is a more straightforward method as early diagnosis is not limited by serocoversion. There are two known types of HIV: HIV-1 and HIV-2. HIV1 is more virulent and easily transmitted compared to HIV-2, and is the cause of the majority of HIV infections globally. ${ }^{25}$ HIV-1 p24, one major core protein of the virus, is the most popular target antigen in commercial enzyme-linked immunosorbent assays (ELISA) for HIV-1 detection. The detection limit of commercial HIV-1 p24 antigen ELISA (e.g. Alliance kit from PerkinElmer, Boston, MA) is $\sim 5 \mathrm{pg} / \mathrm{mL}$. Additionally, ELISA involves a signal amplification process that may result in false positive results.

Here, we developed a fluorescent single-molecule immunosorbent assay (SMISA) for the detection of HIV-1 p24 without amplification. HIV-1 p24 antigen was sandwiched between the capture and detector antibodies on glass slides. Fluorescently labeled secondary antibody served as optical reporters. The surface immunoassay format greatly reduced the interference of the biomatrix through a series of stringent washing steps. Meanwhile, the 
detection background was further decreased by utilizing total internal reflection fluorescence (TIRF) microscopy. The ultimate sensitivity of this assay provides a promising future for early diagnosis of HIV within days post infection.

\section{Experimental Section}

Surface Derivatization. Custom-made SuperClean cover slips of $40 \times 22 \mathrm{~mm}$ were purchased from TeleChem International (Sunnyvale, CA). (3-glycidoxypropyl) trimethoxy silane (GPTS) (Sigma-Aldrich, St. Louis, MO) coating solution was prepared with $2.5 \%$ (v/v) GPTS in ethanol containing $10 \mathrm{mM}$ acetic acid. Untreated cover slips were washed with $100 \%$ ethanol thoroughly to get rid of attached contaminants, then immersed in GPTS coating solution at room temperature for $1 \mathrm{~h}$ with agitation. ${ }^{26}$ The silanized cover slips were rinsed with $100 \%$ ethanol and blown dry under a high purity nitrogen stream.

Capture Antibody Immobilization. Primary antibodies and antigens used in this single-molecule sandwich immunosorbent assay were obtained from GenWay Biotech (San Diego, CA), and Alexa Fluor 532 (AF532) labeled secondary goat-anti-mouse IgG (2nd Ab) was purchased from Invitrogen (Carlsbad, CA). A pair of goat-anti-HIV-1 p24 polyclonal antibody (PA) and mouse-anti-HIV-1 p24 monoclonal antibody (MA), which was recommended for sandwich ELISA by the manufacturer, served as the capture antibody and the detector antibody respectively. In antibody microarrays, supplements of trehalose was utilized to prevent dehydration of the spotting solution and to improve the stability of antibodies. ${ }^{26}$ Therefore, $1 \mathrm{mg} / \mathrm{mL}$ PA stock solution was prepared with $0.5 \%$ trehalose (Sigma-Aldrich) in PBS buffer ( $\mathrm{pH}=7.4$, Invitrogen). A total of $20 \mu \mathrm{L}$ of PA stock solution was added onto the silanized slide before a clean $30 \times 22 \mathrm{~mm}$ lifter slip (Electron Microscopy 
Sciences, Hatfield, PA) was applied. The slides were incubated at room temperature for $1 \mathrm{~h}$. 20× PBS-Tween 20 buffer (Pierce Biotechnology, Rockford, IL) was diluted to $1 \times$ as the washing buffer. After PA was covalently bound to the slide surface, the excessive PAs were rinsed off with washing buffer. The remaining amine-active sites were blocked by immersing the slides into gelatin blocking buffer (Sigma-Aldrich) at room temperature for $1 \mathrm{~h}$ with agitation. The slides were washed 3 times with washing buffer for 5 min per wash, and blown dry with nitrogen stream.

Antigen Binding. HIV-1 p24 antigen recombinant protein was diluted in $1 \times$ PBS buffer to make a series of antigen stock solutions $(0,0.1,1,10,100 \mathrm{pg} / \mathrm{mL})$. To test the tolerance of this methodology to the biomatrix in human blood, $20 \%(\mathrm{v} / \mathrm{v})$ male human serum tested negative for HIV antigens (Sigma-Aldrich) was added to the antigen solutions. All antigen solutions were kept in glass bottles to decrease hydrophobic adsorption of proteins to plastic vials, which was especially adverse at low concentrations. On each slide, a $32 \times 19 \mathrm{~mm}$ silicon gasket perfusion chamber (Electron Microscopy Sciences) was set up to accommodate the solution. A total of $500 \mu \mathrm{L}$ of antigen solution was injected into the gasket and sealed with adhesive sealer. After incubation at room temperature for $1 \mathrm{~h}$ and at $4{ }^{\circ} \mathrm{C}$ for $4 \mathrm{~h}$, the gaskets were peeled off. The slides were submitted again to a 3 washes for 5 min per wash and blown dry.

Detector Antibody Application. MA and AF532-2nd Ab were mixed at an optimized molar ratio of 1:3, and then incubated at room temperature for $1 \mathrm{~h}$. Right before application, the MA/AF532-2nd Ab complex probe solution was diluted by $1 \times$ PBS buffer to make up the detector $\mathrm{Ab}$ to a final concentration of $10 \mathrm{ng} / \mathrm{mL}$. The probe amount is in excess compared with the concentration of antigens (e.g., probe number is $1.2 \times 10^{4}$ times the antigen 
number at $0.1 \mathrm{pg} / \mathrm{mL}$ ). A $19 \times 6 \mathrm{~mm}$ silicon gasket perfusion chamber (Electron Microscopy Sciences) was attached within the antigen binding area on each slide. A total of $70 \mu \mathrm{L}$ of probe solution was injected into the gasket and sealed with adhesive sealer. Slides were enclosed in hybridization chambers (Corning Life Sciences, Lowell, MA) to avoid solution evaporation and incubated at $4{ }^{\circ} \mathrm{C}$ overnight. After removing the silicon gaskets, the slides were submitted to a final 3 times washing for 5 min per wash and gently blown dry with pure nitrogen gas. Prior to imaging, a total of $5 \mu \mathrm{L}$ of $10 \mathrm{mM}$ Gly-Gly buffer ( $\mathrm{pH}=8.2$, SigmaAldrich) was sandwiched between the slide and a cover slip. This buffer was selected because of its low fluorescent background compared to other buffers. The slides were then ready to be imaged.

Imaging System. The TIRF system is similar to the one reported in our previous study, ${ }^{6}$ as shown in Figure 1. A 532-nm solid-state continuous wave laser (45 mW, $\mu$-Green model 4611, Uniphase, San Jose, CA) was used as the excitation source. A Uniblitz mechanical shutter (model LS2Z2,Vincent Associates, Rochester, NY) and a driver (model T132, Vincent Associates) were synchronized to the Pentamax 512-EFT/1EIA intensified charge-coupled device (ICCD) camera (Princeton Instruments, Princeton, NJ). To reduce photobleaching of fluorophores, the shutter restricted passage of the laser beam according to the acquisition time of the ICCD. The laser beam was focused to a reasonable size at the interface of the slide and the buffer so that it exactly covered a whole imaging area. The slide was placed on top of a right-angle fused-silica prism (Melles Griot, Carlsbad, CA) with immersion oil in between. Fluorescence from individual labeled detector antibody complex was collected by a Zeiss 100×/1.3 NA Plan-Neofluar microscope objective lens. Two 532-nm long-pass edge filters (Semrock, Rochester, NY) were located between the objective lens and 
the ICCD chip to cut off scattered light from the excitation beam. The acquisition frequency was set as $2 \mathrm{~Hz}$, with the shutter driver set to 40-ms exposure and 460-ms delay. Singlemolecule movies were acquired by repeating the following steps: moving to a new observation region, focusing, taking at least one clear image on that spot. The slide was manually moved around for imaging various locations. Typically, about 20 locations were imaged on a single slide. Images were obtained with WinView software provided by Princeton Instruments.

Image Analysis. The intensity of the TEM00 mode laser beam was Gaussian across the imaged region, which resulted in a heterogeneous background within the same image. Moreover, the background intensity of different slides also varied with sample concentration, local environment, etc. These factors could affect the setting of the correct threshold and counting the exact number of molecules. Thus, a standard background processing scheme was needed. We herein employed a method based on ImageJ, a public-domain image processing program (version $1.40 \mathrm{~g}$, National Institutes of Health, USA), which was also used extensively for image analysis in our previous single-molecule studies. ${ }^{27,28}$

After a movie file was loaded into ImageJ, the background subtraction function was applied on the image stacks to decrease the background heterogeneity. This function was built on 2-D rolling ball algorithm, and the radius was optimized to 20 pixels. A smoothing function was also performed during this step. The entire movie was converted to a stack of black (value 0 , background) and white (value 255, fluorescent probe molecules) images. The standard threshold was set to be the mean of the background plus $4 \sigma(\sim 1200)$ for all movies. The number of white spots in each frame did not necessarily give the right count of fluorescent molecules because of random noise. However, the noise could be greatly reduced 
by removing all the white signals which were less than $2 \times 2$ pixels in size. Bright spots smaller than 4 pixels were only observed in individual frames and were most likely the result of the ICCD shot noise, as verified by manually checking the movies. In this efficient and accurate way, the fluorescent molecules in each frame was counted and exported from ImageJ.

The final step is manually picking the representative frame of each location on the slides and recording the frame number. With the selected frame number and exported summary from ImageJ, the number of molecules at each location in the movie was readily listed in Microsoft Excel. Four paralleled experimental sets were carried out for each condition. Every molecule count was calculated based on the four movies, thus the final numbers were averaged on at least $80(4 \times 20)$ frames.

\section{Results and Discussion}

Method Development. The order of applying antibodies and antigens could affect the performance of this sandwich immunoassay. There were three candidate schemes, as shown in Figure 2. According to the binding sequence, they were named briefly as MA-Ag(AF532-PA), PA-Ag-(AF532-MA), and PA-Ag-(AF532-2nd Ab/MA). In the first scheme, mouse-anti-HIV-1 p24 IgG was covalently affixed onto the glass slide, then HIV-1 p24 recombinant protein and AF532 labeled goat-anti-HIV-1 p24 IgG were added sequentially. Two aspects rendered this unacceptable in practice. First, the immobilization step required a large amount of primary MA that was usually limited in availability. Second, extensive nonspecific binding was observed even in negative control assays (absence of antigens). In the second approach, the order of addition of MA and PA was exchanged as PA-Ag-(AF532- 
MA). A micro-scale AF532 MA labeling kit from Invitrogen was used to fluorescently label the mouse-anti-HIV-1 p24 antigen. The main issue of this scheme is the low signal intensity due to under-labeled MA, thus it was hard to distinguish individual molecules from the background. To improve the signal intensity, we introduced AF532-2nd Ab/MA complex as the detector probe. AF532-goat-anti-mouse IgG was prepared from affinity-purified antibody that reacted with $\operatorname{IgG}$ heavy chains and all classes of immunoglobin light chains from mouse. The ratio of AF532-2nd Ab to MA was optimized to 3:1 in a compromise between the probe intensity and the background increase from nonspecific adsorption. With the third approach, the signal intensity was greatly increased as the number of fluorophores tripled on each probe complex compared to AF532-MA in the second scheme. Nonspecific adsorption was much less than before since the crossreactivity of $2 \mathrm{nd} \mathrm{Ab}$ was minimized by being exposed to human IgG and human serum prior to conjugation. Moreover, the use of $2 \mathrm{nd} \mathrm{Ab}$ conjugate avoided the time consuming procedure of labeling PA and MA in the first two schemes, and lower the cost of acquiring the labeling kit and MA. Therefore, the third scheme was considered to be the best procedure.

After the optimal assay sequence was determined, other details in this assay need to be evaluated. Selection of the capture and detector antibody matched pair is always a technical challenge yet of vital importance in immunoassays. Even though the antibody pairs are designed to be antigen-specific, they may still have strong interactions with each other. Among the many sets of commercially available antibodies, the pair from Genway Biotech was chosen on the grounds of parallel comparison experiments (results not shown).

Glass surface derivatization is a critical parameter in facilitating high-density immobilization of capture antibody, and at the same time minimizing the fluorescent 
background. Derivatization by GPTS showed unparalleled performance in our experiments. Besides the GPTS modification procedure (Figure 3A), we have also explored the combination of 3-mercaptopropyltrimethoxysilane (MPTS) and heterobifunctional crosslinker N-succinimidyl 4-maleimidobutyrate (GMBS), ${ }^{29}$ as shown in Figure 3B. To test the coverage of capture antibody, AF532 labeled PA was covalently bound to both slides under the same condition. Higher antibody density was found on the GTPS modified surface than on the MPTS/GMBS modified one. Meanwhile, the GTPS fabricated surface had relatively low and homogenous background in the sandwich immunosorbent assay. Additionally, the GTPS procedure was straightforward and time saving as only one chemical reaction and no inert gas bath was needed.

Nonspecific adsorption was further decreased by optimizing the blocking, washing, and incubation conditions. Several blocking buffers, such as StartBlock, SuperBlock (Pierce), bovine serum albumin, casein, gelatin and goat serum (Sigma-Aldrich), were tested for their blocking effects. Gelatin blocking buffer had the best performance among these proteinbased buffers, presumably due to its moderate molecular size $(60 \mathrm{kDa})$. Larger proteins raised the issue of over-block while smaller ones tended to under-block. Different washing solutions $(1 \times$ PBS, $1 \times$ PBS-Tween 80 , and $1 \times$ PBS-Tween 20$)$ and washing procedures (rinsing, 3 times washing for 5 min per wash, and brief ultra-sonication) were tested. The most efficient combination was $1 \times$ PBS-Tween 20 solution with 3 times washing for $5 \mathrm{~min}$ per wash. The incubation temperature and time were also key concerns in optimization. Even though incubation at $37{ }^{\circ} \mathrm{C}$ made the probe molecules diffuse faster to increase the chance of conjugating with the antigen, it would magnify nonspecific adsorption as well. Therefore, incubation at $4{ }^{\circ} \mathrm{C}$ overnight was chosen to minimize unwanted binding while preventing 
degradation of proteins.

Quantification of Antigen. After the system was optimized, we applied it to the detection of a series of concentrations of antigen in PBS buffer. Figure 4 shows typical images of this SMISA. Ideally, every bright spot represents one fluorescent detector probe that bound to one antigen molecule. However, in the negative-control sample (Figure 4A), there were still some bright spots due to unavoidable nonspecific adsorption of detector probes to the surface.

The observed numbers of molecules at every antigen concentration are shown in Table 1. Each counting result is averaged from about 80 frames in 4 sets of parallel experiments. The numbers in the first column $(0 \mathrm{pg} / \mathrm{mL})$ represent false positives or blank counts. The detection limit is defined as when the signal equals the blank plus 3 times the standard deviation of blank counts. Therefore, the detection limit of HIV-1 p24 antigen is 0.1 $\mathrm{pg} / \mathrm{mL}(\sim 40 \mathrm{fM})$. This sensitivity of SMISA is 50 times better than the commercial ELISA kit, and no amplification was involved. Table 1 also lists the net counts (subtracting background counts from observed counts). As described in the experimental section, a total of $500 \mu \mathrm{L}$ of antigen solutions $(0,0.1,1,10,100 \mathrm{pg} / \mathrm{mL})$ were deposited in $32 \times 19 \mathrm{~mm}$ silicon gaskets. When the observation area is $0.0132 \mathrm{~mm}^{2}$, the expected number of target molecules $(24 \mathrm{kDa})$ per frame is calculated to be 31 at $0.1 \mathrm{pg} / \mathrm{mL}, 310$ at $1 \mathrm{pg} / \mathrm{mL}$, and so on. The net count of the initial data point ( 30 molecules/frame at $0.1 \mathrm{pg} / \mathrm{mL}$ ) closely matches the expected number. However, the trend of the data approaches a maximum value instead of linear growth. Langmuir isotherm could interpret this phenomenon as follows.

For the first conjugation reaction in this assay:

$$
C^{*}+T \stackrel{K_{1}}{\longleftrightarrow} C T^{*}
$$


In eq $1, \mathrm{C}^{*}, \mathrm{~T}, \mathrm{CT}^{*}$ are the unoccupied capture antibody sites, target antigens, antibody sites occupied by antigens, respectively. The equilibrium constant $K_{l}$ is thus given by the equation:

$$
K_{1}=\frac{\left[C T^{*}\right]}{\left[C^{*}\right][T]}
$$

Because the number of bound sites $\left(\mathrm{CT}^{*}\right)$ is proportional to antigen surface coverage $\theta$, and the number of unbound sites $\left(C^{*}\right)$ is proportional to $1-\theta$. Eq 2 can be rewritten as:

$$
K_{1}=\frac{\theta}{(1-\theta)[T]}
$$

Rearranging eq 3:

$$
\theta=\frac{K_{1}[T]}{1+K_{1}[T]}
$$

In the second conjugation reaction between target antigen and detector probe, the detector probes is far in excess of the target antigen. Therefore, all the antigen molecules are expected to be bound to fluorescently labeled probes. Eq 4 is expressed in terms of the number of detected molecules $(\Gamma)$ and the maximum molecule count $\left(\Gamma_{\max }\right)$ as $[\mathrm{T}]$ approaches infinity:

$$
\Gamma=\frac{\Gamma_{\max } K_{1}[T]}{1+K_{1}[T]}
$$

Figure 5A shows the relation between the observed molecule count and target antigen concentration. The dots and error bars are drawn based on the experimental data in Table 1, and the solid line represents the fitting curve using eq 5 . The best fitting curve is: $\Gamma=\frac{654 \times 0.0577[T]}{1+0.0577[T]}$, thus the Langmuir equilibrium constant $\mathrm{K}_{1}$ equals $0.0577(\mathrm{pg} / \mathrm{mL})^{-1}$, and $\Gamma_{\max }$ is 654 . If the data are displayed in a log-log plot (Figure 5B), a fairly good linear 
correlation is found. This well-fitted line can be applied as the standard curve for quantification with a slope of 0.373 and a dynamic range from $0.1-100 \mathrm{pg} / \mathrm{mL}$.

The antigen was dissolved in diluted human serum to test the compatibility of real biological sample with this assay. Different percentages of human serum in PBS was tested without antigen, and $20 \%$ was found to be the upper limit for acceptable nonspecific adsorption and background levels. With the same methodology of detection described above, antigen was detected and quantified in the biological matrix. The results are shown in Table 1 and Figure 5 C\&D. Considering the dilution factor of 5 , the detection limit of the antigen in pure human serum would be $0.5 \mathrm{pg} / \mathrm{mL}$. The equation of the fitting curve in serum is:

$\Gamma=\frac{842 \times 0.0732[T]}{1+0.0732[T]}$. Therefore, Langmuir equilibrium constant $\mathrm{K}_{1}$ equals $0.0732(\mathrm{pg} / \mathrm{mL})^{-1}$, and $\Gamma_{\max }$ is 842 . In the log-log plot (Figure 5D), the slope of the standard curve is calculated to be 0.353 . Thus, the tolerance of biological fluid in this SMISA is validated.

\section{Conclusions}

We developed a novel strategy to detect HIV-1 p24 antigen in a sandwich fluorescent immunosorbent assay at the single-molecule level. By judicious selection of the experimental parameters, including conjugation schemes, antibody pairs, surface modifications, blocking, washing, and incubation procedures, ultrasensitive SMISA is achieved. The detection limit of HIV-1 p24 antigen was as low as $0.1 \mathrm{pg} / \mathrm{mL}$, which made SMISA 50 times more sensitive than the well accepted commercial ELISA kit. There are typically 2000 copies of p24 protein in one HIV-1 virus, so theoretically the analytical sensitivity could reach 1250 virus $/ \mathrm{mL}$. The linear dynamic range of the log-log standard curve was extended over 4 orders of magnitude 
from 0.1 to $100 \mathrm{pg} / \mathrm{mL}$. Meanwhile, a well fitted Langmuir isotherm model can explain the mechanism behind the non-linear signal increase with target concentration.

To test the tolerance of this assay to biological fluids, HIV-1 p24 antigen was also spiked in $20 \%$ human serum and detected with the same protocol. The results showed good agreement in terms of the detection limit and dynamic range, proving the direct compatibility of our approach with current clinical sampling without any interference. Thus, the whole diagnostic process would involve little more than human serum acquisition, dilution, conjugation and imaging.

Unlike ELISA, no signal amplification was included in this method. Therefore, the false positive rate caused by the amplification step in ELISA is eliminated. Moreover, SMISA could be readily employed to any other antigen detection and quantification, provided specific capture and detector antibodies are available. Ultra sensitive immunoassay only requires a small amount of sample, a characteristic that can be advantages in the case of scarce archival clinical samples. One future direction for SIMSA could be the coupling with a microarray platform, which would deliver robust and accurate results in combination with routine multiplexed application. The performance and operational simplicity shows that SMISA has enormous potential in the early diagnosis and clinical quantification screening for antigens.

\section{Acknowledgement}

We thank Dr. Mary Jo Schmerr and Dr. Gufeng Wang for valuable discussions. E.S.Y. thanks the Robert Allen Wright Endowment for Excellence for support. The Ames Laboratory is operated for the U.S. Department of Energy by Iowa State University under 
Contract No. DE-AC02-07CH1 1358. This work was supported by the Director of Science, Office of Basic Energy Science, Division of Chemical Sciences. 
Table 1. Number of molecules observed in SMISA

\begin{tabular}{|c|c|c|c|c|c|}
\hline $\begin{array}{l}\text { HIV-1 p24 antigen } \\
\text { concentration }(\mathrm{pg} / \mathrm{mL})\end{array}$ & 0 & 0.1 & 1 & 10 & 100 \\
\hline $\begin{array}{l}\text { Observed number in } \\
\text { buffer }\end{array}$ & $12 \pm 8$ & $42 \pm 12$ & $98 \pm 42$ & $223 \pm 58$ & $560 \pm 110$ \\
\hline $\begin{array}{l}\text { Net molecule counts } \\
\text { in buffer }\end{array}$ & 0 & 30 & 86 & 211 & 548 \\
\hline $\begin{array}{l}\text { Expected molecule } \\
\text { counts }^{\mathrm{b}}\end{array}$ & 0 & 31 & 310 & 3100 & 31000 \\
\hline $\begin{array}{l}\text { Observed number in } \\
20 \% \text { human serum }\end{array}$ & $24 \pm 11$ & $63 \pm 30$ & $161 \pm 46$ & $324 \pm 82$ & $747 \pm 127$ \\
\hline $\begin{array}{l}\text { Net molecule counts } \\
\text { in } 20 \% \text { human serum }\end{array}$ & 0 & 39 & 137 & 300 & 723 \\
\hline \multicolumn{6}{|c|}{$\begin{array}{l}{ }^{a} \text { Net molecule counts }=(\mathrm{Ol} \\
\text { negative-control samples })\end{array}$} \\
\hline \multicolumn{6}{|c|}{${ }^{b}$ Expected molecule counts $=$ Number of molecules expected in one frame when the } \\
\hline \multicolumn{6}{|c|}{ conjugation efficiency is $100 \%$ without nonspecific adsorption, which are the same for both } \\
\hline
\end{tabular}




\section{References}

(1) Howorka, S.; Cheley, S.; Bayley, H. Nat. Biotechnol. 2001, 19, 636-639.

(2) Ma, Y. F.; Shortreed, M. R.; Li, H. L.; Huang, W. H.; Yeung, E. S. Electrophoresis 2001, 22, 421-426.

(3) Wabuyele, M. B.; Farquar, H.; Stryjewski, W.; Hammer, R. P.; Soper, S. A.; Cheng, Y. W.; Barany, F. J. Am. Chem. Soc. 2003, 125, 6937-6945.

(4) Storhoff, J. J.; Lucas, A. D.; Garimella, V.; Bao, Y. P.; Muller, U. R. Nat. Biotechnol. 2004, $22,883-887$.

(5) Li, J.; Lee, J. Y.; Yeung, E. S. Anal. Chem. 2006, 78, 6490-6496.

(6) Lee, J. Y.; Li, J.; Yeung, E. S. Anal. Chem. 2007, 79, 8083-8089.

(7) Jain, K. K. Clin. Chem. 2007, 53, 2002-2009.

(8) Seidel, M.; Niessner, R. Anal. Bioanal. Chem. 2008, 391, 1521-1544.

(9) Chan, W. C. W.; Nie, S. M. Science 1998, 281, 2016-2018.

(10) Bieschke, J.; Giese, A.; Schulz-Schaeffer, W.; Zerr, I.; Poser, S.; Eigen, M.;

Kretzschmar, H. Proc. Natl. Acad. Sci. U. S. A. 2000, 97, 5468-5473.

(11) Tetin, S. Y.; Swift, K. M.; Matayoshi, E. D. Anal. Biochem. 2002, 307, 84-91.

(12) Tetin, S. Y.; Stroupe, S. D. Curr. Pharm. Biotechnol. 2004, 5, 9-16.

(13) Nalefski, E. A.; D'Antoni, C. M.; Ferrell, E. P.; Lloyd, J. A.; Qiu, H. Q.; Harris, J. L.; Whitney, D. H. Clin. Chem. 2006, 52, 2172-2175.

(14) Qiu, H.; Ferrell, E. P.; Nolan, N.; Phelps, B. H.; Tabibiazar, R.; Whitney, D. H.; Nalefski, E. A. Clin. Chem. 2007, 53, 2010-2012. 
(15) Han, A.; Creus, M.; Schurmann, G.; Linder, V.; Ward, T. R.; de Rooij, N. F.; Staufer, U. Anal. Chem. 2008, 80, 4651-4658.

(16) Weiss, R. A. Science 1993, 260, 1273-1279.

(17) Dybul, M.; Fauci, A. S.; Bartlett, J. G.; Kaplan, J. E.; Pau, A. K. Ann. Intern. Med. 2002, 137, 381-433.

(18) Saville, R. D.; Constantine, N. T.; Cleghorn, F. R.; Jack, N.; Bartholomew, C.;

Edwards, J.; Gomez, P.; Blattner, W. A. J. Clin. Microbiol. 2001, 39, 2518-2524.

(19) MMWR. Morb. Mortal. Wkly. Rep. 1996, 45, 468-480.

(20) MMWR Recomm. Rep. 1998, 47, 1-33.

(21) MMWR Recomm. Rep. 2001, 50, 1-52.

(22) Cardo, D. M.; Culver, D. H.; Ciesielski, C. A.; Srivastava, P. U.; Marcus, R.; Abiteboul, D.; Heptonstall, J.; Ippolito, G.; Lot, F.; McKibben, P.; Bell, D. M. N. Engl. J. Med. 1997, 337, 1485-1490.

(23) Wang, S. A.; Panlilio, A. L.; Doi, P. A.; White, A. D.; Stek, M.; Saah, A.; Grp, H. P. R. Infect. Control Hosp. Epidemiol. 2000, 21, 780-785.

(24) Panlilio, A. L.; Cardo, D. M.; Grohskopf, L. A.; Heneine, W.; Ross, C. S. MMWR Recomm. Rep. 2005, 54, 1-17.

(25) Reeves, J. D.; Doms, R. W. J. Gen. Virol. 2002, 83, 1253-1265.

(26) Kusnezow, W.; Jacob, A.; Walijew, A.; Diehl, F.; Hoheisel, J. D. Proteomics 2003, 3, 254-264.

(27) He, Y.; Li, H. W.; Yeung, E. S. J. Phys. Chem. B 2005, 109, 8820-8832.

(28) Fang, N.; Zhang, H.; Li, J.; Li, H. W.; Yeung, E. S. Anal. Chem. 2007, 79, 6047-6054. 
(29) Bhatia, S. K.; Shriverlake, L. C.; Prior, K. J.; Georger, J. H.; Calvert, J. M.; Bredehorst, R.; Ligler, F. S. Anal. Biochem. 1989, 178, 408-413. 


\section{Figure Captions}

Figure 1. Schematic illustration of the evanescent field illumination setup: Laser, 532$\mathrm{nm}$ continuous-wave solid-state laser; FP, fused-silica right angle prism; IO, immersion oil; CG, cover glass; PA: goat-anti-HIV-1 p24 polyclonal antibody; Ag: HIV-1 p24 antigen; AF532-2nd Ab/MA: Alexa Fluor 532 labeled goatanti-mouse IgG/ mouse-anti-HIV-1 p24 monoclonal antibody complex; OB, $100 \times$ NA 1.30 objective lens.

Figure 2. Three single-molecules sandwich immunosorbent assay schemes. (A) MAAg-(AF532-PA) sequence: CG, cover glass; MA: mouse-anti-HIV-1 p24 monoclonal antibody; Ag: HIV-1 p24 antigen; AF532-PA: Alexa Fluor 532 labeled goat-anti-HIV-1 p24 polyclonal antibody. (B) PA-Ag-(AF532-MA) sequence: PA: goat-anti-HIV-1 p24 polyclonal antibody; AF532-MA: Alexa Fluor 532 labeled mouse-anti-HIV-1 p24 monoclonal antibody. (C) PA-Ag(AF532-2nd Ab/MA) sequence: AF532-2nd Ab/MA: Alexa Fluor 532 labeled goat-anti-mouse IgG/ mouse-anti-HIV-1 p24 monoclonal antibody complex.

Figure 3. Schematic diagrams of cover glass surface modification. (A) GPTS modification, GTPS: (3-glycidoxypropyl) trimethoxy silane. (B) MPTS/GMBS modification, MPTS: Mercaptopropyltrimethoxysilane; GMBS: $\mathrm{N}$-succinimidyl 4-maleimidobutyrate.

Figure 4. Representative single-molecule images for detection HIV-1 p24 antigen in 1× PBS buffer. (A) 0, (B) 0.1, (C) 1, (D) 10, and (E) $100 \mathrm{pg} / \mathrm{mL}$ antigen. All of the images are displayed with the same contrast (2000-4095) for comparison. 
Figure 5. HIV-1 p24 antigen detection results. (A) and (B) are the plots for detection of antigen in $1 \times$ PBS buffer only, while (C) and (D) are the ones for detection of antigen in $20 \%$ human serum. (A) Original data plot from Table 1 . The points depict the average over four experiments (at least 80 frames for each data point), and the error bars are the standard deviations. The solid line shows the fit of the data points to a Langmuir isotherm: $\Gamma=\frac{654 \times 0.0577[T]}{1+0.0577[T]}$. Standard curve of quantification of antigen in buffer with SMISA. Both axes are logarithmic scales. The equation of the trend line is: $\log \Gamma=1.99+0.373 \log [T]$. (C) Original data plot from Table 1. The points depict the average over four experiments (at least 80 frames), and the error bars are the standard deviations of these above 80 frames. The solid line shows the fit of the data points to a Langmuir isotherm: $\Gamma=\frac{842 \times 0.0732[T]}{1+0.0732[T]}$. (D) Standard curve of quantification of antigen in buffer with SMISA. Both axes are logarithmic scales. The equation of the trend line is: $\log \Gamma=2.17+0.353 \log [T]$. 
Figure 1.

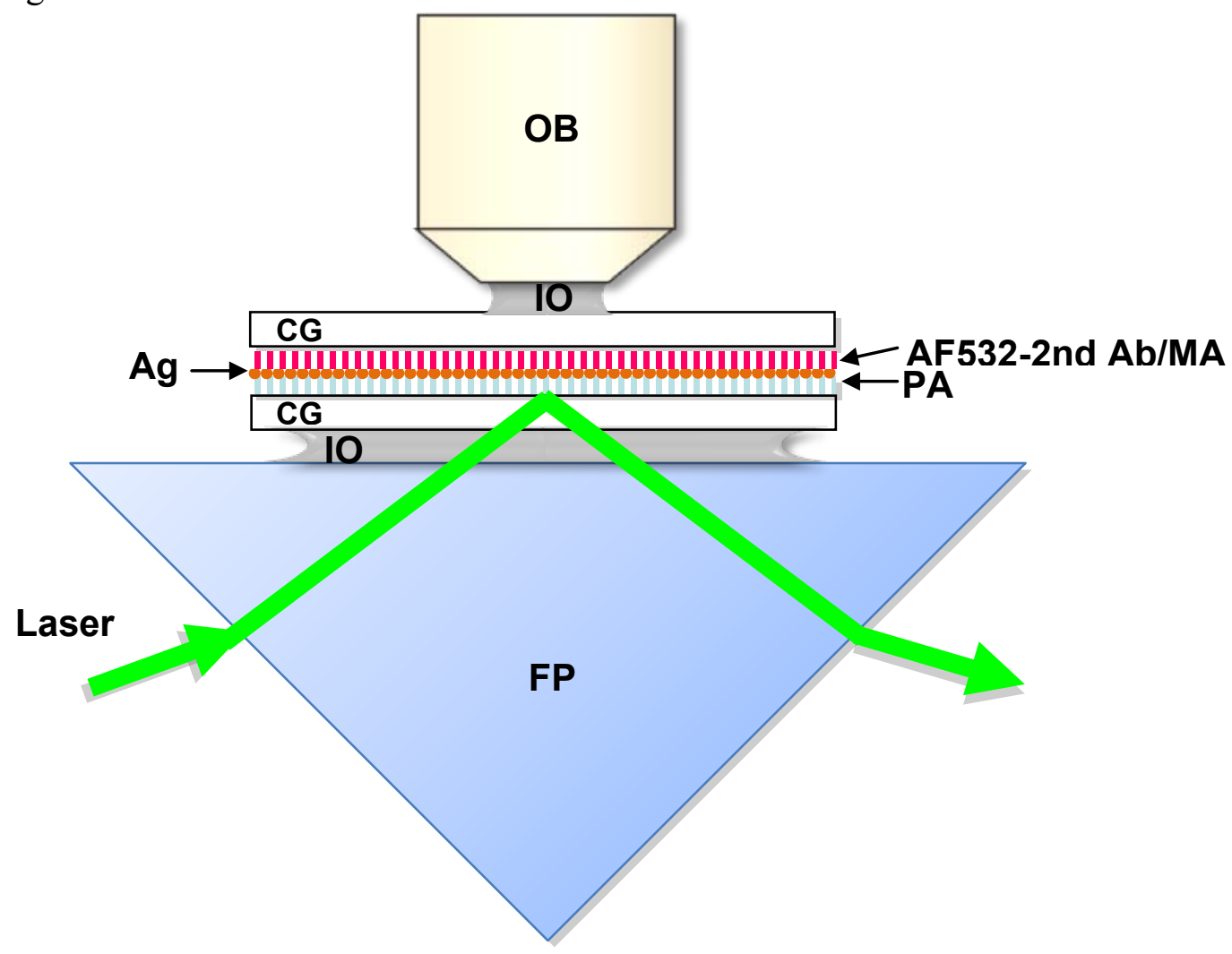


Figure 2.

A

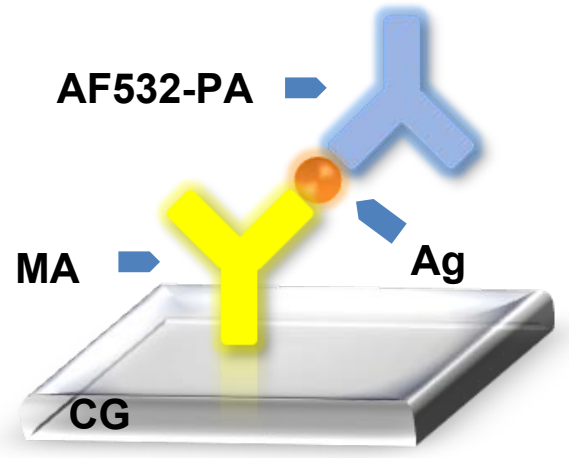

B

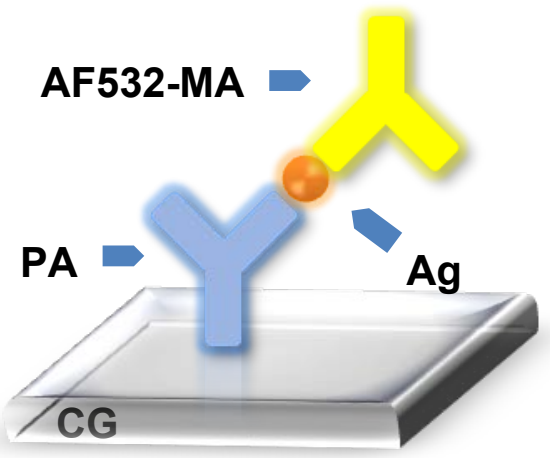

C

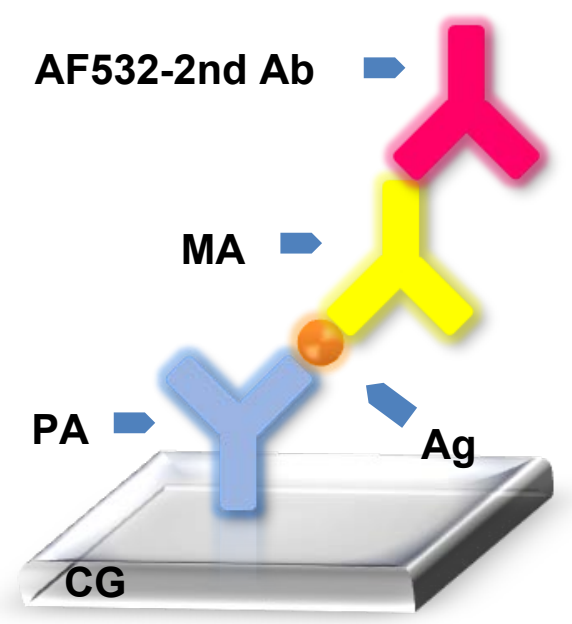


Figure 3.
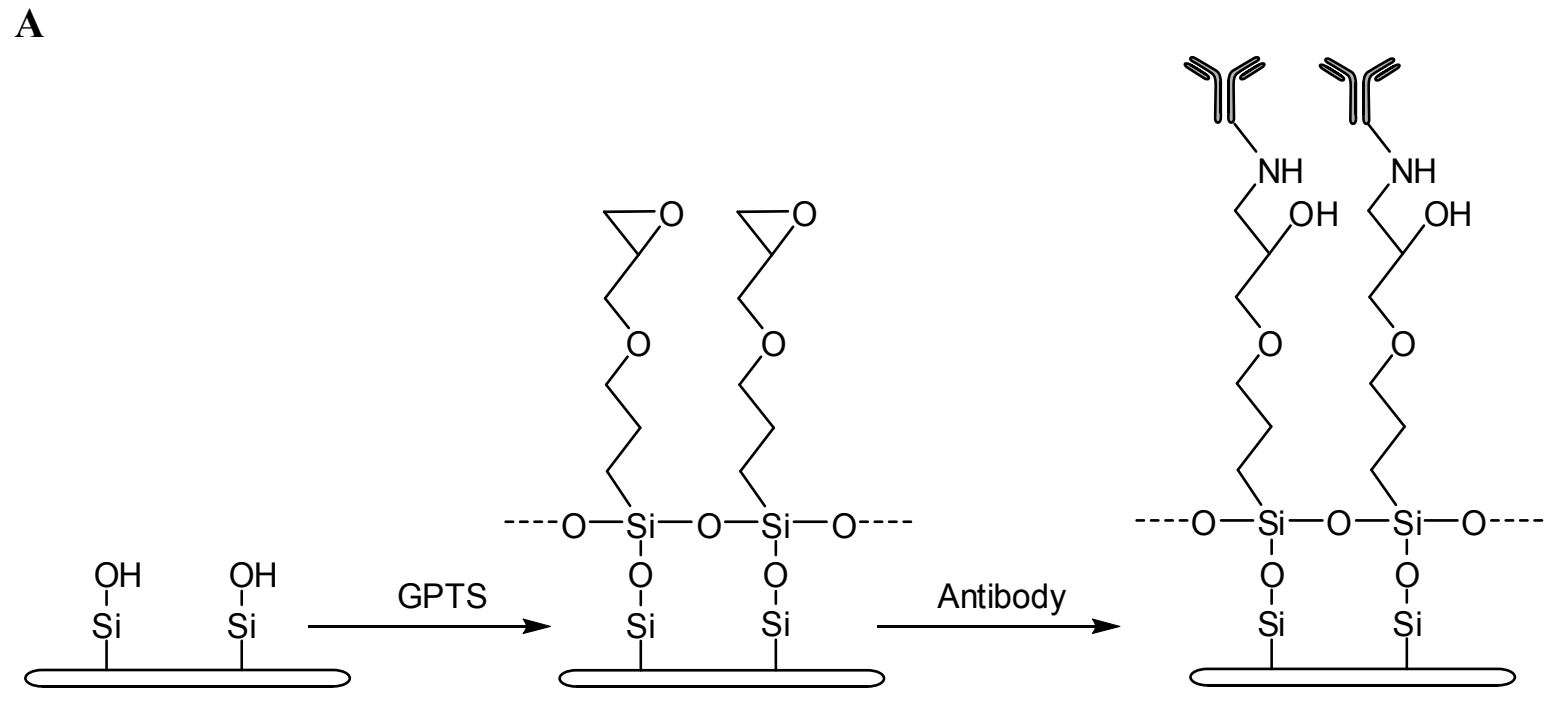

\section{B}

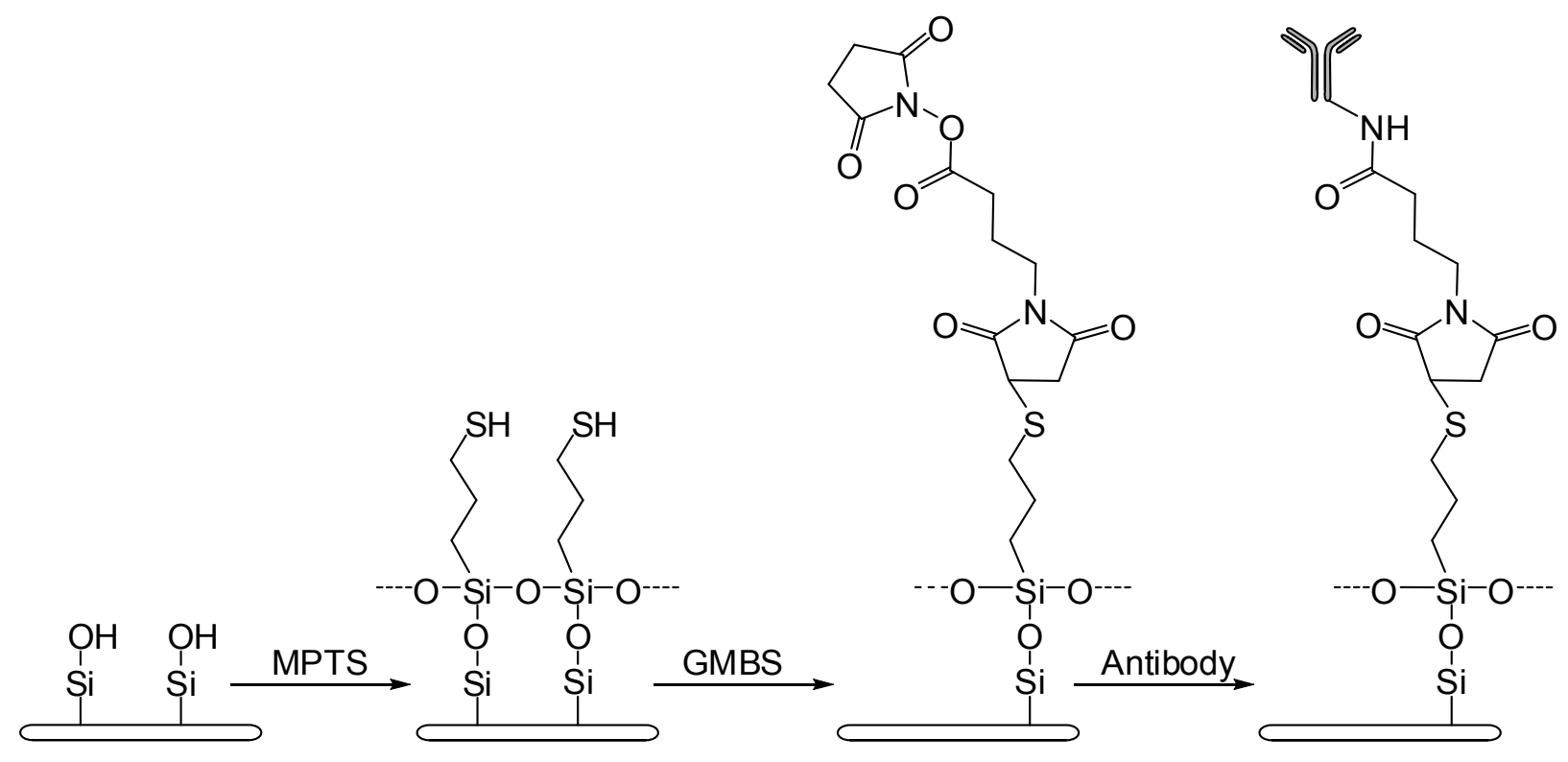


Figure 4.
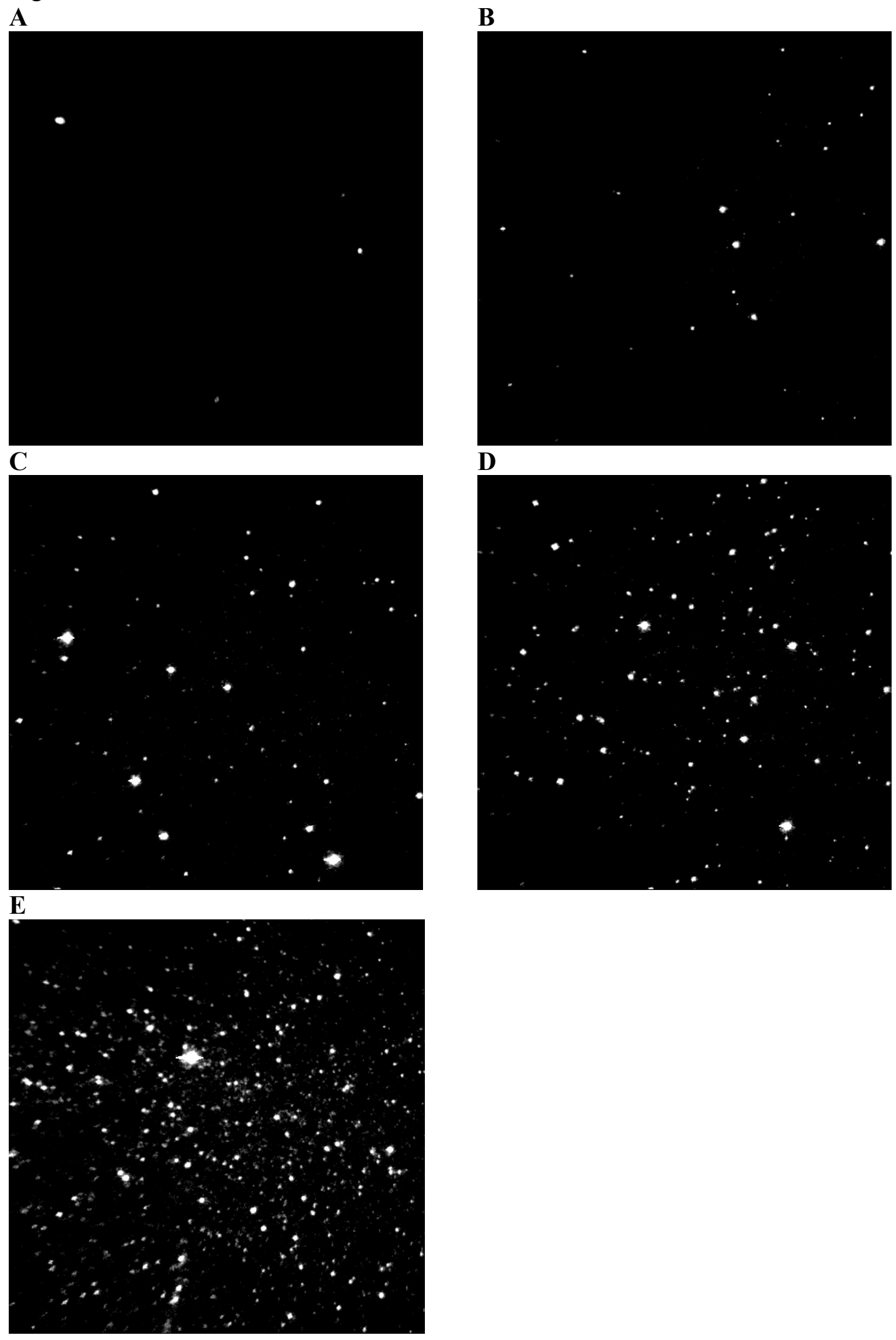
Figure 5.

A

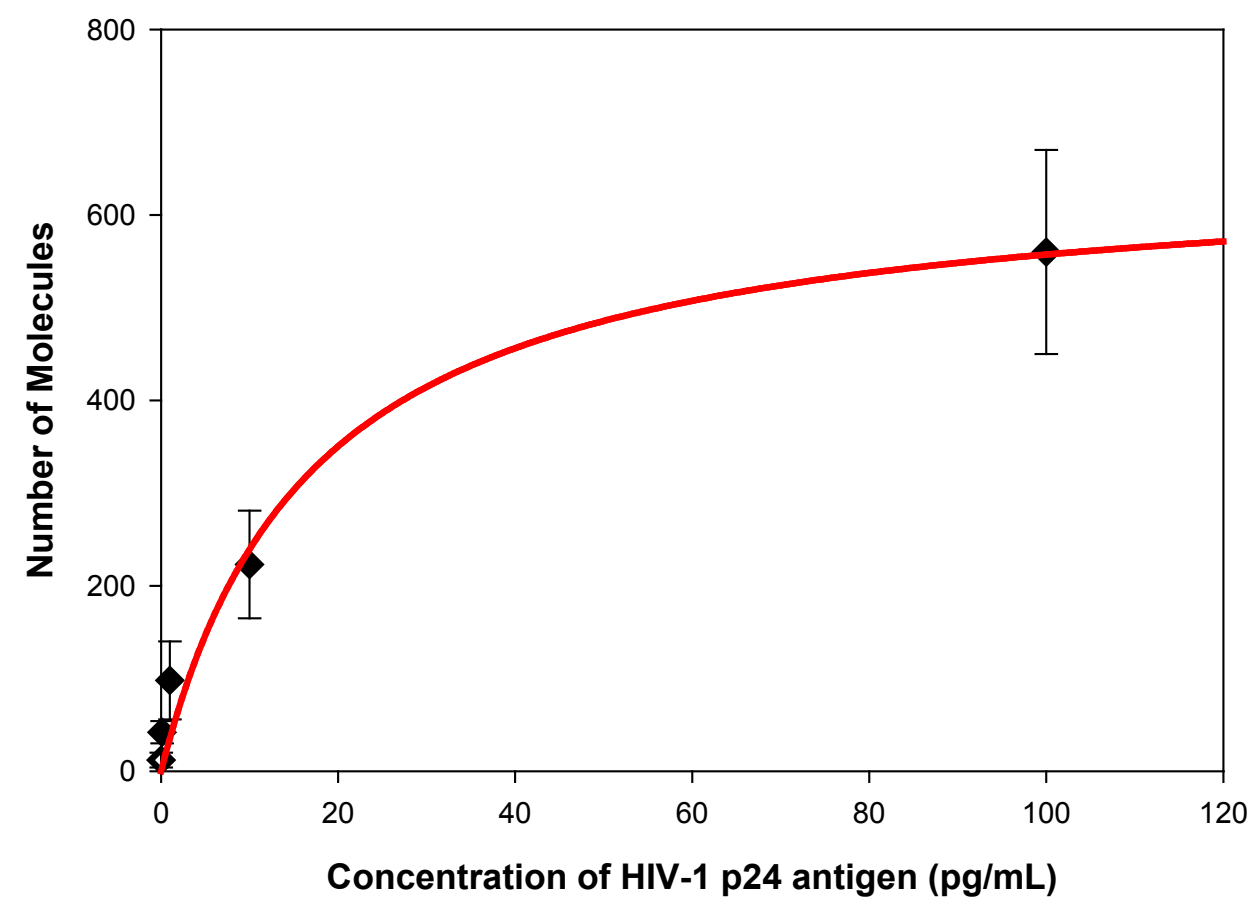

B

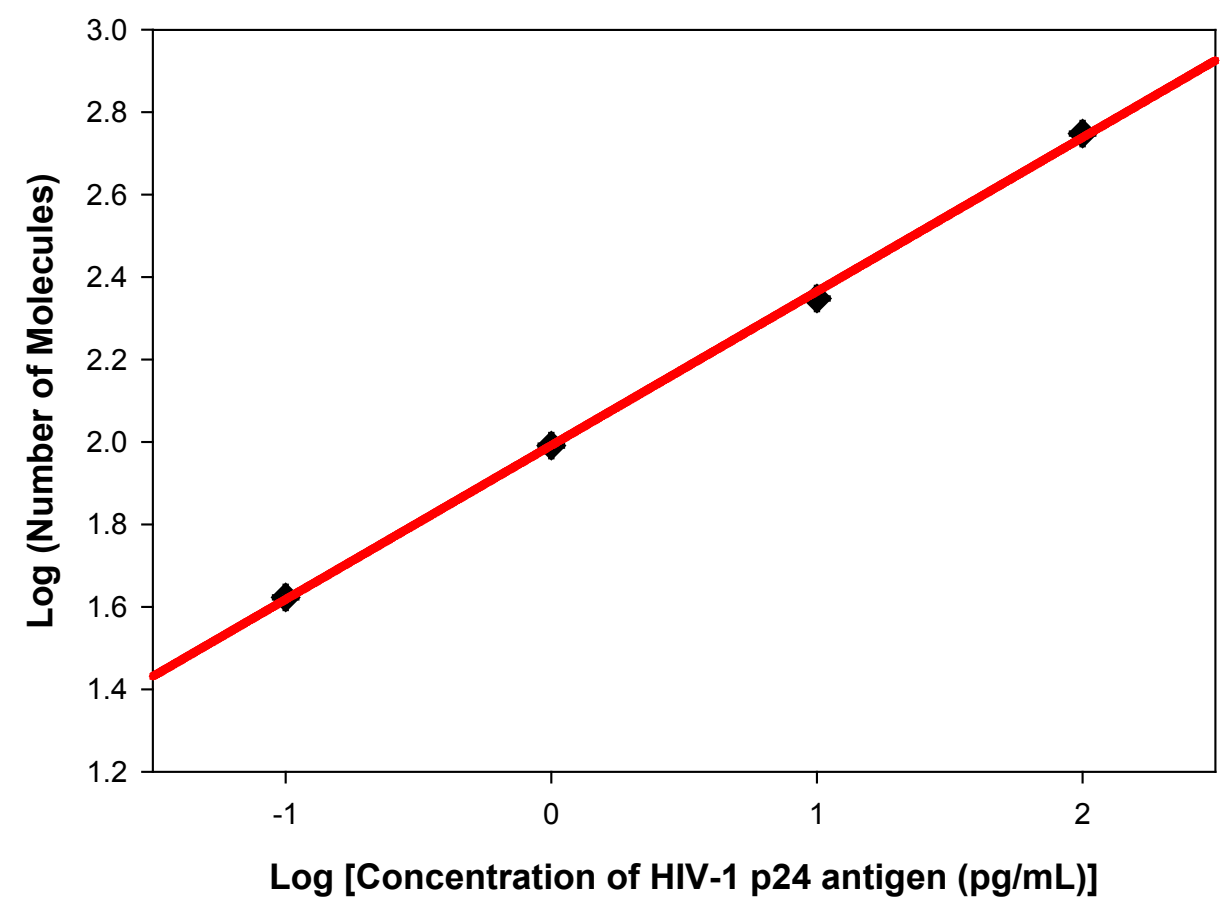


Figure 5. (Contd)

C

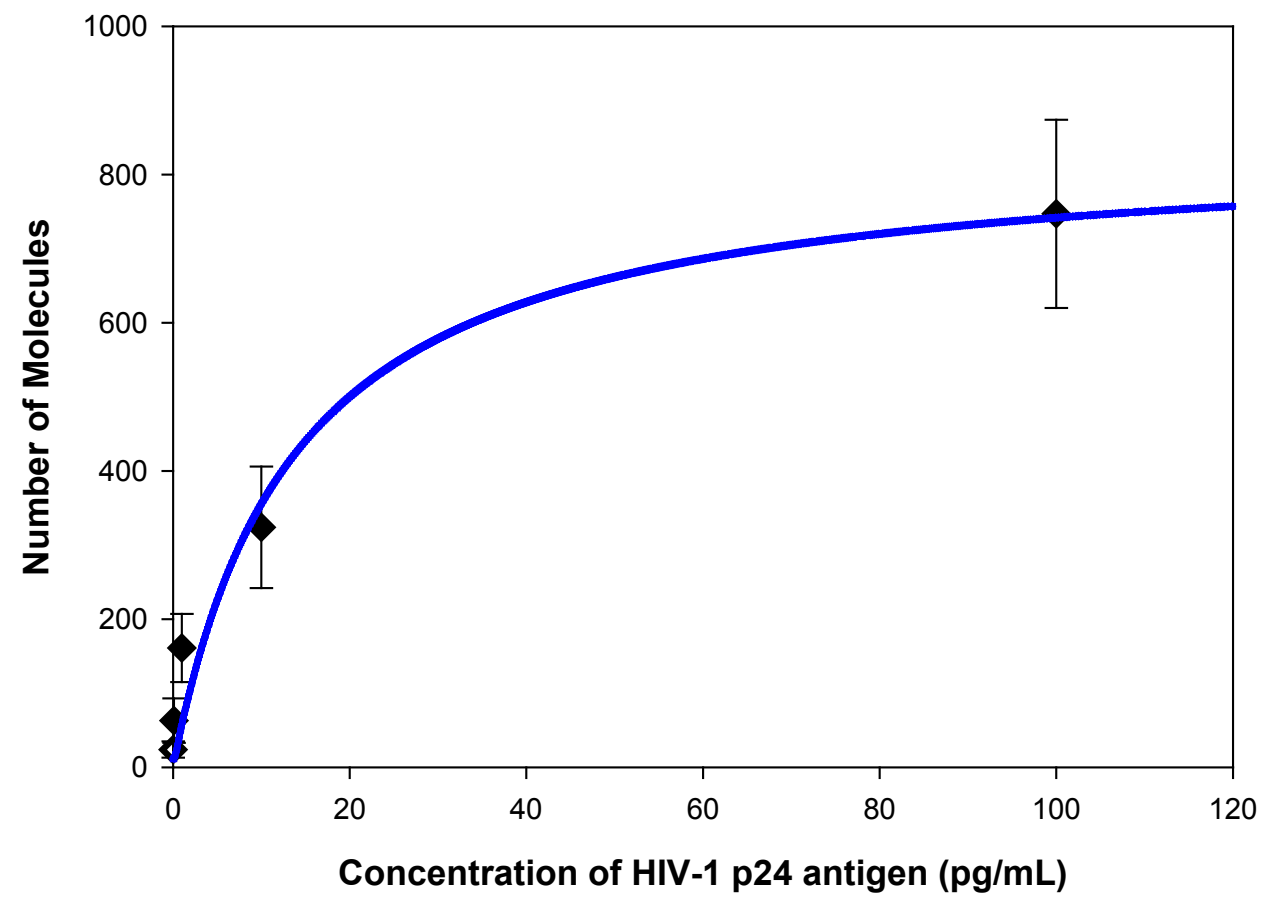

D

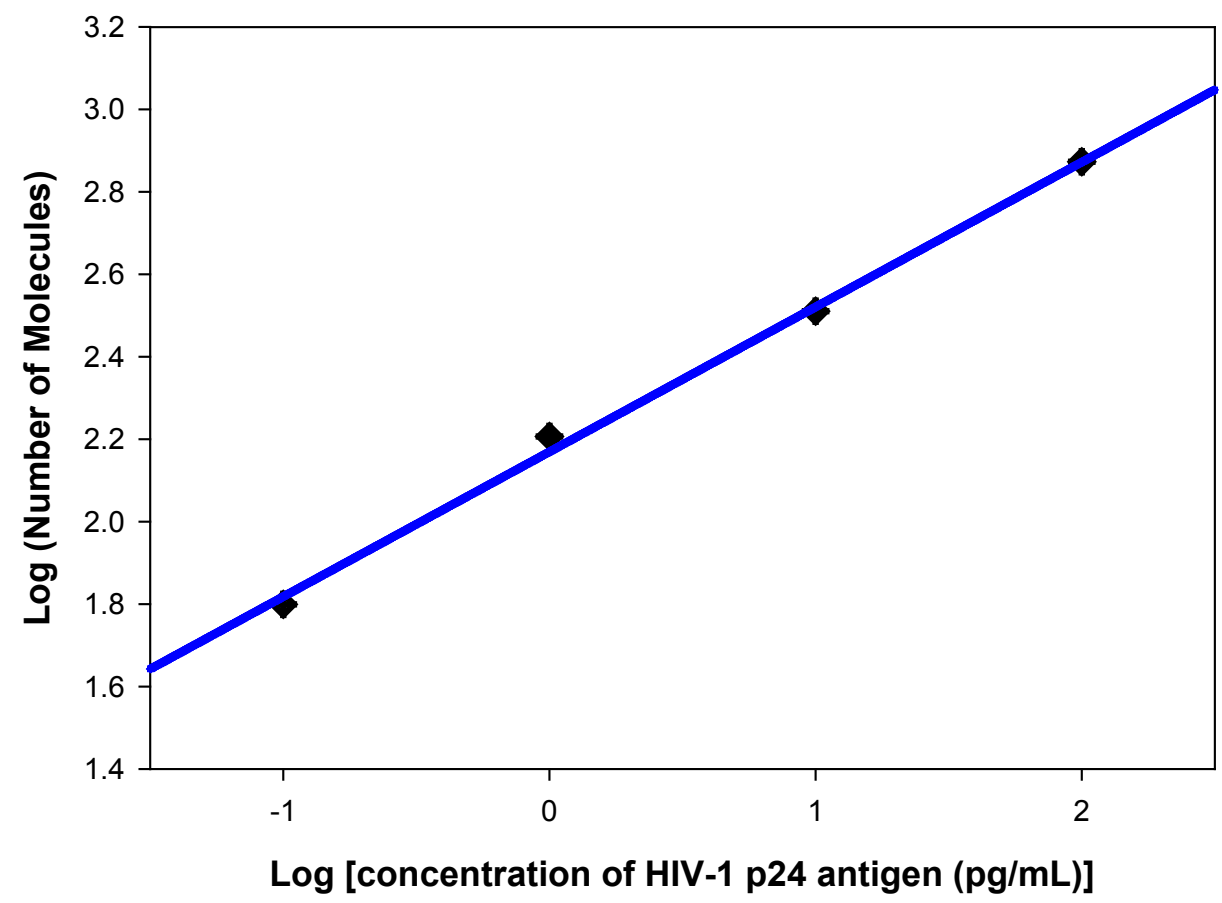




\title{
CHAPTER 5. REAL-TIME SINGLE-MOLECULE KINETICS OF TRYPSIN PROTEOLYSIS
}

\author{
A paper accepted for publication in Analytical Chemistry* \\ Jiangwei Li and Edward S. Yeung
}

\begin{abstract}
Single-molecule enzymatic kinetics and enantioselectivity were monitored in real time by using total internal reflection fluorescence (TIRF) microscopy. 300-kDa poly(Llysine) (PLL) or poly(D-lysine) (PDL) was labeled with Alexa Fluor 532 and was covalently immobilized on a dithiobis(succinimidyl undecanoate) self-assembled monolayer (DSU SAM) prepared on a gold substrate. The PLL/PDL chains were more accessible to trypsin on DSU SAM than when they were immobilized on a bare glass substrate. Short-chain PDL was further used as a blocking agent to prevent readsorption of the hydrolyzed lysine fragments. Chain shortening due to enzymatic hydrolysis resulted in the reduction of the individual fluorescence intensities. A broad distribution was obtained when 100 single-molecule halflives were analyzed. However, the detailed hydrolysis process involved also a long-lived component and an induction period that varied significantly among molecules. Charge and steric heterogeneity at the surface are responsible for these features. In contrast, standard

\footnotetext{
* Reprint with permission from Analytical Chemistry, 2008
}

Copyright@2008 American Chemical Society
\end{abstract}


Michaelis-Menten fitting of the decrease in molecule numbers with time masked out all such details.

\section{Introduction}

Single-molecule spectroscopy has proven itself to be a powerful tool in biological macromolecular research. Numerous scientific issues have been addressed by this technique, including DNA sequencing, ${ }^{1}$ molecular motors, ${ }^{2,3}$ membrane fusion, ${ }^{4}$ and diffusion analysis. ${ }^{5-7}$ Moreover, single-molecule screening has found use as biosensors ${ }^{8,9}$ and for the early diagnostics of diseases. ${ }^{10,11}$ New insights about enzymology were also derived from this approach. Xue and Yeung monitored the reactions of individual molecules of lactate dehydrogenase $\mathrm{e}^{12}$ and observed large variations in single-molecule reaction rates that have since been confirmed in related experiments. ${ }^{13,14}$ Enzymatic kinetics and activities of the restriction endonuclease EcoR1 were monitored by dual-color fluorescence cross-correlation spectroscopy. ${ }^{15}$ Single cleavage of a DNA strand by a restriction enzyme has been recorded in real time. ${ }^{16}$ Enzymatic turnovers of single cholesterol oxidase molecules were observed by detecting fluorescence from the active site. ${ }^{17}$ The inhibition kinetics of single $\beta$-galactosidase molecules by D-galactal was characterized in an array of ultra-small reaction containers and substrate turnovers were observed with fluorescence microscopy. ${ }^{18}$ However, previous works have not focused on the delineation of surface effects or the enantioselectivity of enzymatic reactions.

Enzymatic enantioselectivity is of great interest for the pharmaceutical, fine chemical, and food industries. ${ }^{19-21}$ Examples include the synthesis of $(R)$-3-(4-fluorophenyl)-2hydroxypropionic $\operatorname{acid}^{22,23}$ and the production of high-fructose corn syrup by xylose 
isomerase, which catalyzes the isomerization of D-glucose to D-fructose. ${ }^{24,25}$ Methods such as circular dichroism, ${ }^{26,27}$ high-performance liquid chromatography, ${ }^{28-30}$ gas

chromatography, ${ }^{31}$ nuclear magnetic resonance, ${ }^{32}$ and mass spectrometry ${ }^{33}$ have been used to elucidate the basis for enantioselectivity. However, these techniques can only reveal the average (bulk) characteristics of the reaction. Single-molecule detection should enable us to undertake an in-depth investigation on enantioselectivity, down to an individual event in a controlled environment.

Here, we investigated single-enzyme activity and enantioselectivity near a surface by using total internal reflection fluorescence (TIRF) microscopy to provide high throughput, low background, and high detection sensitivity. Trypsin is a serine protease that cleaves peptide chains at the carboxyl side of lysine and arginine residues. It is known that Dpeptides are generally more resistant to enzymatic hydrolysis than L-peptides in solution. ${ }^{34}$ The question remains as to whether selectivity is retained when the enzyme or the peptide is near a surface, where charge or steric effects are present.

\section{Experimental Section}

Slide Pretreatment and SAM Formation. Coverslips with dimensions of $35 \times 22$ mm (Electron Microscopy Sciences, Hatfield, PA) were cleaned in an ultrasonic bath for 30 min with 5\% Contrad 70 solution (Decon Labs, King of Prussia, PA), 30 min in ultrapure 18 $\mathrm{M} \Omega$ water, and $30 \mathrm{~min}$ in methanol (twice). The substrates were dried under a high purity nitrogen stream and then coated with $5 \mathrm{~nm}$ of chromium at $0.1 \mathrm{~nm} / \mathrm{s}$ followed by $30 \mathrm{~nm}$ of gold $\left(99.99 \%\right.$ purity) at $0.1 \mathrm{~nm} / \mathrm{s}$ under high vacuum $\left(10^{-7}\right.$ torr $)$ in an Airco Temscal BJD1800 E-beam evaporator (Berkeley, CA). The gold substrates were used immediately 
upon removal from the evaporator. The thin coating of gold allowed adequate light transmission for fluorescence excitation while maintaining uniform surface coverage. Dithiobis(succinimidyl undecanoate) (DSU) and $N, N$-dimethylformamide (DMF) were purchased from Dojindo Molecular Technologies (Gaithersburg, MD) and Fisher Scientific (Fair Lawn, NJ), respectively. Optically transparent gold-coated substrates were immersed in DMF solutions of $0.1 \mathrm{mM}$ DSU for $\sim 20 \mathrm{~h}$. The slides were then rinsed with ethanol and dried under nitrogen gas, and the DSU SAM surface was ready to use.

Sample Preparation. Long-chain poly(L-lysine) (PLL) and poly(D-lysine) (PDL) (MW 300 kDa, Sigma-Aldrich, St. Louis, MO) were labeled with an Alexa Fluor 532 protein labeling kit (Invitrogen, Carlsbad, CA) according to the manufacturer's instructions. AF532-PLL/PDL were diluted to $1 \mu \mathrm{g} / \mathrm{mL}$ for incubation experiments. For real-time experiments, labeled PLL/PDL were mixed with unlabeled short-chain PDL (MW 4 kDa), which served as the blocking agent, to 1 and $100 \mu \mathrm{g} / \mathrm{mL}$, respectively, in $50 \mathrm{mM}$ borate buffer ( $\mathrm{pH}=8.5$, Pierce, Rockford, IL). Twenty microliters of sample solution was added onto the slides with DSU SAM and covered with $22 \times 22 \mathrm{~mm}$ coverslips (Electron Microscopy Sciences). The slides were incubated at room temperature overnight. After PLL/PDL binding to DSU SAM, excess PLL/PDL were washed off by brief ultrasonication with $1 \%$ Tween 80 (Fisher) in $25 \mathrm{mM}$ borate buffer. The slides were then rinsed with ultrapure $18 \mathrm{M} \Omega$ water and dried under nitrogen gas.

Incubation Experiments. Hydrolysis reactions that took place without real-time observation were referred to as incubation experiments. Trypsin (Sigma-Aldrich) was dissolved in $10 \mathrm{mM}$ Tris and $50 \mathrm{mM}$ sodium chloride buffer $(\mathrm{pH}=7.4)$ to a concentration of $1 \mathrm{mg} / \mathrm{mL}$. On each slide, a $19 \times 6 \mathrm{~mm}$ silicon gasket perfusion chamber (Invitrogen) was set 
up to accommodate the solution. A total of $70 \mu \mathrm{L}$ of trypsin solution was injected into the chamber and sealed with adhesive sealers. Slides with samples were enclosed in the chambers to avoid evaporation and were incubated at $37^{\circ} \mathrm{C}$ for $2 \mathrm{~h}$. After the hydrolysis reaction, the slides were submitted to ultrasonication for 2 min with $1 \%$ Tween 80 in $25 \mathrm{mM}$ borate buffer. After washing with ultrapure $18 \mathrm{M} \Omega$ water, the slides were dried under a gentle nitrogen stream and kept in a dark box. Right before imaging, the slide was hydrated with $5 \mu \mathrm{L}$ of PBS buffer ( $\mathrm{pH} 7.4$, Invitrogen) and covered with a clean $22 \times 22 \mathrm{~mm}$ coverslip.

Real-Time Experiments. Real-time experiments were those in which the real-time hydrolysis reaction was recorded with single-molecule spectroscopy. The microscope stage was preheated, and the temperature of the quartz prism surface was kept at $37^{\circ} \mathrm{C}$. Five microliters of $10 \mathrm{mM}$ Tris and $50 \mathrm{mM}$ sodium chloride buffer (reaction buffer, $\mathrm{pH}$ 7.4) was added onto the slide before a clean $22 \times 22 \mathrm{~mm}$ coverslip was applied. Then, the slide was mounted on the imaging system. Five microliters of $2 \mathrm{mg} / \mathrm{mL}$ trypsin solution was added to the edge of the coverslip to initiate the reaction so that the concentration of trypsin in between the coverslip and the slide was $1 \mathrm{mg} / \mathrm{mL}$. The capillary flow generated by adding trypsin solution in this manner ensured rapid mixing and facilitated flushing away of the cut polylysine fragments.

Imaging System. The TIRF system was similar to the previous apparatus used in our group $^{11}$ with some modifications (Figure 1). The slide was located on top of a right-angle fused-silica prism (Melles Griot, Carlsbad, CA), with immersion oil in between them. The slide on the prism was heated indirectly through an aluminum holder that was connected to the heating stage of the microscope. A 532-nm, solid-state, continuous-wave laser (45 mW, $\mu$-Green model 4611, Uniphase, San Jose, CA) was used as the excitation source. A Uniblitz 
mechanical shutter (model LS2Z2, Vincent Associates, Rochester, NY) and a driver (model T132, Vincent Associates) were synchronized to the Pentamax 512-EFT/1EIA intensified charge-coupled device (ICCD) camera (Princeton Instruments, Princeton, NJ). To reduce photobleaching, the shutter only let the laser beam pass through when the ICCD was on. Fluorescence from individual labeled polylysine molecules was collected by a Zeiss $100 \times / 1.3$ NA Plan-Neofluar objective lens. Two 532-nm long-pass edge filters (Semrock, Rochester, NY) were placed between the objective lens and the ICCD to cut off scattering from the excitation beam. The sampling frequency was $2 \mathrm{~Hz}$, with the shutter driver set to $10-\mathrm{ms}$ exposure and 490-ms delay. For incubation experiments, the slide was manually moved around to image various locations. Typically, $\sim 30$ locations were imaged on a single slide. For real-time experiments, the imaged area was kept still until the hydrolysis reaction was complete. Images were obtained with WinView software provided by Princeton Instruments. ImageJ, a public-domain image processing program (version 1.38, National Institutes of Health, Bethesda, MD), was used for the data analysis.

\section{Results and Discussion}

Commercially available synthetic long-chain PLL and PDL are ideal candidates as substrates since data interpretation is simplified by eliminating heterogeneous proteolysis due to different amino acid residues. ${ }^{35}$ Moreover, Alexa Fluor 532 dye reacts efficiently with primary amines to form a stable fluorescent dye-protein conjugate. Multiple residues in each molecule could be labeled without affecting the proteolysis rate, making detection possible at low laser excitation powers, thereby avoiding problems with photobleaching.

For a bare glass surface, AF532-PLL/PDL molecules were added directly onto the 
slide. The highly positively charged polylysine molecules were strongly adsorbed onto the negatively charged surface. After incubation with $1 \mathrm{mg} / \mathrm{mL}$ trypsin solution at $37^{\circ} \mathrm{C}$ for $1 \mathrm{~h}$, neither PLL nor PDL was found to be hydrolyzed, as indicated by the constant number of molecules found on the surface (data not shown). The reason is that the entire polylysine chain was adsorbed to the surface (Figure 2A), and steric hindrance and electrostatic repulsion prevented trypsin molecules from approaching the cleavage sites.

To make polylysine exposed and available to trypsin digestion, a DSU SAM surface was created (Figure 2B). A uniform coating of 5-nm chromium and 30-nm gold was first introduced on the slides. On top of the metal coating, an amine-active cross-linker, DSU SAM, was formed to covalently immobilize AF532-PLL/PDL molecules. After the free peptide molecules were removed, the slide was incubated with $1 \mathrm{mg} / \mathrm{mL}$ trypsin at $37{ }^{\circ} \mathrm{C}$ for $1 \mathrm{~h}$. The trypsin and cut polylysine fragments were then thoroughly washed off. Figure 3 shows that intact PLL and PDL molecules had similar fluorescence intensities and surface number densities before trypsin was introduced. However, it is clear that trypsin digested PLL but not PDL. From over 30 images of different areas of the slides, for PLL, the average numbers of molecules counted were $227 \pm 16$ and 0 per frame before and after hydrolysis, respectively. In contrast, the corresponding numbers for PDL were $241 \pm 15$ and $234 \pm 20$ per frame, respectively.

As explained in Emil Fischer's analogy of the lock and key, ${ }^{36}$ the L-isomer can fit the active site of trypsin better than the D-isomer. One reason is that only the L-isomer undergoes a coil to $\alpha$-helix transition upon binding with the enzyme, while the D-isomer remains disordered. ${ }^{37}$ Immobilization of the two peptides on the surface did not change their interactions with the enzyme, despite the presence of electrostatic and steric effects. Because 
DSU is less negatively charged compared to glass at $\mathrm{pH} 7.4$, the polycationic peptide backbone is less attracted to it. Once one amine group binds to the DSU surface, the other parts of polylysine tend to stretch out into the solution. This allows trypsin molecules to approach the peptide and react.

The reaction kinetics was further studied by observing real-time cleavage at the single-molecule level. AF532-PLL/PDL molecules were immobilized on DSU together with short-chain unlabelled PDL (Figure 2C). The latter is an effective blocking agent because it is resistant to trypsin cutting and maintains a net positive charge on the surface, which in turn prohibits hydrolyzed, positively charged PLL fragments from being readsorbed and counted. Five microliters of reaction buffer was sandwiched between the bottom slide and a coverslip on top of a fused-silica prism mounted on the microscope. After heating the slides for 2 min at $37^{\circ} \mathrm{C}$, fluorescence images were acquired at a fixed location. Then, $5 \mu \mathrm{L}$ of $2 \mathrm{mg} / \mathrm{mL}$ trypsin solution was added to the edge of the coverslip to infuse trypsin into the observation region via capillary force. We have shown previously that the time for introducing reagents in this manner was $\sim 0.2 \mathrm{~s}^{16}$

The detection parameters were optimized to 10-ms exposure at $2 \mathrm{~Hz}$. We confirmed through control experiments that lack trypsin that AF532-PLL/PDL did not photobleach for at least $10 \mathrm{~min}$. Therefore, any reduction in molecule number or fluorescence intensity during the reaction time was entirely due to proteolysis and not photobleaching. ImageJ was used for counting the number of molecules in the images as in previous work. ${ }^{38}$ The number of white spots in each frame did not necessarily give the right count of fluorescent molecules because of random noise. However, false counts could be greatly reduced by removing all white spots which were less than $2 \times 2$ (contiguous) pixels in size. 
The initial PLL surface density was observed to be $\sim 200$ molecules per image area of $115 \times 115 \mu \mathrm{m}^{2}$, or $\sim 410000$ lysine residues, while the total number of trypsin molecules in the solution above it was calculated to be $6.9 \times 10^{9}$. We can thus simplify the MichaelisMenten equation by assuming that the enzyme concentration is constant. Thus, the substrate concentration $[\mathrm{S}]$ at time $\mathrm{t}$ will be:

$$
[S]=[S]_{0} e^{-K^{\prime} t}
$$

where $[\mathrm{S}]_{0}$ is the initial substrate concentration and $\mathrm{K}^{\prime}$ is the apparent first-order rate constant. Figure 4 shows the relation between the observed number of molecules and the incubation time. From nonlinear regression fitting, the rate constant $\mathrm{K}^{\prime}$ was found to be $0.091 \mathrm{~s}^{-1}$ and the half-life was $7.62 \mathrm{~s}$. These values are similar to those for bulk solution measurements.

Instead of counting molecules, more details can be derived by monitoring the chain shortening of single molecules. Figure 5 A displays four frames in the movie at $0,8,11$, and $30 \mathrm{~s}$, showing that the three molecules were cut stochastically in time instead of simultaneously. By utilizing the time-series analyzer plug-in of ImageJ, the time dependence of the fluorescence intensity of each molecule, as marked in a $10 \times 10$ pixels region of interest, was obtained. The background of each data series was set as the average intensity over the last $50 \mathrm{~s}$ (100 data points). After subtracting the background, all intensities were normalized to the initial intensity of each molecule. It is clear that there was an induction period associated with the decay curves in Figure 5B and that it varied substantially among molecules (Figure 6). The median of this distribution was $5.5 \mathrm{~s}$. This can be attributed to the average time needed for enzyme molecules in solution to approach the individual chains on the surface, which was much longer than that for simple ions. ${ }^{16}$

The presence of an induction period prevents fitting of the data to eq 1. Half-lives can 
be determined independent of the induction period as the interval between the $90 \%$ and the $45 \%$ intensity points. As shown in the inset of Figure 5B, the full intensity trajectories resemble exponential decays similar to that in Figure 4. However, each molecule had its unique half-life in the early stages. As AF532 dye labels the lysine residues randomly, the fluorescence intensity should track the length of the peptide. Here, the dependence is nonlinear as the chains are not uniformly oriented with respect to the surface and the evanescent field (EF) decays exponentially away from the surface. It is noteworthy that all decay curves were monotonic, i.e., without sudden large jumps. This indicates that, despite the abundance of enzyme molecules, cleavage preferentially started at the exposed end of the peptide and proceeded towards the immobilized end at the surface. Such behavior is not expected in free solution and is indicative of the presence of antagonistic surface effects.

The half-lives of 100 molecules were plotted as a histogram in Figure 7. The variation in half-lives among molecules probably reflects the local environment, including distance from the surface, chain orientation, enzyme concentration, $\mathrm{pH}$, diffusion rate, surface morphology, etc. The median of this distribution was $1.96 \mathrm{~s}$. This is very different from the half-life obtained by fitting the time course of the number of molecules observed (Figure 4). A closer examination of Figure 5B shows that the decay rates also slowed down with time; i.e., they were multi-exponential. So, the fit in Figure 4 was skewed by those molecules with long induction periods or long lifetimes, as well as the short-lived molecules with long-lived decay components. Thus, the fitted lifetime from Figure 4 was not meaningful. Indeed, the ensemble half-life (7.62 s) from Figure 4 is consistent with the sum of the single-molecule median half-life $(1.96 \mathrm{~s})$ and median induction period $(5.5 \mathrm{~s})$. This underscores the difference between counting molecules and counting intact lysine residues on each molecule. 
We note that exponential decay of the EF exaggerates intensity contributions from the proximal lysine groups such that a constant proteolysis rate would have led to a faster decay in the intensity at long times, not slower as in Figure 5B. The gradual decrease in the singlemolecule hydrolysis rate further supports the presence of an antagonistic surface effect due to a combination of charge and steric hindrance. Trypsin proteolysis of AF532-PDL was also conducted in real-time experiments. After adding trypsin, no reduction in molecule count or intensity was observed during the same reaction period as the PLL experiments (results not shown). This is additional confirmation that PDL was resistant to trypsin cutting.

\section{Conclusions}

With the SAM-assisted TIRF assay, we can study the proteolysis of many individual surface-bound peptide chains simultaneously. This is then a high-throughput approach for testing the selectivity of reactions that requires a minimum amount of enzyme and substrates. By judicious assembly of peptide or oligonucleotide chains such that their orientations with respect to the surface are all identical, the dependence of reaction rates on distances from a surface or a marker can be quantified. Another possible future direction is to investigate the interactions between chiral small molecules and biological macromolecules. Other aspects about enzymatic reactions could be studied with this approach as well, such as temperature, enzyme/substrate concentration, $\mathrm{pH}$, ionic strength, local morphology, surface composition.

\section{Acknowledgment}

We thank Dr. Ning Fang for valuable discussions. E.S.Y. thanks the Robert Allen Wright Endowment for Excellence for support. The Ames Laboratory is operated for the U.S. 
Department of Energy by Iowa State University under Contract No. DE-AC02-07CH11358. This work was supported by the Director of Science, Office of Basic Energy Sciences, Division of Chemical Sciences. 


\section{References}

(1) Braslavsky, I.; Hebert, B.; Kartalov, E.; Quake, S. R. Proc. Natl. Acad. Sci. U. S. A. 2003, 100, 3960-3964.

(2) Noji, H.; Yasuda, R.; Yoshida, M.; Kinosita, K. Nature 1997, 386, 299-302.

(3) Sowa, Y.; Rowe, A. D.; Leake, M. C.; Yakushi, T.; Homma, M.; Ishijima, A.; Berry, R. M. Nature 2005, 437, 916-919.

(4) Bowen, M. E.; Weninger, K.; Brunger, A. T.; Chu, S. Biophys. J. 2004, 87, 35693584.

(5) Zurner, A.; Kirstein, J.; Doblinger, M.; Brauchle, C.; Bein, T. Nature 2007, 450, 705708.

(6) Nishimura, S. Y.; Lord, S. J.; Klein, L. O.; Willets, K. A.; He, M.; Lu, Z. K.; Twieg, R. J.; Moerner, W. E. J. Phys. Chem. B 2006, 110, 8151-8157.

(7) Xu, X. H.; Yeung, E. S. Science 1997, 275, 1106-1109.

(8) Bayley, H.; Cremer, P. S. Nature 2001, 413, 226-230.

(9) Shortreed, M. R.; Li, H.; Huang, W. H.; Yeung, E. S. Anal. Chem. 2000, 72, 28792885.

(10) Li, J.; Lee, J. Y.; Yeung, E. S. Anal. Chem. 2006, 78, 6490-6496.

(11) Lee, J. Y.; Li, J.; Yeung, E. S. Anal. Chem. 2007, 79, 8083-8089.

(12) Xue, Q. F.; Yeung, E. S. Nature 1995, 373, 681-683.

(13) Tan, W.; Yeung, E. S. Anal. Chem. 1997, 69, 4242-4248.

(14) Hsin, T.-M.; Yeung, E. S. Angew. Chem. Int. Ed. 2007, 46, 8032-8035.

(15) Kettling, U.; Koltermann, A.; Schwille, P.; Eigen, M. Proc. Natl. Acad. Sci. U. S. A. 1998, 95, 1416-1420. 
(16) Li, H. W.; Yeung, E. S. Anal. Chem. 2005, 77, 4374-4377.

(17) Lu, H. P.; Xun, L. Y.; Xie, X. S. Science 1998, 282, 1877-1882.

(18) Gorris, H. H.; Rissin, D. M.; Walt, D. R. Proc. Natl. Acad. Sci. U. S. A. 2007, 104, 17680-17685.

(19) Schulze, B.; Wubbolts, M. G. Curr. Opin. Biotechnol. 1999, 10, 609-615.

(20) Huisman, G. W.; Gray, D. Curr. Opin. Biotechnol. 2002, 13, 352-358.

(21) Patel, R. N. Curr. Opin. Biotechnol. 2001, 12, 587-604.

(22) Tao, J. H.; McGee, K. Org. Process Res. Dev. 2002, 6, 520-524.

(23) Straathof, A. J. J.; Panke, S.; Schmid, A. Curr. Opin. Biotechnol. 2002, 13, 548-556.

(24) Jensen, V. J.; Rugh, S. Methods Enzymol. 1987, 136, 356-370.

(25) Schmid, A.; Dordick, J. S.; Hauer, B.; Kiener, A.; Wubbolts, M.; Witholt, B. Nature 2001, 409, 258-268.

(26) de Jong, J. J. D.; Lucas, L. N.; Kellogg, R. M.; van Esch, J. H.; Feringa, B. L. Science 2004, 304, 278-281.

(27) Ishida, K.; Maksimenka, K.; Fritzsche, K.; Scherlach, K.; Bringmann, G.; Hertweck, C. J. Am. Chem. Soc. 2006, 128, 14619-14624.

(28) Hsieh, C. Y.; Huang, J. D. J. Chromatogr. B. Biomed. Appl. 1992, 575, 109-115.

(29) Hadley, M. R.; Oldham, H. G.; Damani, L. A.; Hutt, A. J. Chromatographia 1998, 48, 664-670.

(30) Bachmann, B. M.; Seebach, D. Macromolecules 1999, 32, 1777-1784.

(31) Overbeeke, P. L. A.; Jongejan, J. A. J. Mol. Catal. B: Enzym. 2003, 21, 89-91.

(32) Cainelli, G.; De Matteis, V.; Galletti, P.; Giacomini, D.; Orioli, P. Chem. Commun. 2000, 2351-2352. 
(33) Utsumi, R.; Izumi, S.; Hirata, T. Chem. Lett. 2001, 892-893.

(34) Sturtevant, J. M. J. Am. Chem. Soc. 1955, 77, 1495-1498.

(35) Waley, S. G.; Watson, J. Biochem. J. 1953, 55, 328-337.

(36) Fischer, E. Ber. Dtsch. Chem. Ges. 1890, 23, 2611-2624.

(37) Paradossi, G.; Chiessi, E.; Malovikova, A. Biopolymers 1999, 50, 201-209.

(38) Fang, N.; Zhang, H.; Li, J.; Li, H. W.; Yeung, E. S. Anal. Chem. 2007, 79, 6047-6054. 


\section{Figure Captions}

Figure 1. Schematic illustration of the TIRF setup: HS, heating stage of the Zeiss microscope; laser, 532-nm continuous-wave solid-state laser; FP, fused-silica right-angle prism; IO, immersion oil; CS, coverslip; GS, glass slide; Cr, 5-nm chromium coating; Au, 30-nm gold coating; DSU SAM, DSU self-assembled monolayer; AF532-PLL/PDL, Alexa Fluor 532 labeled 300 kDa PLL or PDL; BF, buffer solution; OB, 100× NA 1.30 objective lens.

Figure 2. Three AF532-PLL/PDL (300 kDa) immobilization schemes. (A) Bare glass; (B) DSU SAM surface; and (C) DSU SAM with the blocking agent 4-kDa PDL. GS, glass slide; Cr, 5-nm chromium coating; Au, 30-nm gold coating.

Figure 3. Single-molecule images of incubation experiments on a DSU SAM surface. The imaged area was $115 \times 115 \mu \mathrm{m}^{2}$. Each spot represents one AF532PLL/PDL molecule. (A) PLL slide before trypsin cutting; (B) PLL slide after trypsin cutting; (C) PDL slide before trypsin cutting; and (D) PDL slide after trypsin cutting. All images are displayed in the same contrast range (10004095) for comparison.

Figure 4. Relation between the number of immobilized molecules and reaction time for incubation experiments. Black dots are experimental data while the red curve shows the fit of the data points to a single-exponential decay:

$[S]=235 \exp (-0.091 t)$.

Figure 5. Three representative molecules showing heterogeneous hydrolysis rates and induction periods. (A) Sequence of images recorded after introduction of 
trypsin solution $(0,8,11,30 \mathrm{~s})$. (B) Trajectories of normalized fluorescence signals for the three molecules marked in (A). The inset shows the full reaction time course. The initial half-lives of the molecules were calculated from the 90 to $45 \%$ points to be $2.5,1.0$, and $3.5 \mathrm{~s}$ and the induction periods were $3.5,7$, and $8 \mathrm{~s}$.

Figure 6. Distribution of 100 single-molecule hydrolysis induction periods. The median was $5.5 \mathrm{~s}$.

Figure 7. Distribution of 100 single-molecule hydrolysis half-lives. The median was 2.0 S. 
Figure 1.

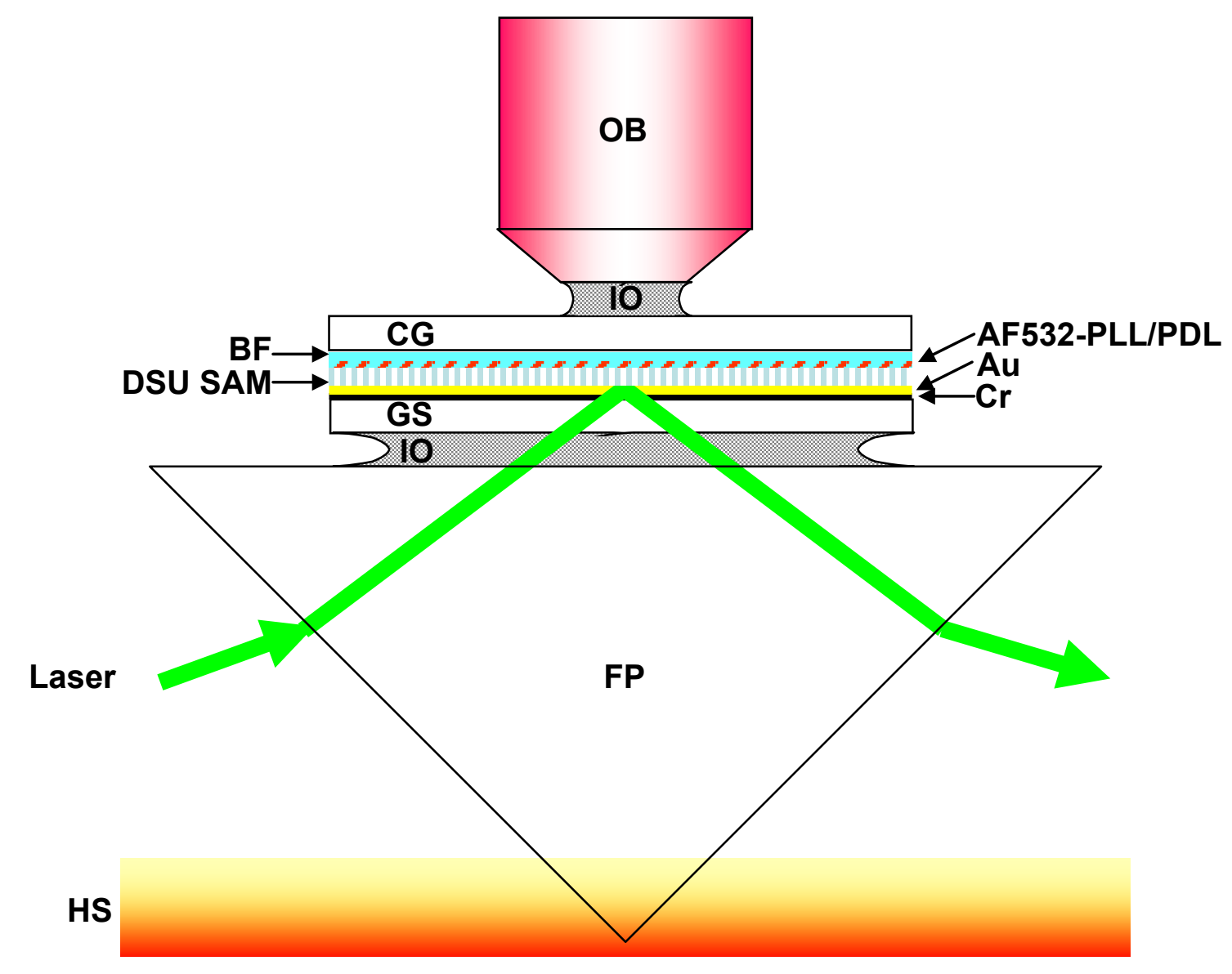


Figure 2.

A

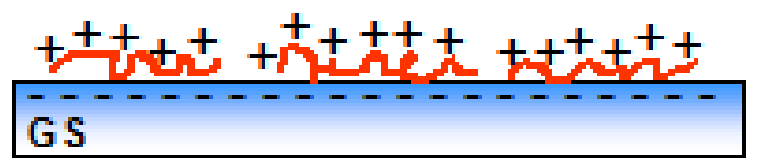

AF 532-

PLL/PDL

B

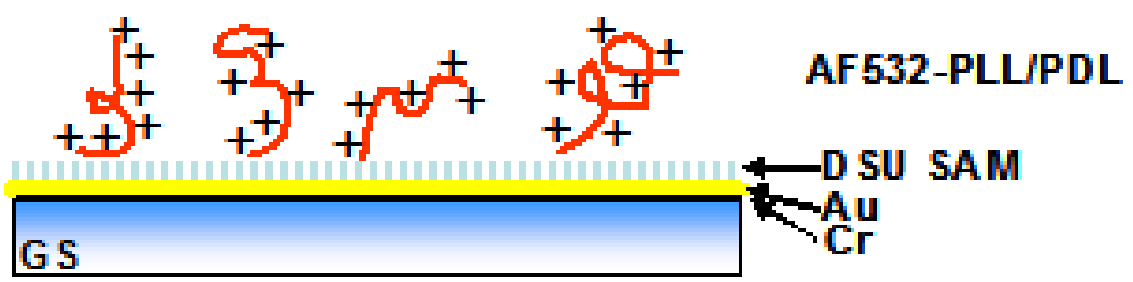

C

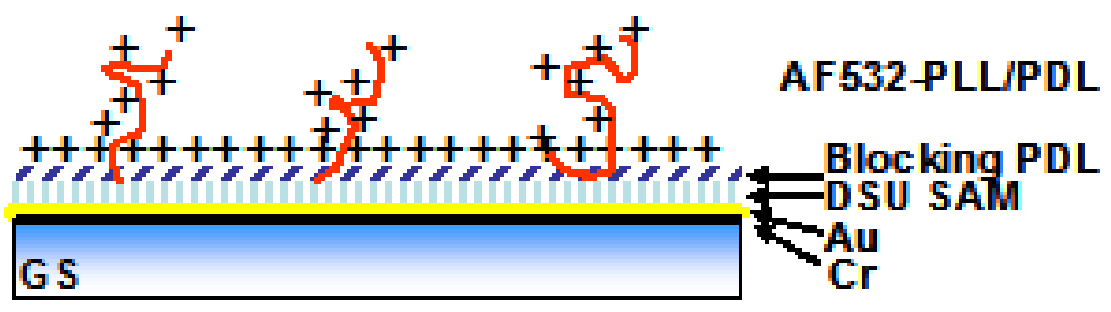


Figure 3.

A

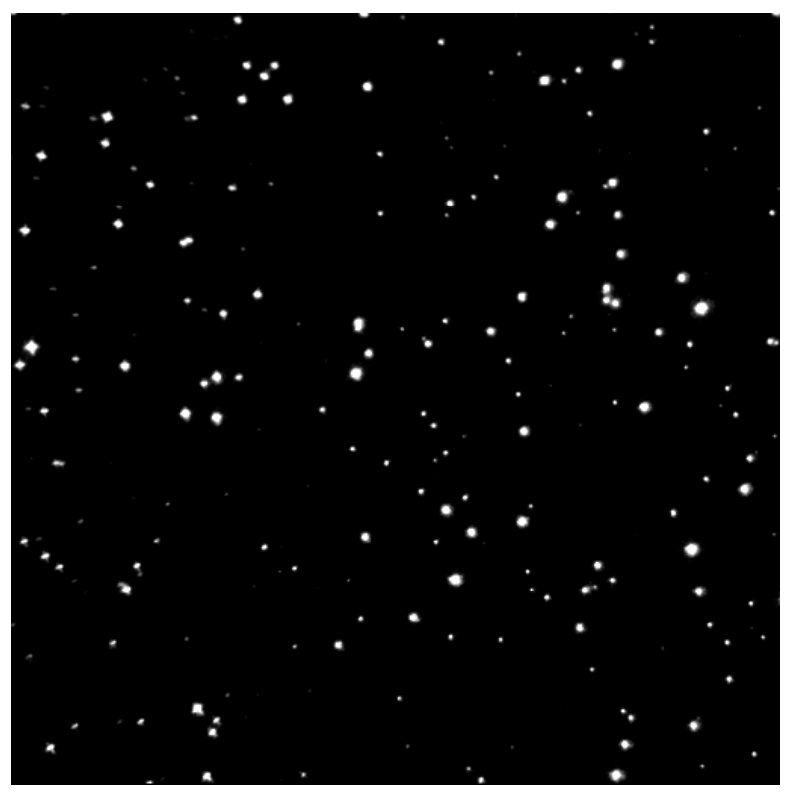

C

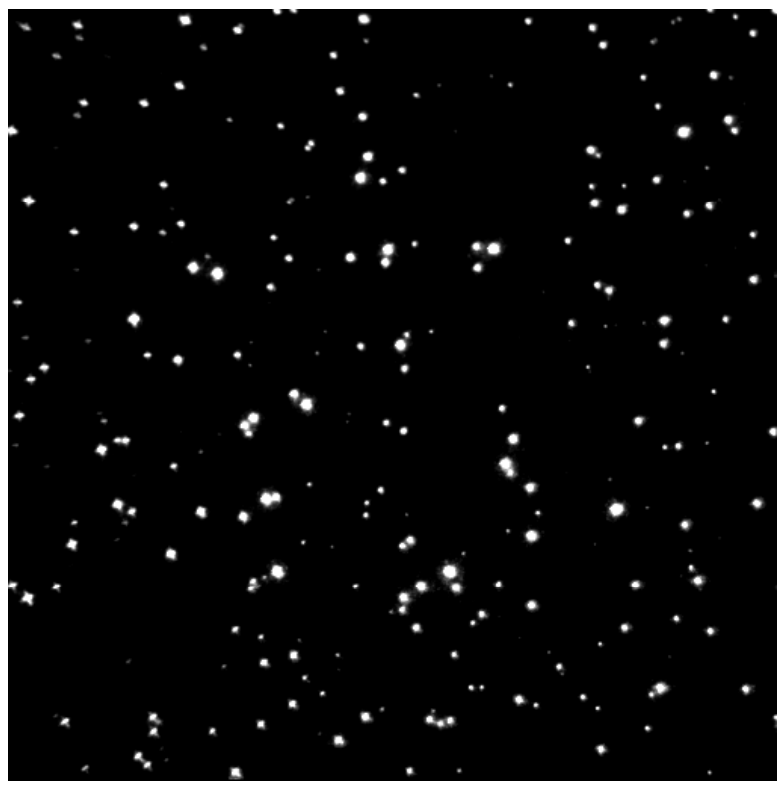

B

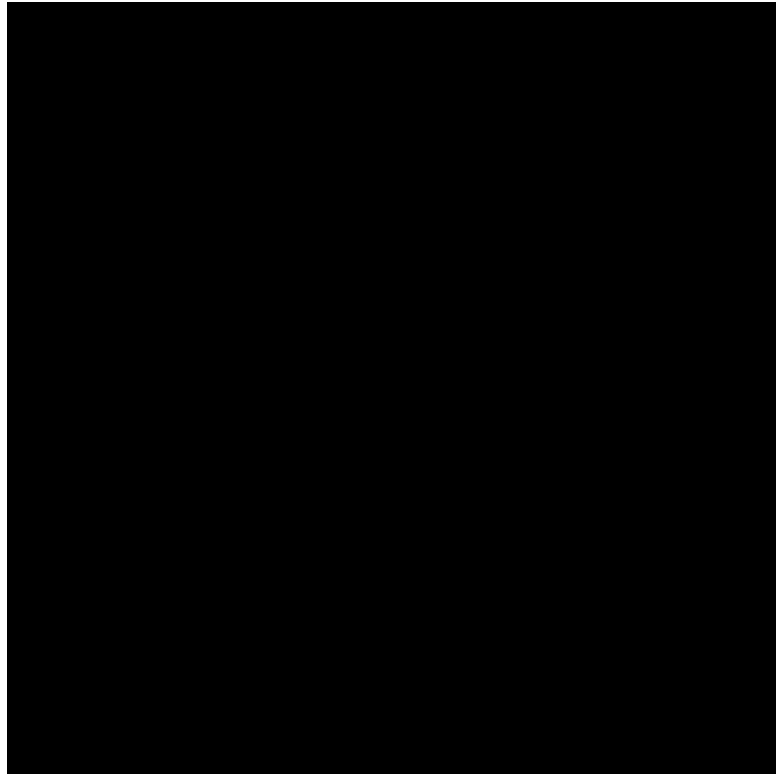

D

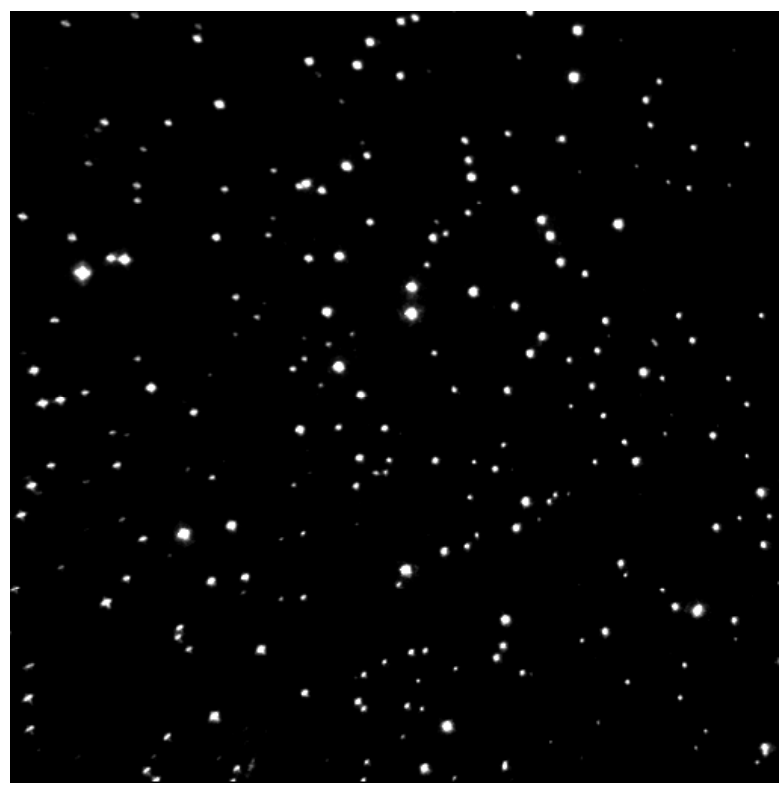


Figure 4.

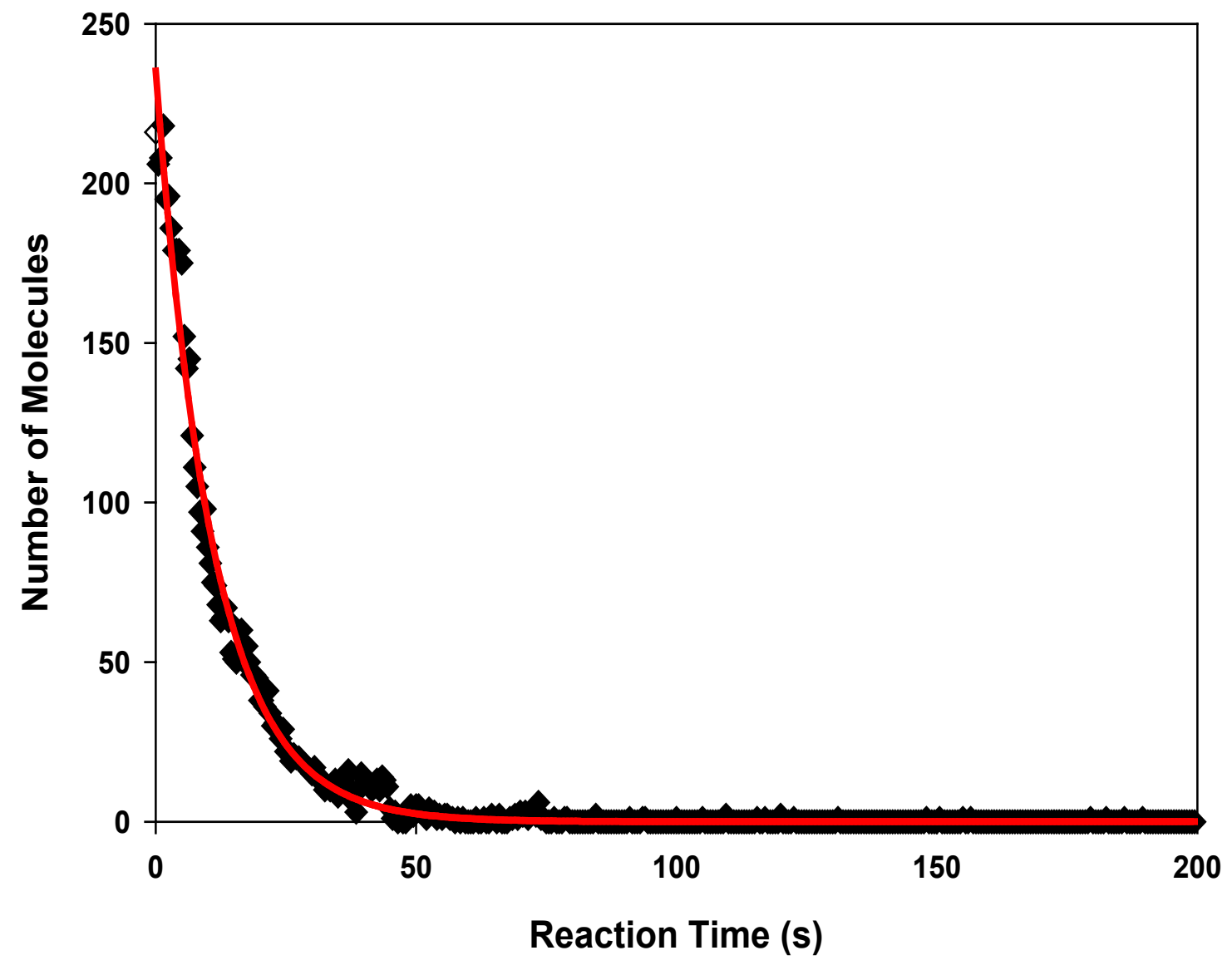


Figure 5.

\section{A}
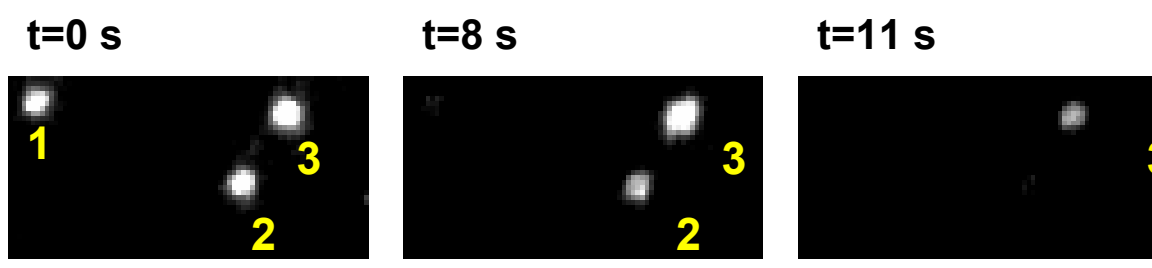

$$
t=30 \mathrm{~s}
$$

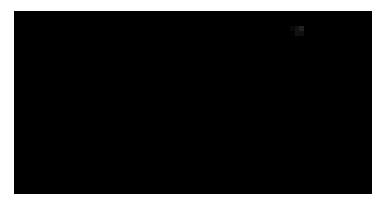

B

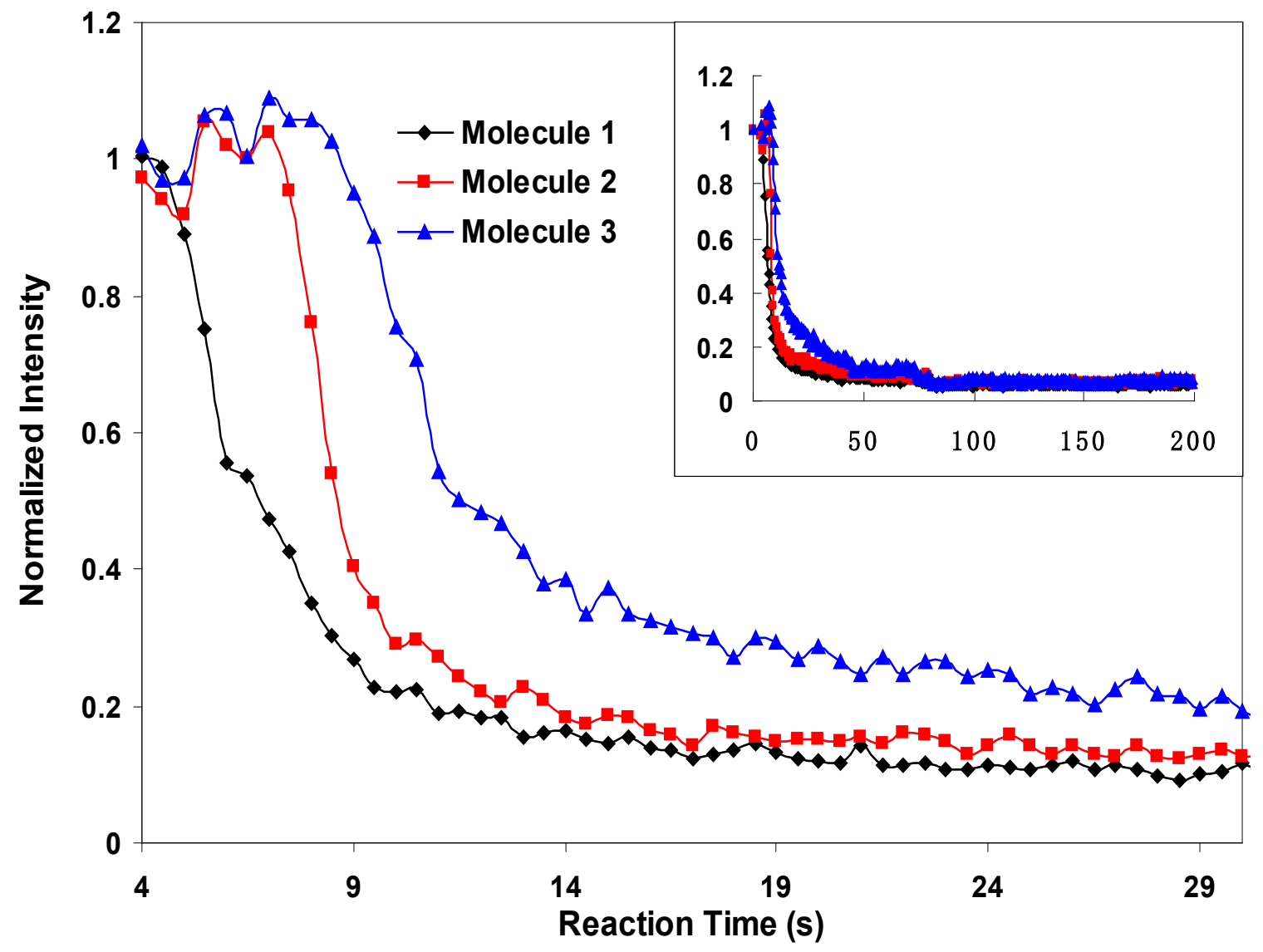


Figure 6.

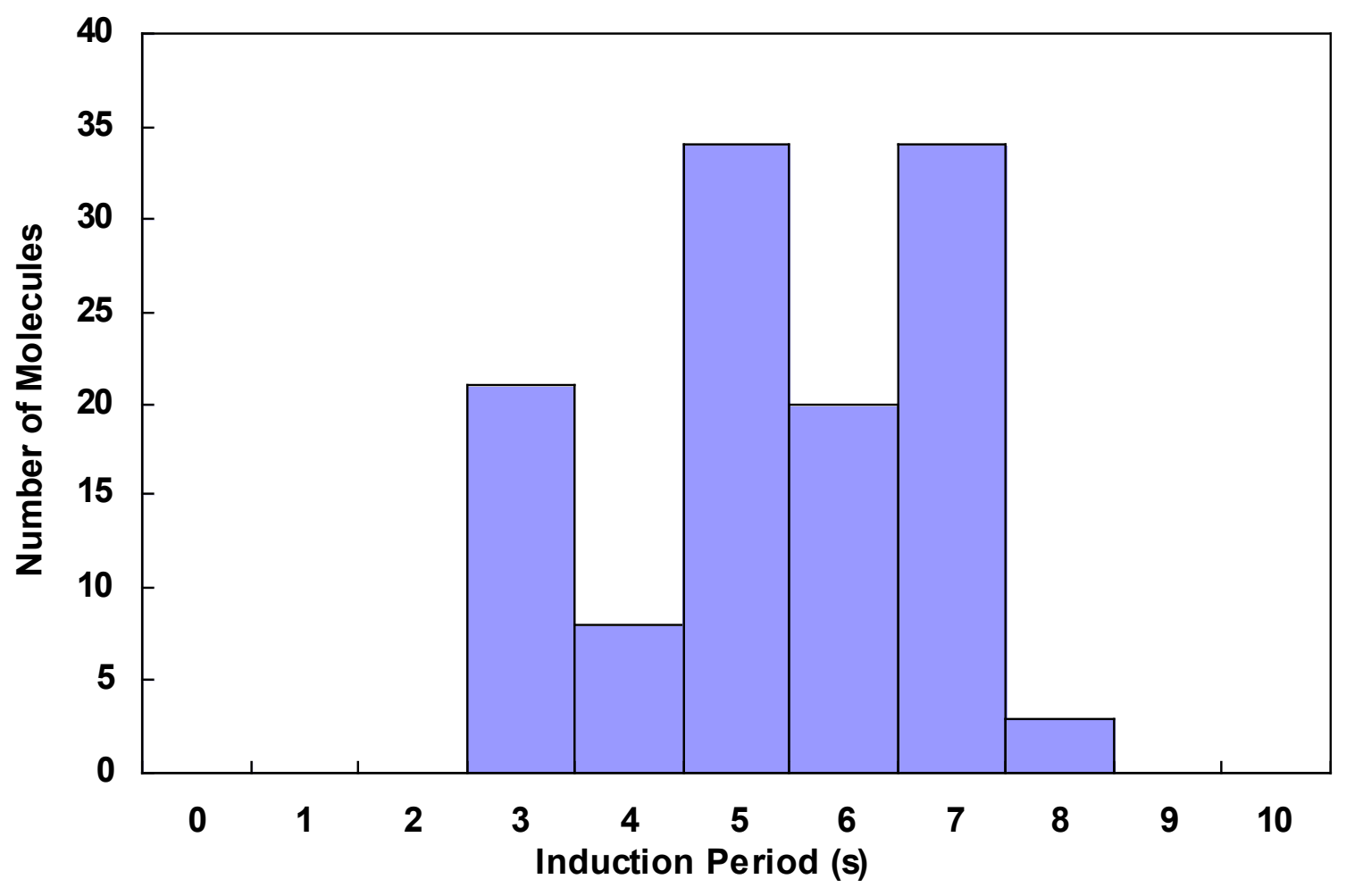


Figure 7.

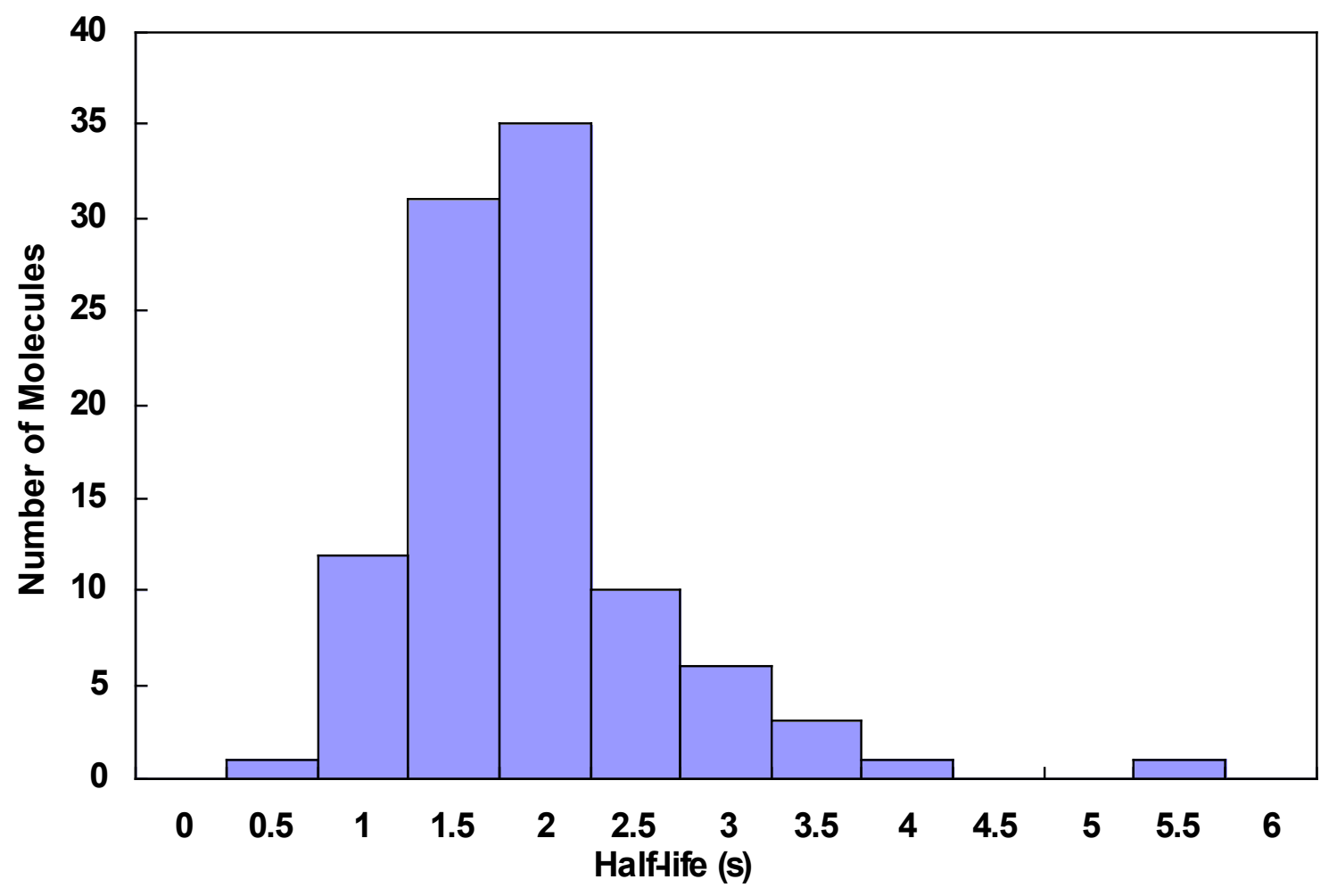




\section{CHAPTER 6. GENERAL CONCLUSIONS}

Single-molecule detection has proven itself as a powerful bioanalytical tool, and led to an explosive growth in biological and clinical applications. The intrinsic features of this technique make it an ideal candidate in the early-diagnostics area: (a) ultimate sensitivity down to single-molecule level, (b) no amplification-induced false positive result, and (c) small sample volume required. The basic mechanism study of enzymatic reaction revealed the detailed hydrolysis process of each individual reaction, which was usually obscured in the ensemble-average experiments.

In this dissertation, three novel early diagnostic methods were developed based on single-molecule study. In terms of target molecules, they fall into two categories: DNA and antigen screening. Robust DNA-based detections alleviate the concerns about the nonspecific interactions between the fluorescent probe and target molecules as DNA-DNA hybridization is highly specific. Antigen-based detection has a larger potential in clinical practice since antigens are more common clinical biomarkers than DNAs. The diagnostic methods can also be differentiated by the sample format, which is either solution or surface system. Both systems have their own merits: the main advantage of the solution system includes good linear standard curve for quantification and wide dynamic range (over 6 orders of magnitude): while the surface system offers higher detection efficiency, higher throughput, and lower interference of the biomatrix (removed by washing steps) than flow system.

This dissertation work bodes well for a promising future of single-molecule detection application, both in the early clinical diagnosis and the basic biological research field. 


\section{ACKNOWLEDGEMENT}

It is a great pleasure to thank the many people who made this thesis possible.

First of all, I am deeply indebted to my supervisor, Dr. Edward S. Yeung, for his excellent guidance, patience, and constant support during my whole doctoral research. With his enthusiasm, his creativity, his inspirations and his great efforts to explain scientific issues clearly, he helped to make analytical chemistry fun and attractive for me. By all means, Dr. Yeung set such a wonderful example for me to learn from for life.

I would like to express my sincere gratitude to my POS committee members, both current and former: Drs. Robert S. Houk, Klaus Schmidt-Rohr, Emily Smith, Basil Nikolau, Daniel W. Armstrong, and Daniel F. Voytas. They have provided, with kindness, their insight and suggestions, which are precious to me. Special thanks to Dr. Mary Jo Schmerr for her useful academic advice and being a great senior friend in my personal life.

I give my appreciations to all my collaborating colleagues during these years: Dr. Jiyoung Lee, Dr. Ning Fang, Dr. Sabastian Donner, Dr. Hui Zhang, Wenjun Xie for detailed tutoring, brilliant ideas, valuable discussion and assistance with experiments.

Many thanks to all members of Yeung's group: Hung-Wing Li, Guoxing Lu, Aoshuang Xu, Frank Li, Dragon Isailovic, Slavica Isailovic, Yun Zhang, Sangwong Cha, Bob Hsin, Wei Sun. I appreciate their mutual exchange of knowledge, encouraging attitudes, and valuable friendship.

Lastly, and most importantly, I wish to thank all my families. Foremost, I am sincerely grateful for my parents for raising me, giving me the courage to pursue a $\mathrm{Ph} . \mathrm{D}$ degree in US, and always being there for me. With gratitude I recognize the consideration, 
caring, and support from my elder brother and sister in law. Especially, I am grateful for my husband, Hui, for his company, understanding, encouragement, emotional support throughout the years. The invaluable happiness in the small and lovely Ames will always last. It is to them that I dedicate this work.

This work was performed at Ames Laboratory under Contract No. DE-AC02-

07CH11358 with the US. Department of Energy. The United States government has assigned the DOE Report number IS-T2588 to this thesis. 